\author{
UNIVERSIDADE DE SÃO PAULO \\ INSTITUTO DE ENERGIA E AMBIENTE \\ PROGRAMA DE PÓS-GRADUAÇÃO EM ENERGIA
}

ROMARIO DE CARVALHO NUNES

O PAPEL DA PESQUISA E DESENVOLVIMENTO PARA O MONITORAMENTO DAS INSTALAÇÕES DE ARMAZENAMENTO DE CARBONO E SUA RELEVÂNCIA NO CONTEXTO DE ESG

SÃO PAULO 
ROMARIO DE CARVALHO NUNES

\title{
O PAPEL DA PESQUISA E DESENVOLVIMENTO PARA O MONITORAMENTO DAS INSTALAÇÕES DE ARMAZENAMENTO DE DIÓXIDO DE CARBONO E SUA RELEVÂNCIA NO CONTEXTO DE ESG
}

\begin{abstract}
Dissertação apresentada ao Programa de PósGraduação em Energia do Instituto de Energia e Ambiente da Universidade de São Paulo para a obtenção do título de Mestre em Ciências.
\end{abstract}

Orientadora: Profa. Dra. Hirdan Katarina de Medeiros Costa

Versão Corrigida

(Versão original disponível na Biblioteca do Instituto de Energia e Ambiente e na Biblioteca Digital de Teses e Dissertações da USP)

SÃO PAULO 
AUTORIZO A REPRODUÇÃO E DIVULGAÇÃO TOTAL OU PARCIAL DESTE TRABALHO, POR QUALQUER MEIO CONVENCIONAL OU ELETRÔNICO, PARA FINS DE ESTUDO E PESQUISA, DESDE QUE CITADA A FONTE.

FICHA CATALOGRÁFICA

Nunes, Romario de Carvalho.

$O$ papel da pesquisa e desenvolvimento para o monitoramento das instalações de armazenamento de dióxido de carbono e sua relevância no contexto de ESG. /Romario de Carvalho Nunes; orientadora: Hirdan Katarina de Medeiros Costa. - São Paulo, 2021.

$105 \mathrm{f}:$ il; $30 \mathrm{~cm}$.

Dissertação (Mestrado em Ciências) - Programa de PósGraduação em Energia - Instituto de Energia e Ambiente da Universidade de São Paulo.

1. Mudança climática. 2. Dióxido de carbono - monitoramento. I. Título.

Elaborado por Maria Penha da Silva Oliveira CRB-8/6961 
Nome: NUNES, Romario de Carvalho

Título: O papel da pesquisa e desenvolvimento para o monitoramento das instalações de armazenamento de dióxido de carbono e sua relevância no contexto de ESG

Dissertação apresentada ao Programa de Pós-Graduação em Energia do Instituto de Energia e Ambiente da Universidade de São Paulo para a obtenção do título de Mestre em Ciências.

Aprovado em:

Banca Examinadora

Prof(a). Dr(a)

$\operatorname{Prof}(a) . \operatorname{Dr}(\mathrm{a})$.

Prof(a). Dr(a).

Prof(a). Dr(a).

\section{SÃO PAULO}



A Deus,

Aos familiares, mãe, pai (in memoriam), irmãos e irmã, e amada esposa, pois, sem vossos suportes, amor e apoio, meus caminhos não seriam esses! 


\section{AGRADECIMENTOS}

Agradeço a Deus, pela condição financeira, intelectual e oportunidade única de conseguir realizar esse desejo de infância, em estudar em uma grande universidade,

Aos meus amados pais, Graça e José (in memoriam), pelo carinho, amor, educação e empenho de sempre, fazendo-me tornar o homem que hoje sou,

À minha amada esposa Natalia, pela parceria e incentivo desde o início da jornada, sem a qual não teria sequer iniciado esse percurso, bem como pela compreensão pelas longos dias e noites dedicados aos estudos,

À minha estimada orientadora Hirdan, que desde o início acreditou em meu potencial, incentivou meu aprendizado, ajudando-me a desenvolver constantemente, oferecendo oportunidades ímpares para contribuição com meus estudos e o avanço do conhecimento, como convites para publicações de artigos, capítulos de livros, congressos, monitoria, dentre outros. Sem dúvidas, o meu sucesso se deu em grande parte pela dedicação e cuidado ao qual teve comigo, fazendo-se valer portanto todo o conceito por trás de seus inúmeros títulos: o de ensinar e contribuir para o avanço da ciência.

Ao meu gerente Rodrigo Lobo, pela parceria de sempre, incentivo aos meus estudos e desenvolvimento profissional e intelectual, pelas condições de trabalho dadas que oportunizaram a realização deste mestrado bem como por acreditar em meu potencial profissional e,

Ao Instituto de Energia e Ambiente, seus professores e colaboradores - em especial da secretaria, que me ajudaram em toda a jornada acadêmica. 
Com sabedoria se constrói a casa, e com discernimento se consolida. Pelo conhecimento os seus cômodos se enchem do que é precioso e agradável. (Provérbios 24:3-4) 


\section{RESUMO}

NUNES, Romario de Carvalho. 0 papel da pesquisa e desenvolvimento para o monitoramento das instalações de armazenamento de dióxido de carbono e sua relevância no contexto de ESG. Dissertação (Mestrado), Programa de PósGraduação em Energia, Instituto de Energia e Ambiente. Universidade de São Paulo, 2021.

Esta dissertação dispõe sobre as vertentes nas quais a pesquisa e desenvolvimento podem interferir na execução das atividades de armazenamento de dióxido de carbono (CCS) em estrutura geológica sob arcabouço legal e regulatório que permita os operadores das instalações de armazenamento obterem os melhores resultados financeiros e de segurança, sob ótica do ESG (Environmental, Social and Governance), por meio de instrumentos regulatórios, de tecnologias e ferramentas e gestão de riscos - principalmente por meio do Plano de Monitoramento, para, em ambiente de transição energética para uma economia de baixo carbono. Também visa contribuir para o avanço da implementação e utilização da tecnologia de CCS e melhor aceitação perante as partes envolvidas, principalmente investidores e o público em geral. Por meio de pesquisas sistemáticas e documentais, bem como pesquisa expost-facto, foram abordados conceitos, históricos e uso do P\&D, CCS e ESG e suas correlações, bem como o panorama das tecnologias e ferramentas utilizadas atualmente na atividade de monitoramento das instalações de armazenamento de $\mathrm{CO}_{2}$. Fora explorada a relevância do P\&D para gerenciamento dos riscos envolvendo tal atividade e eventuais consequências sob a ótica operacional e do ESG além da construção de caminhos que evidenciam a relevância da etapa do monitoramento bem como suas contribuições na visão regulatória, de segurança de processos e aspectos relacionados a responsabilizações das partes. Através de pesquisa ex-post-facto, foi possível abordar dois acidentes de processos aos quais envolveram as três vertentes trabalhadas nesta dissertação, e analisar o papel que o P\&D e o monitoramento tiveram nestes casos, associando-os aos impactos - positivos e negativos - sob a ótica do ESG. Além disso, foram apresentados os desafios para o progresso do P\&D na indústria e a relevância no contexto mundial atual de ESG. O desenvolvimento deste trabalho, a partir do referencial teórico, permite concluir que o P\&D, de fato, exerce um papel protagonista e fundamental para a atividade de CCS, sobretudo na fase de monitoramento das instalações de armazenamento de $\mathrm{CO}_{2}$, impactando diretamente todos os parâmetros que englobam o ESG, permitindo pleno atendimento às regulamentações aplicáveis. Com isso, a hipótese investigada ao longo da dissertação fora confirmada, mostrando que avanços em pesquisas e conhecimentos são aplicáveis à atividade de armazenamento de $\mathrm{CO}_{2}$ e que existem diversos benefícios advindos desta prática no contexto atual, principalmente às empresas operadoras e ao ESG. O trabalho ainda permitiu a proposição de diversas ações a serem desenvolvidas pelas empresas operadoras, órgãos regulares e academia bem como construção de importantes materiais através dos Apêndices.

PALAVRAS-CHAVE: CCS, pesquisa e desenvolvimento, mudanças climáticas, monitoramento, instalações de armazenamento de $\mathrm{CO}_{2}$, ESG. 


\begin{abstract}
NUNES, Romario de Carvalho. The role of research and development for monitoring carbon dioxide storage facilities and their quality in the context of ESG. Thesis (Master's degree), Energy Post graduate Program, Institute of Energy and Environment. University of São Paulo, 2021.

This dissertation deals with the aspects in which research and development can interfere in the execution of carbon dioxide storage activities (CCS) in a geological structure under a legal and regulatory framework that allows operators of storage facilities to obtain the best financial and safety, from the perspective of ESG (Environmental, Social and Governance), through regulatory instruments, technologies and tools, and risk management - mainly through the Monitoring Plan, to contribute to the advancement of implementation in an environment of the energy transition to a low carbon economy and use of CCS technology and better acceptance by stakeholders, especially investors and the general public. Through bibliographic and documentary research and ex-post-facto research, concepts, history, and use of R\&D, CCS, and ESG and their correlations were addressed, as well as the overview of technologies and tools currently used in the activity of monitoring facilities of $\mathrm{CO}_{2}$ storage. The relevance of $R \& D$ for risk management involving such activity and possible consequences from an operational and ESG perspective was explored, in addition to the construction of paths that show the relevance of the monitoring stage as well as its contributions to the regulatory, process safety, and aspects related to the responsibilities of the parties. Through ex-post-facto research, it was possible to address two process accidents involving the three parts worked in this dissertation and to analyze the role that $R \& D$ and monitoring had in these cases, associating them with impacts - positive and negative - from the perspective of ESG. In addition, it presented challenges to the progress of R\&D in the industry and the relevance in the current world context of ESG. Based on the theoretical framework, the development of this work allows us to conclude that R\&D plays a leading and fundamental role in the CCS activity, especially in the monitoring phase of $\mathrm{CO}_{2}$ storage facilities, directly impacting all parameters that encompass the ESG, allowing full compliance with applicable regulations. Thus, the hypothesis investigated throughout the dissertation was confirmed, showing that advances in research and knowledge are relevant to the $\mathrm{CO}_{2}$ storage activity and that several benefits are arising from this practice in the current context, especially for operating companies and ESG. The work also allowed the proposition of several actions to be developed by operating companies, regular bodies, academia, and the construction of essential materials through the Appendices.
\end{abstract}

KEYWORDS: CCS, research and development, climate change, monitoring, $\mathrm{CO}_{2}$ storage facilities, ESG. 


\section{LISTA DE FIGURAS}

Figura 1. Locais propícios ao armazenamento geológico .25

Figura 2. Concentrações globais de $\mathrm{CO}_{2}$ na atmosfera em partes por milhão (ppm) nos últimos 800.000 anos.

Figura 3. Comportamento do $\mathrm{CO}_{2}$ submetido a altas pressões .27

Figura 4. Regiões do planeta com maior número de instalações de armazenamento de $\mathrm{CO}_{2}$

Figura 5. Esquemática das principais práticas identificadas na revisão de literatura envolvendo P\&D e monitoramento de instalações de armazenamento de $\mathrm{CO}_{2}$....34 Figura 6. Esquemática das principais bases consultadas durante a pesquisa documental 40

Figura 7. Tecnologias e ferramentas utilizadas para o monitoramento das instalações de armazenamento de $\mathrm{CO}_{2}$ onshore e offshore .43

Figura 8. Riscos de armazenamento geológico de $\mathrm{CO}_{2}$ 49

Figura 9. Fases de um projeto de CCS de acordo com o - Model Regulatory Framework .51

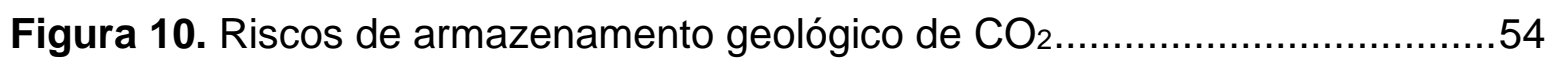

Figura 11. Esquemática do diagrama de Bowtie ...............................................66

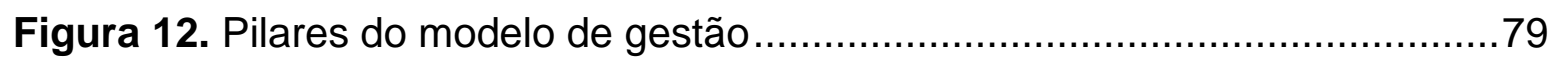




\section{LISTA DE TABELAS}

Tabela 1. Atividades relacionadas à pesquisa e desenvolvimento .23

Tabela 2. Tecnologias e ferramentas utilizadas para realização do monitoramento onshore e offshore 43

Tabela 3. Exemplos de técnicas utilizadas para monitoramento das instalações de armazenamento de $\mathrm{CO}_{2}$

Tabela 4. Categorias e ramos industriais presentes no Ranking 2021 da B Corporations .82 


\section{SUMÁRIO}

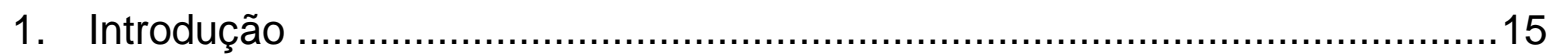

1.1. Motivação, Justificativa e Relevância do Tema .............................................18

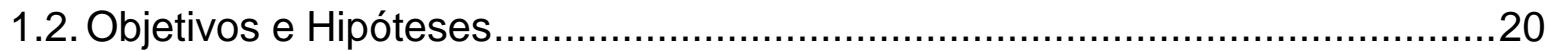

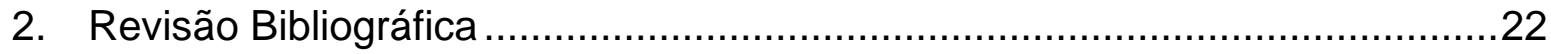

2.1 Conceitos gerais sobre P\&D - Pesquisa e Desenvolvimento .........................22

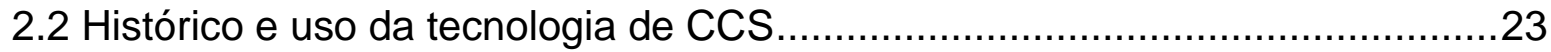

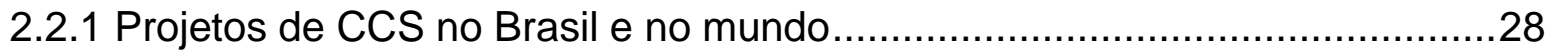

2.3 Contexto do ESG na atual conjuntura mundial ............................................

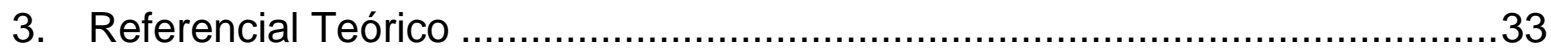

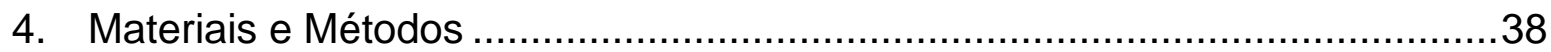

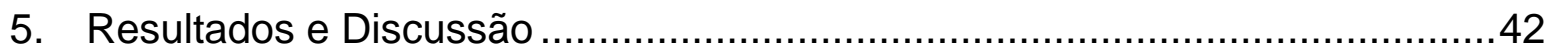

5.1 Panorama das tecnologias e ferramentas para armazenamento de $\mathrm{CO}_{2}$ no

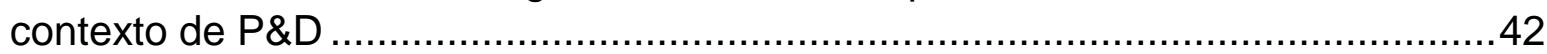

5.2 A relevância do P\&D para gerenciamento dos riscos associados ao

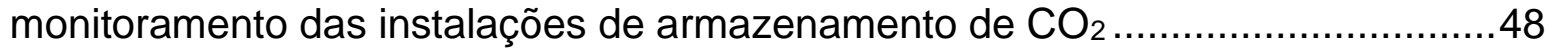

5.2.1 Definições de risco e correlação com a etapa de monitoramento no CCS ...48

5.2.2 Riscos operacionais e suas consequências .............................................53

5.2.3 Riscos para o ESG e suas consequências .............................................55

5.3 A relevância do monitoramento das instalações de armazenamento de $\mathrm{CO}_{2}$ na

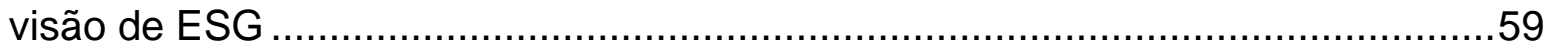

5.3.1 Estruturas regulatórias associadas ao comissionamento e operação das

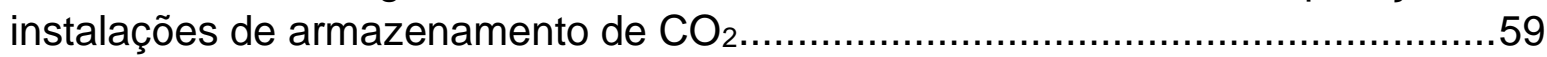

5.3.2 O papel chave do monitoramento na garantia da integridade e segurança das

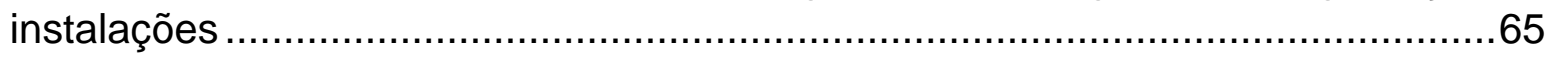

5.3.3 Falhas no processo de monitoramento e responsabilização das partes.......70

5.3.4 O papel do P\&D e monitoramento na prevenção de acidentes de processos e

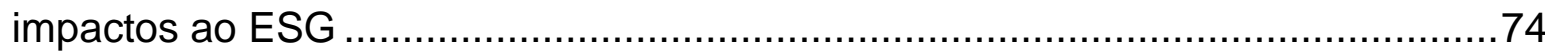

5.4 Desafios para o progresso da pesquisa e desenvolvimento e sua relevância no

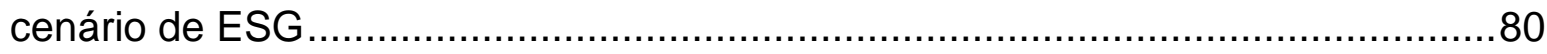

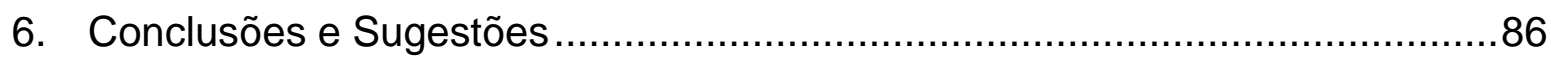

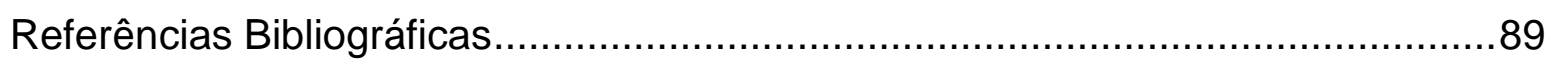

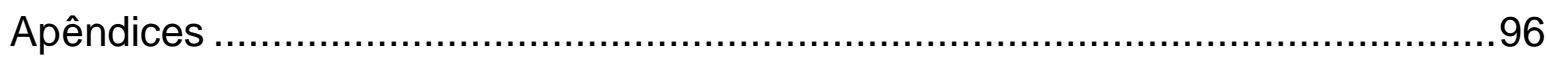

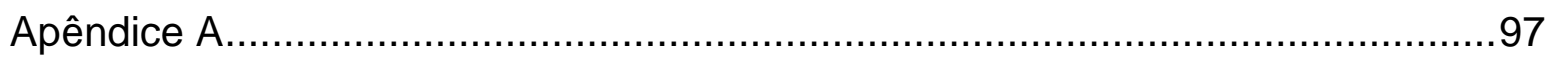

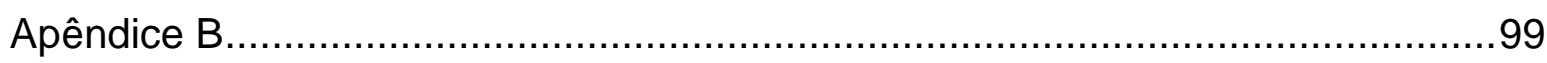


Apêndice $C$

101

Apêndice $D$

103

Apêndice $\mathrm{E}$

105 


\section{Introdução}

A tecnologia de captura e armazenamento de carbono (Carbon Capture and Storage - CCS) pode ser entendida como um conjunto de tecnologias voltadas para redução das emissões de $\mathrm{CO}_{2}$ e aplicável a grandes empreendimentos cujos processos resultam em geração de elevados volumes de gás, já que ainda dependemos de processos industriais que emitem quantidade significativa de $\mathrm{CO}_{2}$ (SEIXAS, 2015; DNV, 2021). Este $\mathrm{CO}_{2}$ é removido dos gases de combustão emitidos nos processos, transportados por gasodutos, caminhões ou navios e estocado permanentemente no subsolo em grandes profundidades em vez de ser liberado na atmosfera, como campos de óleo e gás depletados e formações salinas profundas, ou ainda utilizados como método de recuperação avançada de óleo (EOR - Enhanced Oil Recovery) (IEA, 2010; CÂMARA, 2011; SEIXAS, 2015; GLOBAL CCS INSTITUTE, 2018; TARAKKI, 2018). A tecnologia também é uma das soluções atualmente disponíveis para ajudar no cumprimento das metas estabelecidas no Acordo de Paris para diminuir as emissões de gases do efeito estufa e, ao mesmo tempo, diminuir a poluição causada pelo uso de carvão e outros combustíveis fósseis, que atendem às crescentes necessidades energéticas do mundo (ASHWORTH, 2010; JENKINS, 2011; ANYOSA, 2021; ZHANG, 2021).

A prática do monitoramento das instalações de armazenamento de $\mathrm{CO}_{2}$ é fundamental, dada à complexidade e riscos envolvidos na operação e potenciais danos causados em eventual vazamento de $\mathrm{CO}_{2}$ (IEA, 2010). Monitorar as atividades de CCS é essencial para apoiar vários elementos cruciais de segurança e proteção e envolverá um portfólio de técnicas e esquemas de monitoramento para detectar, o quanto antes, o vazamento de $\mathrm{CO}_{2}$ (IEA, 2010; ANYOSA, 2021).

A atividade de monitoramento exige estudos e análises complexas, tanto para atender à regulação aplicável quanto à segurança das instalações (NUNES, 2019). A materialização disso se dá pela elaboração e implementação do Plano de Monitoramento, que reflete os princípios e critérios das boas práticas internacionais para o monitoramento de locais de armazenamento geológico e abrange análises 
tecnológicas e econômicas, dado o alto valor de investimento (DIXON, 2015; ANYOSA, 2021; ZHANG, 2021).

A complexidade e riscos envolvidos nas atividades de armazenamento de $\mathrm{CO}_{2}$ remete à necessidade de investimento em pesquisa e desenvolvimento de novas tecnologias e ferramentas tanto para o monitoramento quanto para contingência de vazamentos nas instalações de armazenamento de $\mathrm{CO}_{2}$. A pesquisa e desenvolvimento (P\&D) é um instrumento de suma importância para tal atividade, que contribui inclusive para o crescimento sustentável dos países e também das empresas, uma vez que é peça fundamental para o crescimento dos mercados e da produtividade (MANUAL DE OSLO, 2005; UGONNA, 2021). O P\&D também desempenha um papel importante na inovação, que nos últimos anos, ocupou posição de destaque como um dos principais motores do crescimento econômico e da redução da pobreza (UNESCO, 2010). As experiências, inovações tecnológicas, pesquisas e o próprio desenvolvimento de protocolos de monitoramento das instalações são peças-chaves para o êxito do projeto de armazenamento de $\mathrm{CO}_{2}$ como um todo (STEPHENS, 2010; LAI, 2012; STORSET, 2019; ROBERTS, 2020; LONGA, 2020; LORIA, 2021).

No contexto do escopo deste trabalho, O P\&D torna-se ferramenta essencial para, por exemplo, atender as regulações inerentes à atividade de CCS (DIXON, 2015; HVIDEVOLD, 2015; HARBERT, 2016; DEAN, 2017), atendimento à contabilização do armazenamento de $\mathrm{CO}_{2}$ e eventual vazamento (DIXON, 2015), redução dos custos de monitoramento e intervenção - no caso de vazamento (DIXON, 2015; HARBERT, 2016; DEAN, 2017) bem como na redução do tempo para contenção do vazamento (DIXON, 2015; DEAN, 2017).

Nessa esteira, o P\&D está estritamente ligado ao Environmental, Social and Governance (ESG), principalmente em virtude dos potenciais impactos socioambientais que a tecnologia de CCS, quando não desenvolvida ou mal empregada, pode causar. Esses impactos, associados à aceitação econômica e social, são um dos motivos para a não implementação ampla de CCS atualmente (DEAN, 2017). 
Um exemplo prático voltado ao tema desse trabalho é a pesquisa realizada em 2018 pela Ernst \& Young, que detectou que os investidores estão usando cada vez mais ferramentas e informações de desempenho não financeiras para tomada de decisão (EY, 2018). Nesse caso, as informações não financeiras das empresas que utilizam a tecnologia de CCS seriam, por exemplo, relatórios com os métodos - incluindo tecnologia e ferramentas utilizadas para coleta dos dados - e resultados obtidos com base no Plano de Monitoramento das suas instalações de armazenamento de $\mathrm{CO}_{2}$.

Além disso, a pesquisa revelou que os dois primeiros parâmetros que incentivam empresas a relatarem detalhes sobre atividades não financeiras e ESG são justamente a conformidade regulatória e a gestão de riscos (EY, 2018), ambos pilares abordados neste trabalho. Soma-se ao fato que pesquisas sociais constataram que a opinião pública se baseia em julgamentos intuitivos de riscos, denominados "percepções de riscos" para se avaliar os riscos (BOYD, 2016), trazendo a necessidade de a empresa não somente ser, mas também transparecer ao público como uma instituição com excelência em gestão de riscos.

Em paralelo, o papel que a tecnologia de CCS pode desempenhar para mitigar os impactos de uma empresa que possui atividades intensivas em $\mathrm{CO}_{2}$, ou as pressões externas enfrentadas como resultado disso, é amplamente inexplorado. Pesquisas sugerem que, os benefícios do uso da tecnologia de CCS para o ESG interessarão a investidores e empresas, que podem demonstrar seus compromissos com a redução de $\mathrm{CO}_{2}$ e melhoria de sua percepção junto ao público em geral e investidores (GLOBAL CCS INSTITUTE, 2021b).

Portanto, esta dissertação irá abordar sobre qual seria o papel do $\mathrm{P \& D}$ para a atividade de monitoramento das instalações de armazenamento de $\mathrm{CO}_{2}$ e quais as correlações existentes e possíveis impactos no ESG da empresa operadora da instalação de armazenamento de $\mathrm{CO}_{2}$ no contexto global atual. Para tanto, durante a seção de revisão bibliográfica será abordado os conceitos, o histórico e o contexto dos macros temas abordados neste trabalho: P\&D, CCS e ESG. O referencial teórico irá discorrer sobre a construção dos conceitos-chave tratados na pesquisa, em consonância com a linha de pesquisa e teoria adotadas neste trabalho enquanto a seção de materiais e métodos abordará os métodos de pesquisas utilizadas no 
trabalho bem como os principais materiais utilizados como base. A seção de resultados e discussões será organizada trazendo primeiramente um panorama das tecnologias e ferramentas utilizadas na etapa de armazenamento de $\mathrm{CO}_{2} \mathrm{em}$ um contexto de P\&D. Em seguida, será explorada a relevância do P\&D para gerenciamento dos riscos operacionais e riscos para o ESG - relacionados à etapa de monitoramento - trazendo inclusive as definições de riscos para melhor compreensão da temática. Depois será dada ênfase na relevância do monitoramento das instalações de armazenamento de $\mathrm{CO}_{2}$ numa visão de ESG, demonstrando as estruturas regulatórias para operação com segurança e atendimento aos requisitos legais, o seu papel chave para garantia da integridade e segurança das instalações bem como falhas no processo de monitoramento e consequente responsabilização das partes. Ainda nessa seção, serão abordados dois casos reais - um sobre o rompimento da barragem de Mariana no Brasil em 2015 e outro sobre a suspeita de vazamento de $\mathrm{CO}_{2}$ na Fazenda Kerr - Canadá, em 2011, que demonstrará como o P\&D e o monitoramento são capazes de prevenir acidentes de processos e, consequentemente, os efeitos adversos que poderiam causar na visão de ESG. Na última seção será trabalhado os desafios para o progresso do P\&D para as atividades de CCS e sua relevância no cenário de ESG.

\subsection{Motivação, Justificativa e Relevância do Tema}

No contexto contemporâneo, o tema mitigação das mudanças climáticas é objeto de extrema relevância internacional, onde empresas e governos buscam alternativas para tratar as mudanças climáticas, causadas, sobretudo, pelo aquecimento global, decorrente da intensificação da emissão de gases do efeito estufa. Dentre projetos capazes de amenizar a emissão destes gases, encontra-se a tecnologia denominada Carbon Capture and Storage (CCS) (EGMOND, 2012; NUNES, 2019; ASL, 2020). Além disso, a tecnologia deve desempenhar o papel central como um dos quatro principais pilares da transição energética de baixo carbono global, juntamente com a eletrificação baseada em energia renovável, bioenergia e hidrogênio (IEA, 2010). 
Porém, para que a atividade de CCS possa auferir todos os benefícios intrínsecos, é necessário que a etapa mais crítica - o monitoramento - seja realizada de forma a atender às regulamentações inerentes à atividade. $O$ atendimento à regulamentação, além de diminuir as chances de vazamento, interfere diretamente no cumprimento do ESG da empresa operadora da instalação de armazenamento de $\mathrm{CO}_{2}$, já que eventual acidente de processo e consequentemente vazamento de $\mathrm{CO}_{2}$ afetaria as três esferas do ESG - ambiental, social e governança, como será abordado ao longo deste trabalho. Além disso, a tecnologia de CCS se apresenta cada vez mais como capaz de atender às expectativas relacionadas tanto à transição para o mundo Net-Zero quanto ao cumprimento do ESG, sendo, portanto, necessário garantir o atendimento a tais expectativas (BLACKFORD, 2010; DEAN, 2017; GLOBAL CCS INSTITUTE, 2020).

Além da relevância da CCS, o tema ESG vem se destacando nos últimos anos, tornando-se requisito indispensável na construção de portifólios de investimentos pelas grandes instituições de investimentos mundiais e variados segmentos de investidores. As Nações Unidas e diversos órgãos relevantes no cenário internacional vêm incentivando empresas a investirem em todas as vertentes de ESG. Pesquisas e estudos mostram que empresas e instituições que investem no ESG obtêm diversas vantagens dentre as demais - como melhora na percepção pública além de vantagens financeiras, e servem como parâmetros para avaliar, por exemplo, o desempenho da sustentabilidade corporativa (EY, 2018; CNN,2021; DíAZ, 2021; GLOBAL CCS INSTITUTE, 2021b; KANAMURA, 2021; UN GLOBAL COMPACT, 2021).

Para tanto, com fins de cumprimento da regulamentação vigente para armazenamento de $\mathrm{CO}_{2}$ e atendimento ao ESG, é necessário avanço em P\&D e inovação para que a atividade de CCS possa, de fato, ser realizada com segurança e trazer os ganhos advindos do investimento em ESG pela empresa operadora (DIXON, 2015; HVIDEVOLD, 2015; HARBERT, 2016; DEAN, 2017).

Todos esses fatores apresentados motivaram o avanço na fronteira do conhecimento em relação a este tema de dissertação de mestrado. Porém, outros três fatores impulsionaram essa motivação para exploração do assunto: 
O primeiro motivador foi o fato de existirem dois eventos relevantes (um deles envolvendo diretamente a tecnologia de CCS), que correlacionam o P\&D e ESG, e que são antagônicos. O evento do rompimento da barragem de Mariana no Brasil em 2015 mostrou não só as consequências de um monitoramento deficiente, mas talvez principalmente os efeitos adversos que a empresa sofreu em todos os âmbitos do ESG - incluindo relevante impacto ambiental e diversos óbitos - e a necessidade de desenvolvimento de tecnologias como pré-requisito para renovação da licença de operação (SOUZA, 2017; EXAME, 2021). O outro evento, sobre a suspeita de vazamento de $\mathrm{CO}_{2}$ na Fazenda Kerr em 2011, demonstra o quão importante é uma gestão de riscos bem estruturada, o uso de tecnologias de ponta para identificação do vazamento de $\mathrm{CO}_{2}$ e tratamento dos dados bem como os efeitos positivos causados em relação ao ESG, influenciando inclusive positivamente a opinião pública a respeito do suposto vazamento (ROMANAK, 2013; BOYD, 2016; IEAGHG, 2021).

Além disso, outro motivador foi o fato de não existir literatura que correlacionasse os três macros temas abordados neste trabalho - P\&D, CCS e ESG, extremamente relevantes no cenário atual.

O último motivador complementa a situação descrita acima. De acordo com o último relatório anual divulgado pelo Global CCS Institute, tem havido pouca consideração sobre o impacto da tecnologia de CCS no ESG. Apenas um número limitado de modelos de classificações especificamente inclui referência ao CCS ou reconhecem suas possibilidades (GLOBAL CCS INSTITUTE, 2021b).

\subsection{Objetivos e Hipóteses}

Este trabalho tem como objetivo principal demonstrar o papel protagonista do $\mathrm{P} \& \mathrm{D}$ para a realização do monitoramento das instalações de armazenamento de $\mathrm{CO}_{2}$ de forma segura e eficaz e que ao mesmo tempo permita o pleno atendimento das regulamentações aplicáveis a atividade. Neste contexto, é verificado a relevância do $P \& D$ no cenário atual de ESG, demonstrando a importância que a pesquisa e o desenvolvimento de tecnologias e ferramentas traz ao 
monitoramento das instalações de $\mathrm{CO}_{2} \mathrm{e}$, consequentemente, ao pleno cumprimento das métricas de ESG da empresa operadora destas instalações.

A esse objetivo principal associam-se os seguintes objetivos específicos:

i. Revisar a literatura na busca de informações sobre a aplicação e importância do P\&D no processo de monitoramento das instalações de armazenamento de $\mathrm{CO}_{2}$ e respectivos impactos no âmbito do ESG;

ii. Construir, a partir dos conhecimentos obtidos, instrumentos e métodos de apoio que possam estruturar uma linha de pesquisa para ser explorada e obter os resultados pretendidos no estudo;

iii. Preencher, a partir dos conhecimentos obtidos, eventuais lacunas bibliográficas relacionadas à utilização na prática de tecnologias e ferramentas para monitoramento das instalações de $\mathrm{CO}_{2} ; \mathrm{e}$

iv. Investigar, através de pesquisa ex-post-facto, possíveis relações de causa e efeito em situações reais envolvendo P\&D, CCS e ESG;

A questão central, por sua vez, que a pesquisa pretende responder pode ser descrita da seguinte forma: "Qual o papel e importância do P\&D no processo de armazenamento de $\mathrm{CO}_{2}$ e quais impactos que pesquisas e desenvolvimentos de novas tecnologias, por exemplo, poderiam trazer no âmbito do ESG às empresas operadoras das instalações de armazenamento de $\mathrm{CO}_{2}$ ?".

Para tanto, a hipótese investigada ao longo da dissertação é que o avanço em pesquisas e desenvolvimento é extremamente necessário na atividade de armazenamento de $\mathrm{CO}_{2}$ e que, por ser uma atividade crítica no que tange a seu escopo de operação, segurança e integridade da instalação de armazenamento de $\mathrm{CO}_{2}$ bem como atendimento à diversas regulamentações e órgãos de fiscalização, 
beneficiaria a empresa operadora, principalmente no âmbito de ESG, e a própria tecnologia.

\section{Revisão Bibliográfica}

\subsection{Conceitos gerais sobre P\&D - Pesquisa e Desenvolvimento}

De acordo com a renomada revista Inc.- especializada em temas corporativos e referência no business americano, "Pesquisa e desenvolvimento (P\&D) é um processo destinado a criar tecnologia nova ou melhorada que possa fornecer uma vantagem competitiva em nível empresarial, industrial ou nacional." (INC., 2020). O Manual de Frascati1 dispõe que "A pesquisa e o desenvolvimento experimental (P\&D) incluem o trabalho criativo empregado de forma sistemática, com o objetivo de aumentar o volume de conhecimentos, abrangendo o conhecimento do homem, da cultura e da sociedade, bem como a utilização desses conhecimentos para novas aplicações" (OECD, 2013). O Manual de Oslo complementa, ao reconhecer que o conhecimento e tecnologia tornaram-se cada vez mais complexos, aumentando a importância das interações entre empresas e outras organizações como uma forma de adquirir conhecimento especializado (MANUAL DE OSLO, 2005).

A partir das definições, e explorando o tema, verifica-se no Manual de Frascati que $\mathrm{P} \& \mathrm{D}$ abrange essencialmente três atividades, conforme Tabela 1:

Tabela 1 - Atividades relacionadas à pesquisa e desenvolvimento

\begin{tabular}{ll}
\hline Atividade & Descrição \\
\hline pesquisa básica & $\begin{array}{l}\text { trabalhos experimentais ou teóricos desenvolvidos } \\
\text { principalmente com a finalidade de adquirir novos conhecimentos } \\
\text { sobre os fundamentos de fenômenos e fatos observáveis }\end{array}$ \\
&
\end{tabular}

\footnotetext{
${ }^{1}$ O Manual de Frascati é um documento-referência que propõe uma metodologia clara para tratar dados e estatísticas referentes à área de P\&D e foi preparado e publicado, inicialmente, pela OCDE. É, até hoje, a principal referência para estudos, análises, levantamentos e comparações de competitividade entre empresas e países no que se refere a atividades de P\&D (OECD,2013).
} 


\begin{tabular}{ll}
\hline pesquisa aplicada & $\begin{array}{l}\text { trabalhos originais empreendidos com o objetivo de adquirir } \\
\text { novos conhecimentos, principalmente direcionado a um objetivo } \\
\text { prático determinado }\end{array}$ \\
\hline $\begin{array}{l}\text { desenvolvimento } \\
\text { experimental }\end{array}$ & $\begin{array}{l}\text { trabalhos sistemáticos com base em conhecimentos existentes } \\
\text { obtidos pela pesquisa ou experiência prática, para lançar a } \\
\text { fabricação de novos materiais, produtos ou dispositivos, para } \\
\text { estabelecer novos procedimentos, sistemas e serviços ou para } \\
\text { melhorar os já existentes em P\&D }\end{array}$ \\
\hline
\end{tabular}

Fonte: Elaborado pelo autor

Há critérios fundamentais que permitem distinguir Pesquisa e Desenvolvimento de atividades correlatas, tais como necessidade da existência na Pesquisa e Desenvolvimento de um elemento de novidade não insignificante e a dissipação de incerteza científica ou tecnológica. Além disso, a solução de um problema não pode parece óbvia para alguém que é conhecedor de todo o conjunto de conhecimento e técnicas básicas comumente utilizadas naquele setor de conhecimento (OECD,2013).

No contexto estudado, seguindo as premissas abordadas no Manual de Frascati, a mera coleta e tratamento de dados para detecção de anomalias e vazamentos de $\mathrm{CO}_{2}$ das instalações de armazenamento de $\mathrm{CO}_{2}$ não configura Pesquisa e Desenvolvimento. Porém, toda técnica, tecnologias e ferramentas desenvolvidas com um objetivo específico - diferente daquele originalmente projetado ou comumente usados - pode ser incluído em Pesquisa e Desenvolvimento, incluindo nesse caso a coleta, tratamento e uso dos dados. Nesse sentido, o progresso em máquinas e ferramentas de produção, as alterações feitas para os procedimentos e controles, o desenvolvimento de novos métodos e padrões aplicáveis ao CCS podem ser classificados como P\&D.

\subsection{Histórico e uso da tecnologia de CCS}

$\mathrm{O}$ armazenamento de $\mathrm{CO}_{2}$ na crosta terrestre tem sido um processo natural desde sua criação. No entanto, a partir da década de 1970 nos EUA, esse armazenamento começou a ser induzido pelo homem. Para melhorar a produção de petróleo em campos maduros, $\mathrm{o} \mathrm{CO}_{2}$ emitido em diversas atividades da indústria 
petrolífera, como por exemplo do processo de refino, foi e continua sendo injetado nos reservatórios, facilitando assim a recuperação do petróleo bruto das rochas (EOR). Inicialmente o processo não tinha como principal objetivo a preservação do meio ambiente, porém tem sido utilizado largamente na indústria petrolífera (BACHU, 1994; KETZER, 2014).

Hoje, grandes empresas do setor de petróleo que estudam tanto 0 armazenamento geológico para fins de EOR quanto permanente, ambos na intenção de mitigar seus efeitos ambientais. Por essa razão, a partir da década de 1990, essa tecnologia mudou de um conceito de pouco interesse para uma tecnologia com grande potencial para enfrentar problemas ambientais (METZ, 2005; KETZER, 2014). No cenário de implementação dessa tecnologia, Kheshgi (2012) afirma que algumas expectativas para o desenvolvimento da CCS não foram realizadas devido a fatores como a falta de implementação de políticas climáticas em muitas partes do mundo, gerando baixos incentivos para a CCS. Ressalta ainda a variação do custo do uso da tecnologia de CCS, atingindo valores ainda mais elevados do que o estimado inicialmente bem como a barreira social quanto à aceitação pública da implementação da CCS (KHESHGI, 2012).

Em relação aos locais propícios ao armazenamento de $\mathrm{CO}_{2}$, foram identificados locais com potencial armazenamento de $\mathrm{CO}_{2}$ tanto em terra como no mar ao longo de todo o planeta, conhecendo-se um grande potencial nas regiões onde estão concentradas as maiores fontes de emissões ou atividades de exploração de hidrocarbonetos, conforme observado na Figura 1 (KETZER, 2016). 
Figura 1: Locais propícios ao armazenamento geológico

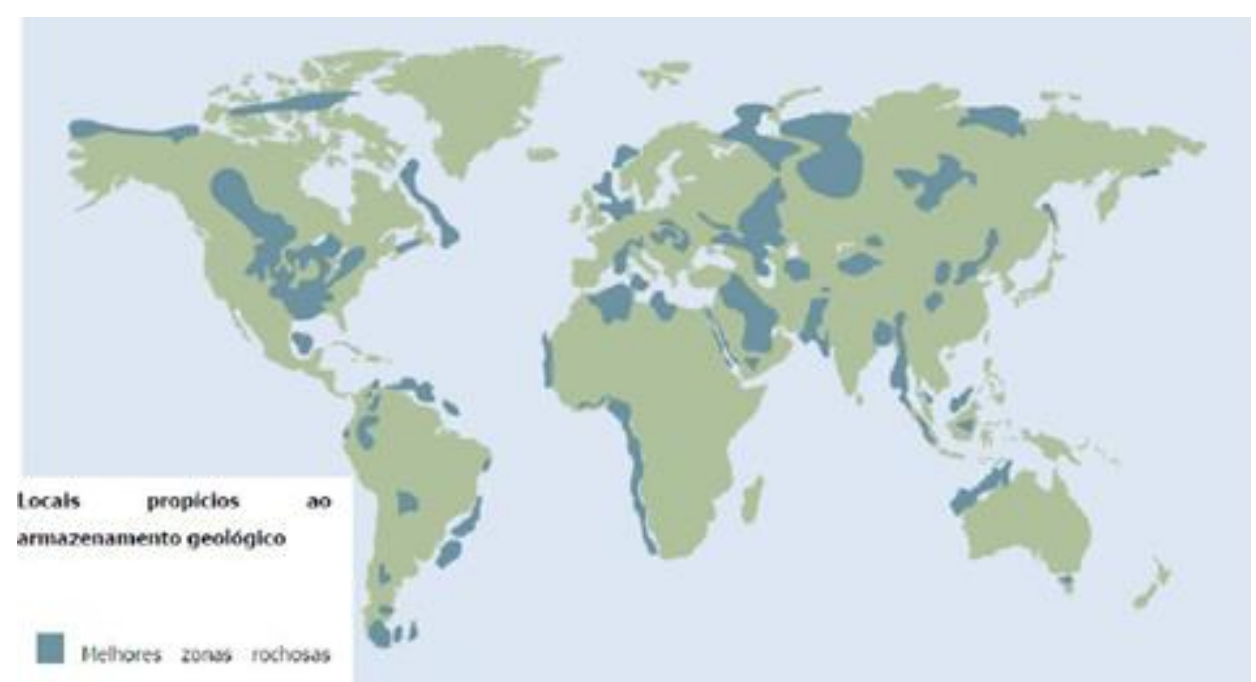

Fonte: KETZER (2016)

$\mathrm{Na}$ indústria de petróleo e gás, a tecnologia de CCS é desenvolvida em reservatórios de petróleo e gás como forma de estimular a produção de hidrocarbonetos em campos maduros ou que requerem maior pressão no reservatório para aumentar a produtividade dos poços de extração. $\mathrm{O}$ armazenamento de $\mathrm{CO}_{2}$ consiste na injeção de $\mathrm{CO}_{2}$ na rocha do reservatório, representando um dos métodos especiais de recuperação terciária do óleo. Esta recuperação especial também é conhecida como avançada ou melhorada e referida em inglês como recuperação aprimorada do óleo $(\mathrm{EOR})^{2}$. Às vezes, a injeção pode não ser apenas $\mathrm{CO}_{2}$ em altas concentrações, mas também misturas compostas principalmente de ar atmosférico e até mesmo gás natural chamado armazenamento subterrâneo de gás natural (GORAIEB, 2005; EPE 2018).

O uso da tecnologia de CCS é fundamental no contexto global atual. Há um forte consenso na comunidade científica que há elo causal entre as atividades humanas com o aumento da concentração de $\mathrm{CO}_{2}$ na atmosfera e consequente aquecimento sistêmico do planeta. A constatação do aquecimento atmosférico global pode ser evidenciada pela análise da variação histórica da concentração de $\mathrm{CO}_{2}$ (ppm)

\footnotetext{
${ }^{2}$ De todos os maiores projetos de CCS do mundo, o Global CCS Institute afirma que o mecanismo $\mathrm{EOR}^{-\mathrm{CO}_{2}}$ teria uma participação de cerca de 58\%. Essa tecnologia de injeção de $\mathrm{CO}^{2}$ acaba sendo considerada uma alternativa segura para o armazenamento desse gás e pode ser comprovada com a operação de dezenas de casos, para a exploração de hidrocarbonetos, em diversos contextos geológicos (ZOBACK, 2007).
} 
nos últimos 800 mil anos, observando considerável aumento dessa concentração desde a Revolução Industrial e, com maior ênfase, a partir de 1950, como pode ser visto na Figura 2.

Figura 2: Concentrações globais de $\mathrm{CO}_{2}$ na atmosfera em partes por milhão (ppm) nos últimos 800.000 anos

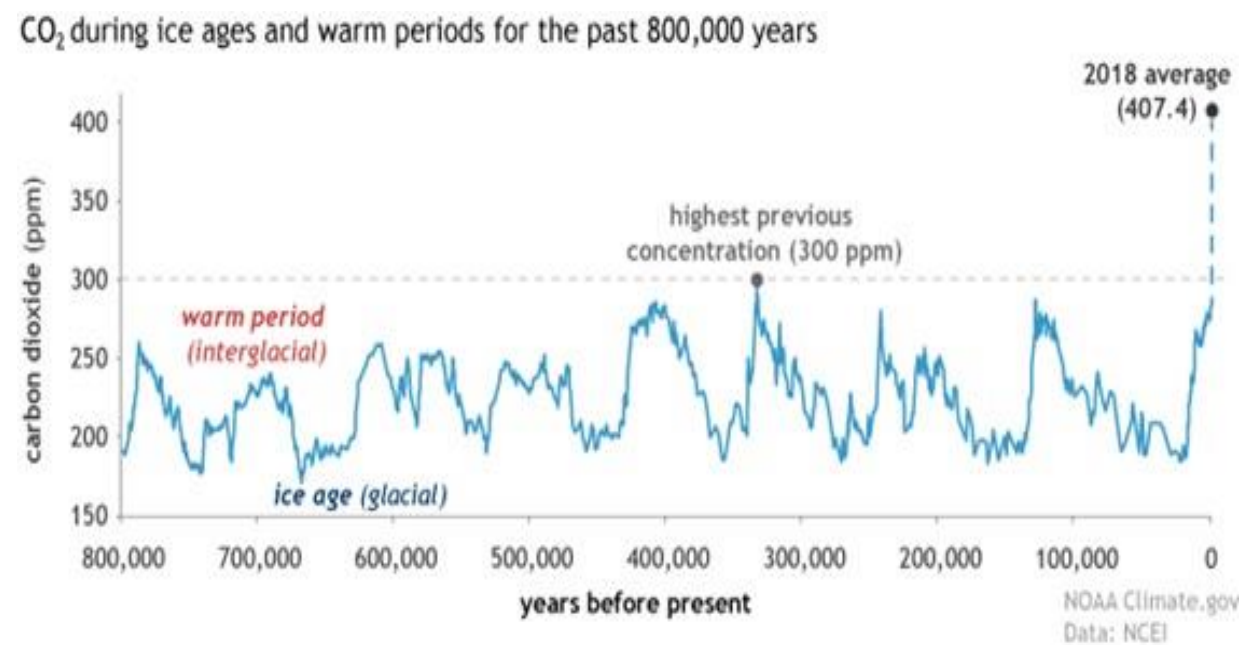

Fonte: NOAA (2021)

Importante relembrar que $\circ \mathrm{CO}_{2}$, assim como outros gases, tais como $\mathrm{CH} 4, \mathrm{~N} 2 \mathrm{O}, \mathrm{CFCs}, \mathrm{HFCs}, \mathrm{PFCs}, \mathrm{SF} 6$ e vapor d'água, é um gás de efeito estufa, que absorve e irradia calor. Aquecidas pela luz solar, as superfícies terrestres e oceânicas irradiam continuamente energia infravermelha térmica (calor). Ao contrário do oxigênio ou nitrogênio (que compõem a maior parte da nossa atmosfera), os gases de efeito estufa absorvem esse calor e o liberam gradualmente ao longo do tempo, como tijolos em uma lareira depois que o fogo se apaga. Sem esse efeito natural do efeito estufa, a temperatura média anual da Terra estaria abaixo de zero em vez de perto de $15,5^{\circ} \mathrm{C}$. Mas o aumento dos gases de efeito estufa desequilibrou o equilíbrio energético da Terra, prendendo calor adicional e elevando a temperatura média do planeta (NOAA, 2021).

Em relação à técnica de armazenamento geológico de $\mathrm{CO}_{2}$, embora cada tipo de reservatórios tenha sua particularidade, na maioria dos casos o $\mathrm{CO}_{2}$ injetado estará em um estado supercrítico. Nessa condição, o $\mathrm{CO}_{2}$ adquire uma densidade típica de líquidos, ocupando, assim, um volume de poro menor, levando a 
um armazenamento mais eficiente. Para garantir o armazenamento em um estado supercrítico, a profundidade mínima estimada para um reservatório é de cerca de 800 metros. Uma rocha reservatória é geralmente adequada para o armazenamento de $\mathrm{CO}_{2}$ quando possui alta permeabilidade e alta porosidade (KETZER, 2016).

Depois, o $\mathrm{CO}_{2}$ é injetado em reservatórios, especialmente em formações salinas profundas, onde irá ao longo do tempo, dissolver-se parcialmente na água subterrânea salina (salmoura) presente nesses reservatórios. A velocidade de dissolução irá variar de acordo com a geologia do reservatório, condições de temperatura e pressão e composição da salmoura. Esse mecanismo é conhecido como aprisionamento iônico ou de solubilidade e pode servir como um mecanismo adicional para imobilizar $\mathrm{o} \mathrm{CO}_{2}$ no reservatório e reduzir os riscos associados à eventual vazamento. $\mathrm{O} \mathrm{CO}_{2}$ dissolvido também pode reagir quimicamente com as rochas e os fluidos do reservatório, causando a precipitação de carbonatos. Esse processo é conhecido como aprisionamento mineral e tem o potencial de imobilizar o $\mathrm{CO}_{2}$ injetado numa fase sólida (KETZER, 2016). A Figura 3 mostra o comportamento do $\mathrm{CO}_{2}$ submetido à altas pressões quando do aumento da profundidade.

Figura 3: Comportamento de $\mathrm{CO}_{2}$ submetido a altas pressões

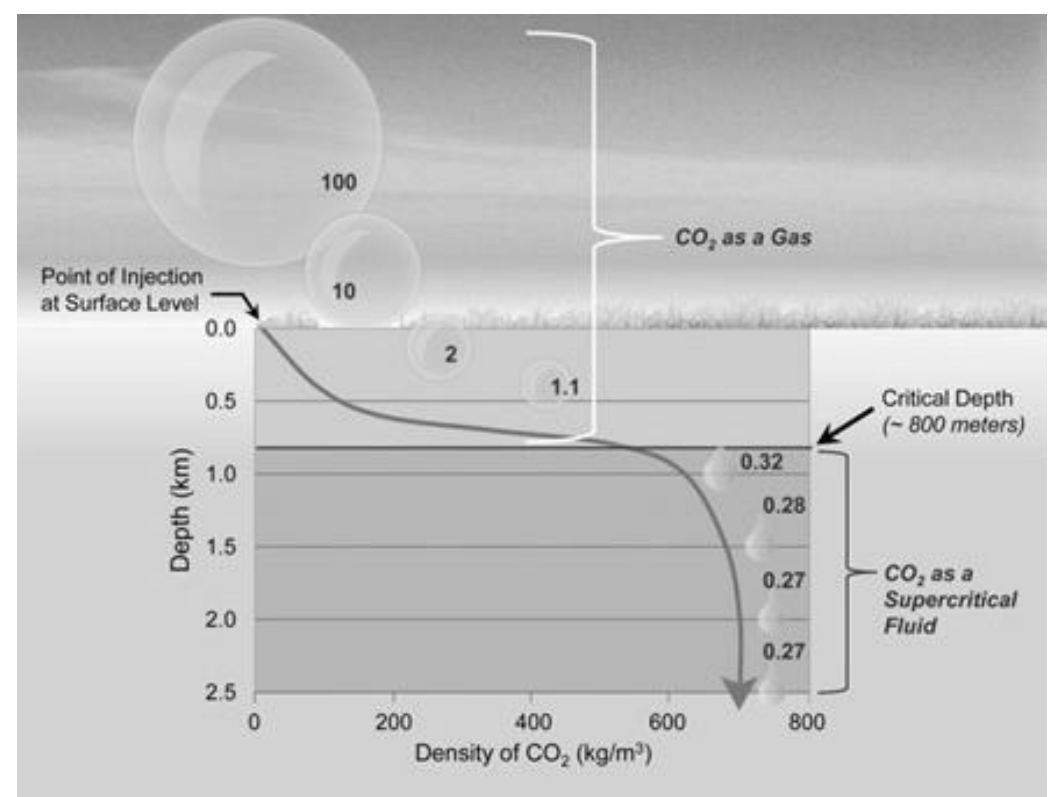

Fonte: NETL (2019) 


\subsubsection{Projetos de CCS no Brasil e no mundo}

Em relação às instalações de armazenamento de carbono, dados do Global CCS Institute mostram que as instalações de armazenamento de $\mathrm{CO}_{2}$ contribuem para captura de, aproximadamente, 37 milhões de toneladas de $\mathrm{CO}_{2}$ por ano (Mtpa), o equivalente à atividade de 8 milhões de carros. Além disso, de acordo com o The Global Status of CCS - 2017, mais de 220 milhões de toneladas de $\mathrm{CO}_{2}$ foram armazenadas cumulativamente até o ano de 2017 (GLOBAL CCS INSTITUTE, 2017). O potencial de armazenamento ainda não é totalmente claro, e há dúvidas em determinar o tamanho da capacidade de armazenamento global. Estima-se que nos reservatórios desativados de petróleo e gás, há uma capacidade de armazenamento entre 675 e 900 Gton de $\mathrm{CO}_{2}$. Nas formações de sal, as estimativas apontam para uma capacidade de pelo menos 1000 Gton, e esses locais podem representar uma capacidade dez vezes maior (METZ, 2005). A título de comparação, as emissões mundiais de $\mathrm{CO} 2$ para todos os setores da economia, inclusive uso do solo, foram 53.5 $\mathrm{GtCO}_{2} \mathrm{em} 2017$ (IPCC, 2018).

A partir dos dados coletados ao longo de 2020 e 2021 no site da Global CCS Institute, foram criados gráficos e infográficos capazes de retratar o panorama atual das instalações de armazenamento de $\mathrm{CO}_{2}$ no mundo e, consequentemente, construir algumas conclusões, às quais encontram-se a seguir (GLOBAL CCS INSTITUTE, 2021a).

Em relação à distribuição geográfica, foi verificado que a maior parte das instalações de armazenamento de $\mathrm{CO}_{2}$ - independente do status de funcionamento dos mesmos, são localizados na América do Norte (43\%) e Europa (26\%), como mostra a Figura 4. 
Figura 4: Regiões com maior número de instalações de armazenamento de $\mathrm{CO}_{2}$

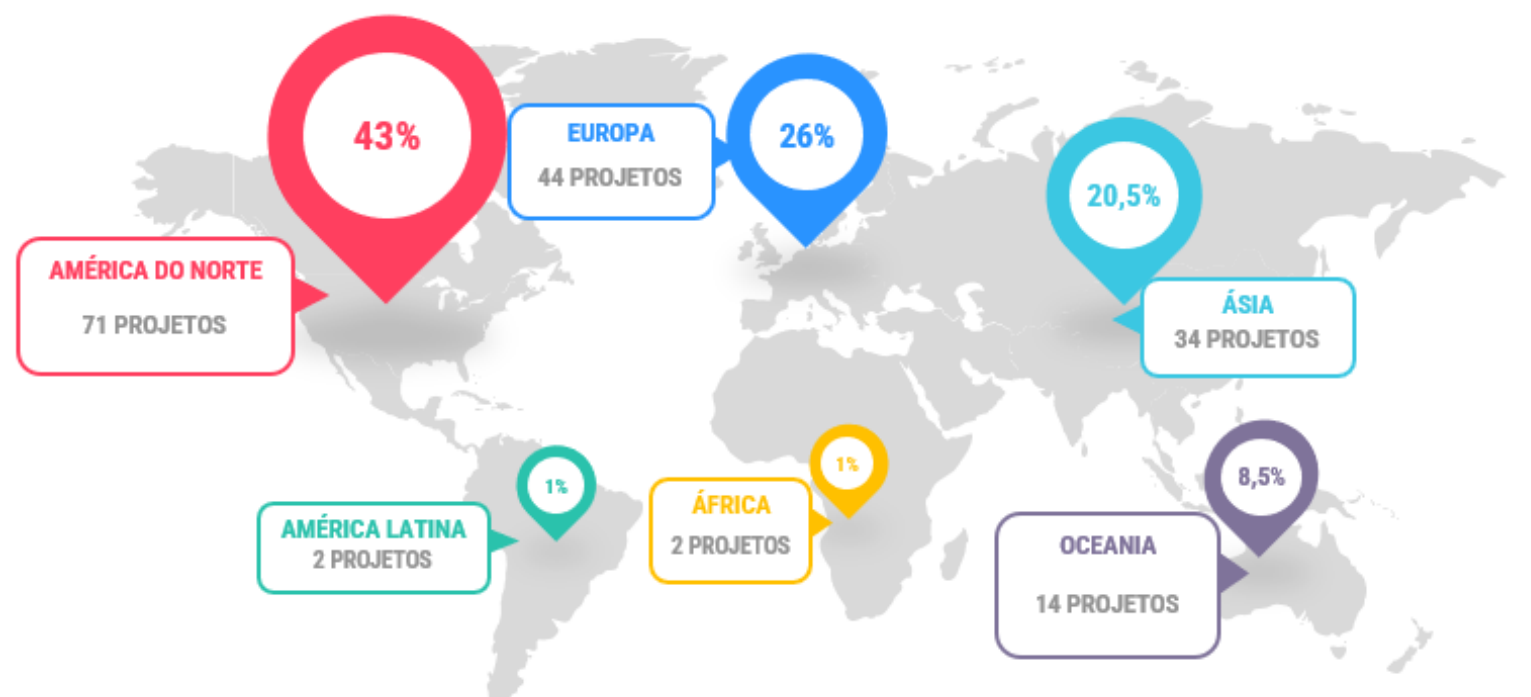

Fonte: Elaborado pelo autor

A figura acima é complementada pelo Apêndice $A^{3}$, mostrando que há uma tendência na instalação e operação das instalações em países que produzem uma quantidade considerável de hidrocarbonetos (Canadá, EUA, Brasil, China, Arábia Saudita, Emirados Árabes Unidos, Argélia, Reino Unido e Noruega), bem como aqueles que o refinam em quantidades consideráveis (Canadá, EUA, Brasil, China, Arábia Saudita e Japão). O motivo seria além do emprego do $\mathrm{CO}_{2}$ capturado na recuperação terciária (EOR), também da infraestrutura já instalada no local no caso dos produtores, bem como quantidades consideráveis de emissões de $\mathrm{CO}_{2}$ durante o refino onde, neste caso, o Japão seria um exemplo. O destaque fica por conta da Austrália, que, embora tenha uma produção, consumo e refino de hidrocarbonetos relativamente baixa, tem um número considerável de instalações. Tal análise pode ser confirmada ao analisar o Gráfico 1, que mostra os países com mais instalações de armazenamento de $\mathrm{CO}_{2}$ no ano de 2021.

Gráfico 1 - Ranking dos 7 países com mais instalações de armazenamento de $\mathrm{CO}_{2}$ do mundo e Brasil

\footnotetext{
${ }^{3} \mathrm{~A}$ tabela do apêndice contém informações dos status de todas as instalações de armazenamento de $\mathrm{CO}_{2}$ do mundo nos últimos dois anos, incluindo instalações operacionais - mas não necessariamente em operação no momento, bem como projetos em desenvolvimento. Dessa forma, é possível verificar eventuais impactos causados pelo cenário da pandemia do COVID-19 na atividade.
} 


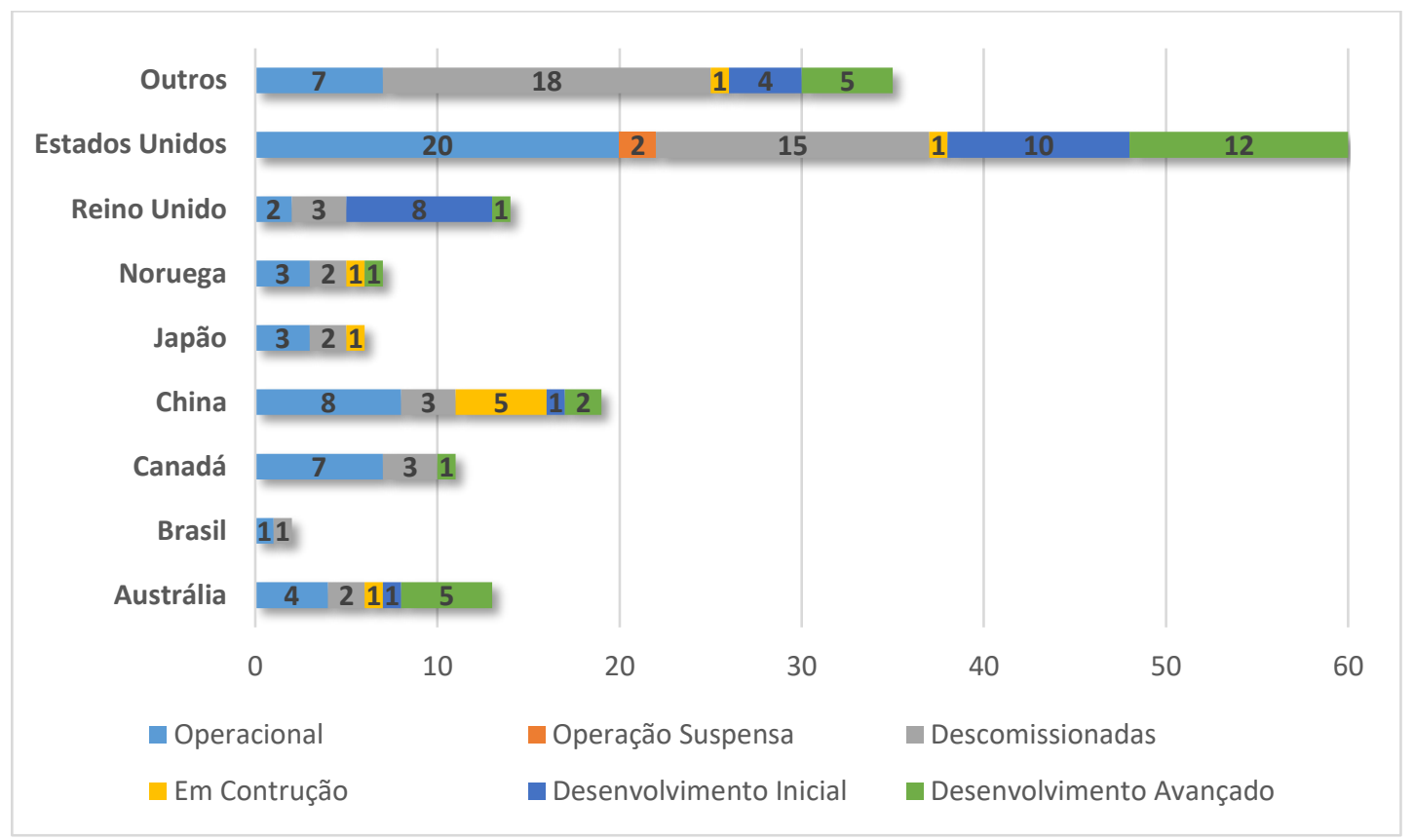

Fonte: Elaborado pelo autor

O gráfico acima mostra a liderança dos Estados Unidos sobre a quantidade de instalações de armazenamento de $\mathrm{CO}_{2}$ no mundo (36\%) e a baixa diversificação entre os países, uma vez que os sete países acima (excluindo o Brasil) concentram cerca de $77,8 \%$ das instalações globais. O gráfico também mostra uma grande concentração de instalações operacionais em 2021 - cerca de 55 instalações - e instalações completas - com cerca de 49 instalações. Atualmente, há 15 países que possuem instalações de armazenamento de $\mathrm{CO}_{2}$ em operação em todo o mundo, uma parte considerável (36\%) nos Estados Unidos, seguidos pela China (14,5\%) e Canadá (13\%), como mostra o Gráfico 2. O Brasil tem participação modesta nesta lista, tendo apenas uma instalação em operação, embora seja considerada uma instalação em larga escala, sendo um dos maiores do mundo.

Gráfico 2: Países com instalações de armazenamento de $\mathrm{CO}_{2}$ em operação em 2021 


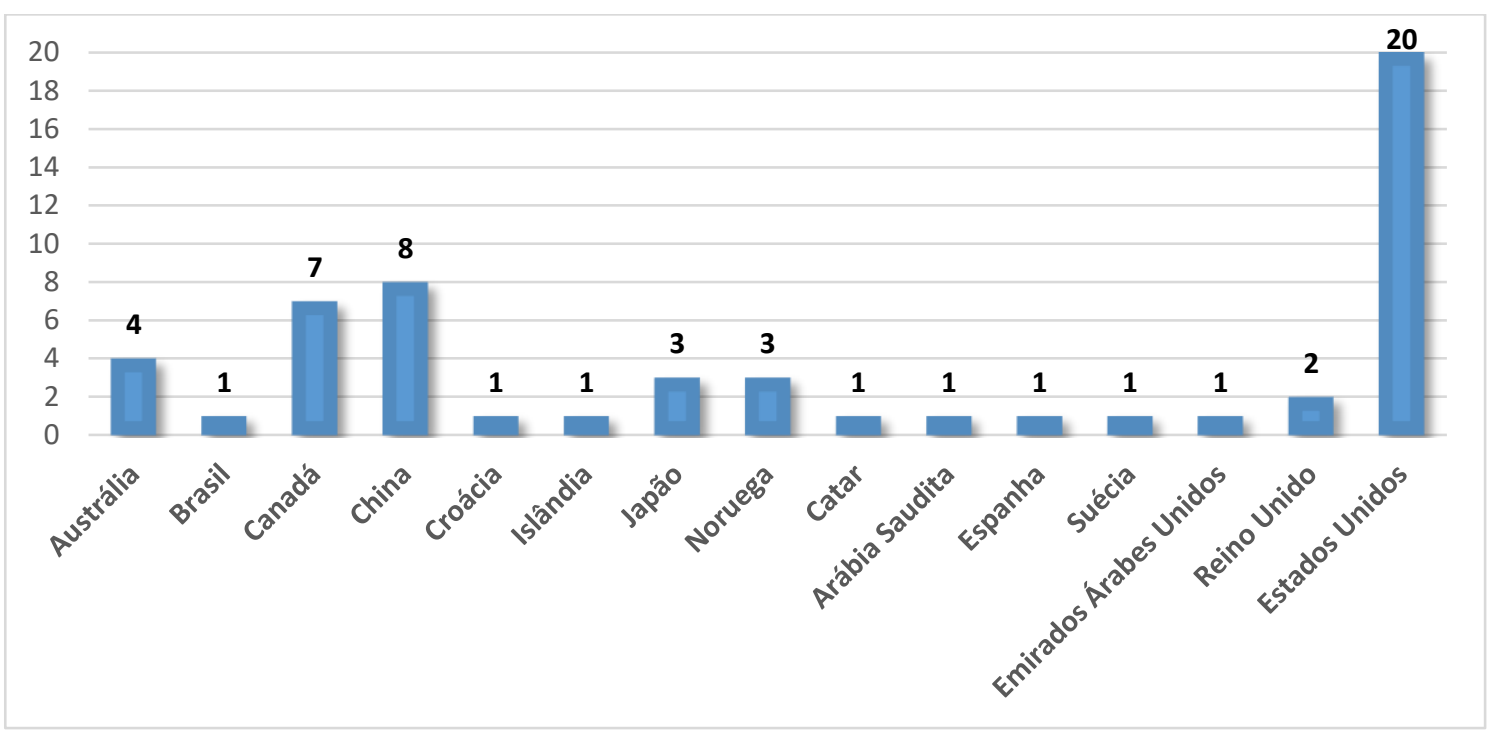

Fonte: Elaborado pelo autor

Embora tenha aumentado por volta de 2020, quando as instalações operacionais representaram cerca de $29 \%$ do total, as instalações em operação ainda representam apenas 1/3 de todas, como observado no Gráfico 3.

No entanto, é importante ressaltar que existem cerca de 61 instalações em construção ou projetos sendo desenvolvidos, o que representa um grande potencial de crescimento na quantidade de $\mathrm{CO}_{2}$ capturado e armazenado globalmente, além dos hubs de CCUS existentes e em projeto no mundo.

Gráfico 3: Status das instalações de armazenamento de $\mathrm{CO}_{2}$ no mundo em 2021

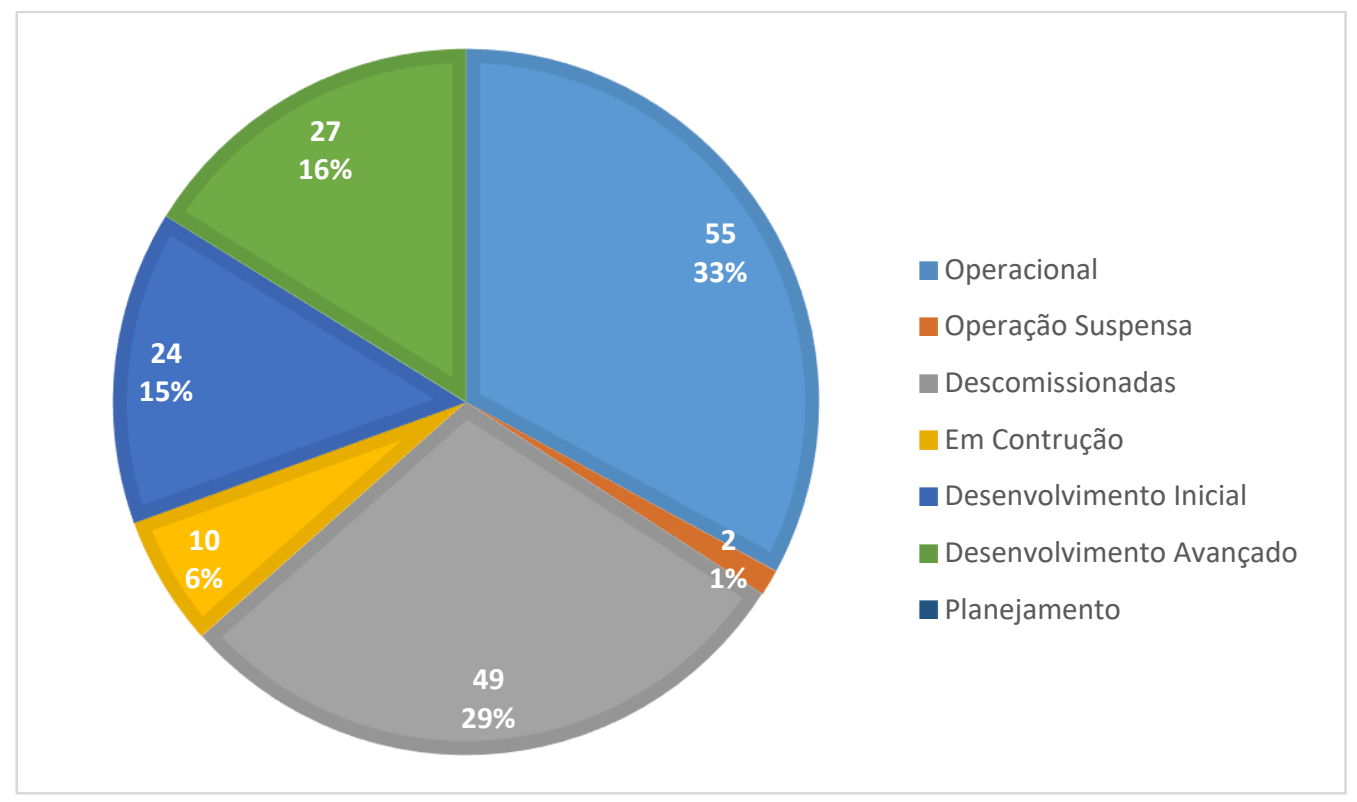

Fonte: Elaborado pelo autor 


\subsection{Contexto do ESG na atual conjuntura mundial}

De acordo com a UN Global Compact, ESG é uma sigla em inglês que significa Environmental, Social and Governance, e corresponde às práticas ambientais, sociais e de governança de uma organização. $O$ termo foi cunhado em 2004 em uma publicação do Pacto Global em parceria com o Banco Mundial, chamada Who Cares Wins. Surgiu de uma provocação do secretário-geral da ONU Kofi Annan a 50 CEOs de grandes instituições financeiras, sobre como integrar fatores sociais, ambientais e de governança no mercado de capitais (UN GLOBAL COMPACT, 2021).

$\mathrm{Na}$ conjuntura atual, observa-se o aumento do engajamento, interesse e investimentos de diversos setores no ESG, principalmente em virtude da necessidade da transição para o mundo Net-Zero. Os consultores ESG estão procurando tecnologias que possam fornecer tal mudança, sendo CCS uma tecnologia cada vez mais bem colocada para atingir tal meta (GLOBAL CCS INSTITUTE, 2020).

Segundo o site da ONU, o Climate Change and Sustainability Services, da Ernest Young, ratifica que as informações ESG são essenciais para a tomada de decisões dos investidores, sendo inclusive totalmente relacionados aos Objetivos de Desenvolvimento Sustentável (ODS) da ONU, tema bastante presente nas discussões no mercado de capitais (UN GLOBAL COMPACT, 2021).

Há um claro direcionamento e corrida corporativa para se adequar e desenvolver aspectos de ESG em suas companhias, se tornando mainstream em investimentos financeiros nos últimos anos em todo o mundo (KANAMURA, 2021). A tendência mundial rumo ao ESG e sua popularidade já se dava antes mesmo da pandemia ${ }^{4}$, onde o The Wall Street Journal relatou, mais precisamente em 24 de junho de 2019, que os investidores estão se tornando cada vez mais seletivos sobre suas

\footnotetext{
${ }^{4} \mathrm{O}$ impacto do Covid-19 afetou formuladores de políticas, investidores e empresas em escala global, tendo o ESG ganhado ainda maior popularidade em todo o mundo. Para se ter ideia, os fundos ESG representam quase um terço de todas as vendas de fundos europeus de abril a junho de 2020, com fundos de ações sustentáveis atraindo $63 \%$ a mais do que seus pares tradicionais. Em escala global, os fundos ESG atraíram entradas de US\$ 71,1 bilhões no segundo trimestre e atingiram um recorde de US\$ 1 trilhão em capitalização de mercado em 2020 (DÍAZ, 2021).
} 
carteiras, aumentando suas participações em empresas que se alinham com seus valores, relacionados em particular, ao meio ambiente e questões sociais (DÍAZ, 2021).

O fato da quantidade emitida de títulos de sustentabilidade, que podem ser chamados de títulos ESG, ter aumentado de 14,8 bilhões de dólares em 2013 para 261,4 bilhões de dólares em 2018, comprova o item anterior. Esse aumento é dezessete vezes mais do que o montante em 2013. Em 2019, foram 465 bilhões de dólares, quase o dobro do montante em 2018 (KANAMURA, 2021).

Além disso, a UN Global Nation destacar em seu site, na versão brasileira, a adoção pela BlackRock - maior gestora de ativos do mundo, com mais de USD 6 trilhões em carteira - do uso de métricas ESG em 2020 em todas as suas análises de riscos. O site ainda destaca a adoção em setembro de 2020 pela B3 bolsa de valores brasileira - do índice S\&P/B3 Brasil ESG, parceria com a S\&P Dow Jones. Esse índice utiliza critérios baseados em práticas ambientais, sociais e de governança para selecionar empresas brasileiras para sua carteira (UN GLOBAL COMPACT, 2021).

Ainda em relação à B3, a bolsa de valores informou em julho de 2021 que alterou a metodologia do Índice de Sustentabilidade Empresarial (ISE) e vai permitir, a partir de janeiro de 2022, que gestores e investidores possam mapear quais são as empresas da bolsa mais avançadas na agenda ESG, verificando notas individualizadas por temas e ranqueamento geral de todas as empresas listadas (D’ÁVILA, 2021).

\section{Referencial Teórico}

Após a revisão bibliográfica, verificou-se que o tema abordado por esta dissertação não era explorado por nenhum outro autor ou referencial documental que correlacionassem os temas P\&D, CCS e ESG, tampouco que oferecesse instrumentos e métodos de apoio ao P\&D para gerenciamento dos riscos associados ao armazenamento de $\mathrm{CO}_{2}$, mais precisamente, ao monitoramento das instalações de 
armazenamento, que pudessem se correlacionar ao ESG. Surgiu, portanto, a necessidade de construir, a partir dos conhecimentos obtidos, um referencial teórico capaz de explorar as hipóteses testadas neste trabalho e oferecer caminhos rumo ao objetivo do mesmo.

Observou-se, a partir de então, que os autores explorados abordavam constantemente quatro aspectos que abrangiam o $\mathrm{P} \& \mathrm{D}$, a prática de monitoramento das instalações de armazenamento de $\mathrm{CO}_{2}$ bem como ESG. Essas práticas abordadas são resumidas na Figura 5 e detalhadas na sequência.

Figura 5: Esquemática das principais práticas identificadas na revisão de literatura envolvendo P\&D e monitoramento de instalações de armazenamento de $\mathrm{CO}_{2}$.

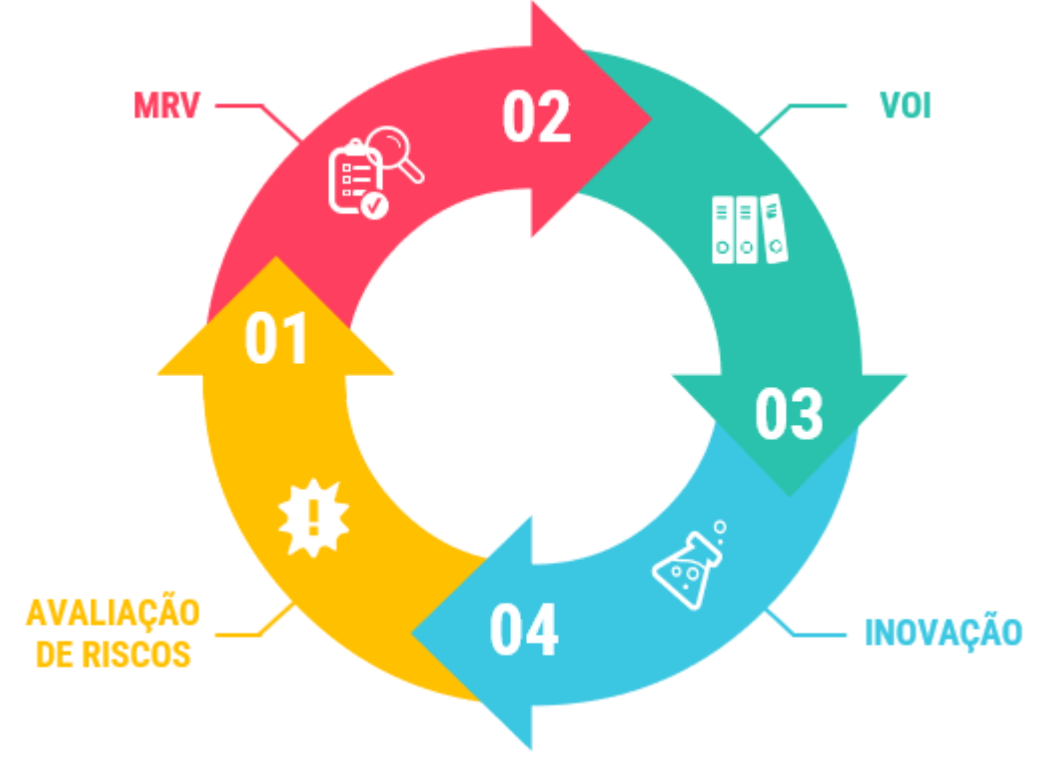

Fonte: Elaborado pelo autor

A avaliação de risco precede a etapa de MRV (Monitoramento, Reporte e Verificação), uma vez que fornece todas as informações e análises necessárias antes mesmo do licenciamento do local onde será alocada a instalação de armazenamento de $\mathrm{CO}_{2}$, bem como o método de avaliação de risco a ser desenvolvido e gerenciado ao longo do armazenamento e pós-descomissionamento da instalação.

A etapa de MRV é a etapa que irá coletar todos os dados, enviar às partes interessadas e aferir o grau de confiabilidade dos mesmos. A etapa precede ao VOI (Valor da Informação), que com base nestes dados, os analisará quantitativamente e qualitativamente, vinculando-os às incertezas, riscos e 
consequências existentes na operação, com intuito de auxiliar em tomadas de decisões, que podem incluir a parada de injeção de $\mathrm{CO}_{2}$ no reservatório.

A etapa do VOI é capaz ainda de fornecer subsídios importantes que determinam as tecnologias que devem ser utilizadas para melhor coleta, tratamento e análise dos dados bem como as inovações necessárias para diminuir os riscos inerentes à atividade. Através das inovações tecnológicas é possível complementar o Plano de Monitoramento contemplando novos métodos de prevenção de acidentes e avaliação de riscos, reiniciando assim o ciclo.

A seguir, encontram-se alguns dos principais autores que abordam os quatro aspectos mencionados:

i) Avaliação de Risco: Um dos métodos de avaliação de risco mais utilizados é o bowtie. O método de avaliação de risco usando o bowtie baseia-se na abordagem bem estabelecida de barreira (salvaguarda) para o gerenciamento de riscos. O objetivo final é identificar as tarefas de monitoramento e as respectivas tecnologias necessárias para reduzir os riscos de armazenamento tão baixos quanto razoavelmente viáveis (DEAN, 2017). O bowtie é um método capaz de identificar previamente as barreiras degradadas para manutenção da integridade da instalação e de propor medidas corretivas para o caso de ocorrência de evento indesejado. $O$ método fornece uma estrutura para avaliação sistemática de riscos de eventos com o potencial de afetar o desempenho do armazenamento (DEAN, 2017).

Há necessidade de revisão constante deste método, uma vez que as ameaças, ou seja, as condições que podem levar ao vazamento, bem como as possíveis consequências, podem mudar constantemente. Além disso, a depender do contexto regulatório destas mudanças, as salvaguardas corretivas e preventivas também podem mudar, sendo necessárias inclusive desenvolvimento de novas tecnologias para contenção do vazamento de $\mathrm{CO}_{2}$ (DEAN, 2017).

Portanto, os conceitos envolvendo bowtie devem ser pauta de constantes pesquisas e desenvolvimentos, para que se evitem que acidentes ocorram, como vazamento de $\mathrm{CO}_{2} \mathrm{e}$, caso ocorram, sejam remediados da melhor forma e no tempo mais rápido possível. 
ii) MRV: Os processos inerentes ao MRV são dinâmicos e mudam de acordo com o ambiente de armazenamento de $\mathrm{CO}_{2}$, das regulamentações aplicáveis e das condições operacionais necessárias a realizar o armazenamento de forma segura (DOE, 2009; BLACKFORD, 2010; JENKINS, 2015; HARBERT, 2016; DEAN, 2017; DOE, 2017). Importante frisar que o monitoramento para contenção é uma tarefa crítica do HSE - Health, Safety and Environment e prevalece sobre o monitoramento da conformidade (DEAN, 2017).

A integração do monitoramento e avaliação de riscos são de interesse das partes interessadas, incluindo pesquisadores, reguladores estaduais e federais, provedores de garantia financeira e operadores de projetos de armazenamento. A Agência de Proteção Ambiental dos Estados Unidos (EPA) e outros reguladores por exemplo exigem que os projetos de CCS implementem sistemas de monitoramento e emissão de relatórios e verificação (MRV) que detectam vazamento de $\mathrm{CO}_{2}$ do reservatório de contenção ou longe do local de armazenamento (HARBERT, 2016).

O MRV tem, de acordo com DEAN (2017), basicamente dois objetivos primários, que é certificar-se do atendimento às conformidades e garantia da contenção. JENKINS (2015) traz uma abordagem mais ampla, mostrando que para manter a conformidade e, consequentemente, manter $\mathrm{O}_{\mathrm{CO}_{2}}$ injetado contido, é necessário simular, testar e calibrar diversos modelos e comportamentos específicos daquele local naquele momento e o comportamento futuro. Porém, é necessário que as tecnologias tenham resolução, sensibilidade e capacidade quantitativa suficientes para testar e calibrar completamente os modelos de simulação (JENKINS, 2015).

Além disso, algo que não é muito explorado, mas é tão importante quanto, é o monitoramento dos impactos biológicos causados por eventual vazamento de $\mathrm{CO}$, que justamente por não ser tão explorado, requer uma série de pesquisas e desenvolvimento. O monitoramento do impacto biológico é problemático e complexo (BLACKFORD, 2010).

iii) VOI - Valor da Informação: O conceito de VOI no contexto da análise de decisões é estudado há décadas, onde envolvem aspectos de como as informações são obtidas, tratadas e usadas, avaliando os graus de incertezas e direcionando à redução dos riscos nas tomadas de decisões. Aplicações de análises 
de VOI para o gerenciamento de operações de captura e armazenamento de $\mathrm{CO}_{2}$ (CCS) são raras na literatura (SATO, 2011).

No contexto deste trabalho, o VOI seria mais indicado para a etapa de monitoramento das instalações de armazenamento de $\mathrm{CO}_{2}$. As estratégias de monitoramento são selecionadas em uma base específica do local, muitas vezes usando meramente o julgamento de especialistas. A avaliação quantitativa de riscos precisa de ferramentas mais rigorosas. A análise quantitativa da decisão e o valor das informações podem auxiliar na vinculação de incertezas e determinar quando informações adicionais podem ser úteis antes de tomar novas decisões, a de por exemplo, parar a injeção de $\mathrm{CO}_{2}$ ou realizar monitoramento adicional (HARBERT, 2016).

Pesquisar e desenvolver técnicas e tecnologias capazes de coletar e tratar as informações de forma otimizada diminuirá os custos envolvidos e aumentará os benefícios do projeto, sendo possível, por exemplo, selecionar a técnica de monitoramento mais adequada para pós-injeção (HARBERT, 2016). Uma avaliação quantitativa de risco permite que as técnicas de monitoramento sejam comparadas diretamente com base em sua capacidade de detectar os riscos mais significativos, como vazamento. Com o desenvolvimento do VOI, há melhoria da relação custobenefício, sendo possível uso de grande número de técnicas de monitoramento para o site (HARBERT, 2016).

iv) Inovação: As inovações tecnológicas associadas ao CCS são citadas e estudadas por diversos autores como sendo um dos pilares para o desenvolvimento e implantação desta tecnologia (STEPHENS, 2010; LAI, 2012; STORSET, 2019; LONGA, 2020; LORIA, 2021). Em 2021, por exemplo, foi realizado um estudo que explorou as lições aprendidas nos 50 anos de projetos de CCS existentes no mundo. No estudo, foi perguntado junto às principais empresas do setor sobre suas experiências e principais insights que obtiveram em seus projetos, ao qual guiariam outros futuros projetos. Além da eficiência operacional, da segurança do armazenamento geológico, da transparência e engajamento das partes interessadas e da construção de hubs e clusters, a inovação foi destacada como um dos principais insights necessários à evolução da indústria de CCS. A inovação tecnológica foi 
identificada como importante motor dos projetos de CCS, principalmente em relação ao monitoramento (LORIA, 2021).

A inovação melhora a economia do projeto, a velocidade na obtenção de autorização e constrói confiança e aceitação com o público em geral sobre a segurança do armazenamento geológico. Uma das partes interessadas entrevistadas mencionou que o desenvolvimento dos sistemas de monitoramento associados com a experiência auxilia, por exemplo, tanto na obtenção de permissões e tempos de licença quanto na melhoria da eficiência da atividade (LORIA, 2021). Outros autores complementam que os métodos de monitoramento podem ser testados, calibrados e desenvolvidos por meio de experiência na aquisição das informações e contribui para o desenvolvimento dos protocolos de monitoramento (ROBERTS, 2020).

Através dessa abordagem, que mostra o assunto sob a ótica de diferentes autores, é possível concluir que este é um referencial teórico capaz de criar uma linha de pesquisa a ser explorada e bem trabalhada. Além disso, a ISO $31000^{5}$, ao abordar aspectos relacionados ao processo de gestão de riscos, cita que neste tipo de processo há aplicação sistemática de políticas, procedimentos e práticas de gestão para as atividades de comunicação, consulta, estabelecimento do contexto, e na identificação, análise, avaliação, tratamento, monitoramento e análise crítica dos riscos (ISO 31000, 2009). Aliás, a ISO 31000 dedica uma parte para trabalhar especificamente sobre a importância do monitoramento dentro do processo de gestão de riscos, ao qual será abordado na seção de Resultados e Discussões (ISO 31000, 2009). Todos esses conceitos são, de certa forma, contemplados dentro desse referencial teórico, criando oportunidade para explorar o tema e os riscos associados à atividade de armazenamento de $\mathrm{CO}_{2}$.

\section{Materiais e Métodos}

\footnotetext{
${ }^{5}$ A ABNT NRB ISO 31000:2009 - Gestão de riscos; Princípio e Diretrizes, tem por objetivo fornecer princípios e diretrizes genéricas para a gestão de riscos, podendo ser aplicada ao longo da vida de uma organização e a uma ampla gama de atividades, incluindo estratégias, decisões, operações, processos, funções, projetos, produtos, serviços e ativos ou ainda aplicadas a qualquer tipo de risco, independentemente de sua natureza, quer tenha consequências positivas ou negativas. (ISO 31000, 2009)
} 
A partir das referências bibliográficas levantadas e do referencial teórico elaborado, a metodologia deste trabalho foi organizada em três etapas principais: (i) revisão sistemática da literatura (RSL), (ii) instrumentos e métodos de apoio ao P\&D para gerenciamento dos riscos associados ao armazenamento de $\mathrm{CO}_{2}$ e (iii) metodologia da pesquisa ex-post-facto.

i. Através de uma revisão integrativa e sistemática de literatura, (AULD, 2014; ZAMAN, 2018; MACURA, 2019; MILJAND, 2020), com uso de artigos acadêmicos e documentos oficiais, jornais e revistas, buscou-se informações sobre a aplicação e importância do P\&D no processo de monitoramento das instalações de armazenamento de $\mathrm{CO}_{2}$ e respectivos impactos no âmbito do ESG. Foram coletadas informações para responder à questão norteadora "Qual o papel e importância do P\&D no processo de armazenamento de $\mathrm{CO}_{2}$ e quais impactos que pesquisas e desenvolvimentos de novas tecnologias, por exemplo, poderiam trazer no âmbito do ESG às empresas operadoras das instalações de armazenamento de $\mathrm{CO}_{2}$ ?". Para a pesquisa bibliográfica (GERHARDT, 2009), foram selecionados principalmente artigos publicados na última década utilizando-se como referência a plataforma ScienceDirect, pesquisando-se pelas palavras-chaves presentes nesta dissertação. Após breve análise, foram selecionados e revisados os artigos acadêmicos referenciados neste trabalho. As análises através da pesquisa sistemática revelaram a necessidade de buscar os conceitos envolvendo o P\&D e monitoramento das instalações de armazenamento de $\mathrm{CO}_{2}$, bem como necessidade de realizar pesquisas especializadas sobre o tema proposto. Desta forma, através da pesquisa documental (GERHARDT, 2009), foram selecionados os principais documentos oficiais, jornais e revistas conceituadas bem como manuais e instituições de relevância internacional para revisão sistemática, como mostra a Figura 6. 
As referências foram segregadas de acordo os tópicos deste trabalho onde são citados.

Figura 6: Esquemática das principais bases consultadas durante a pesquisa documental

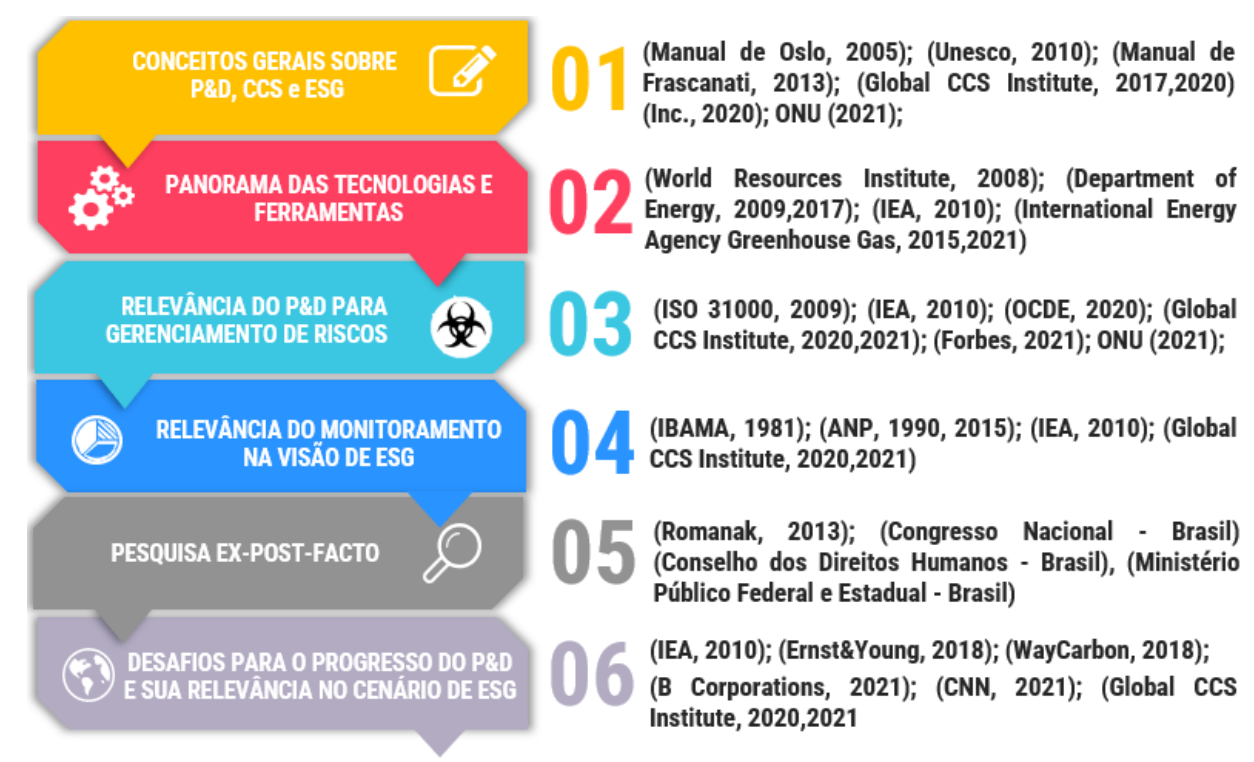

Fonte: Elaborado pelo autor

ii.

Após a revisão sistemática, verificou-se que o tema abordado por essa dissertação não era explorado por nenhum outro autor ou referencial documental, que correlacionassem os temas P\&D, CCS e ESG, havendo necessidade portanto de pesquisas adicionais, como mostrou o Referencial Teórico. Associado a isto, a partir dessa abordagem, também foi possível preencher lacunas bibliográficas e obter os resultados pretendidos no estudo. Uma das lacunas identificadas e supridas por este trabalho se relacionava à ausência de abordagem sobre como as tecnologias e ferramentas (ex.: ROV, AUV, aeronaves, etc) poderiam ser utilizadas na prática para realizar o monitoramento das instalações de armazenamento de $\mathrm{CO}_{2}$. Apenas IEAGHG (2015) abordava, de forma superficial, esse tema. Por isso, em virtude desse gap de informações, foi construído uma esquemática, consolidando em uma única imagem, como as tecnologias e ferramentas podem ser 
utilizadas para monitorar tais instalações, tanto onshore (em terra) quanto offshore (no mar). Além disso, através da pesquisa ex-postfacto (GERHARDT, 2009) identificou-se oportunidade de trazer exemplos práticos acerca do papel do $\mathrm{P} \& D$ e do monitoramento na prevenção de acidentes de processos e desenvolvimento do ESG, reforçando a importância do tema explorado nesta dissertação.

iii. A pesquisa ex-post-facto tem por objetivo investigar possíveis relações de causa e efeito entre um determinado fato identificado pelo pesquisador e um fenômeno ocorrido. A principal característica deste tipo de pesquisa é o fato de os dados serem coletados após a ocorrência dos eventos para serem investigados (GERHARDT, 2009). Portanto a dissertação abordará dois fatos que confirmam como acidentes ambientais afetam a empresa, em todos os níveis de ESG além dos impactos financeiros (rompimento da barragem de Mariana) bem como as percepções de riscos afetam a opinião pública e como uso de tecnologia pode auxiliar na detecção de vazamento de $\mathrm{CO}_{2}$ e trazer maior confiança do uso de CCS (vazamento de $\mathrm{CO}_{2}$ na Fazenda Kerr).

O primeiro fato pesquisado se relaciona ao rompimento de uma barragem, localizada em Mariana, e foi escolhida em virtude de o evento poder se enquadrar em um Acidente de Processo, categoria geralmente associada a acidentes ocorridos nas instalações de armazenamento de $\mathrm{CO}_{2}$. Além disso, na denúncia do Ministério Público Federal (MPF), há uma ênfase em relação ao monitoramento das atividades e condições das barragens, aparecendo tal termo por exemplo mais de 50 vezes no relatório. Inclusive, a denúncia explora a forma como a empresa denunciada realizava o monitoramento das barragens, como por exemplo, se a periodicidade do monitoramento e os instrumentos usados estavam de acordo com seu Plano de Monitoramento que, neste caso, denominava-se "Manual de Segurança e Operação". Este estudo explorou as principais referências oficiais sobre o acidente, 
identificando e classificando todas as consequências decorrentes da tragédia e aferindo o impacto destas consequências em relação ao ESG da empresa denunciada, consolidados no Apêndice D.

O segundo fato pesquisado se relaciona à uma falsa denúncia de vazamento de $\mathrm{CO}_{2}$ armazenado em subsolo na Fazenda Kerr, utilizando-se a tecnologia de CCS (ROMANAK, 2013; BOYD, 2016; IEAGHG, 2021). Esse exemplo foi escolhido em virtude de ser o evento mais famoso relacionado à vazamento de $\mathrm{CO}_{2}$ advindo de CCS e de permitir explorar aspectos relacionados ao P\&D e ESG. Será abordado, por exemplo, importância do uso das melhores técnicas e métodos de monitoramento de vazamento de $\mathrm{CO}_{2}$ para a época, bem como o uso dessa tecnologia pela empresa denunciada afetava a opinião pública e, ao contrário do primeiro caso, reforçou a percepção positiva de ESG da empresa.

\section{Resultados e Discussão}

\subsection{Panorama das tecnologias e ferramentas para armazenamento de $\mathrm{CO}_{2}$ no contexto de P\&D}

Através de pesquisas mencionadas na seção de Materiais e Métodos, esta dissertação identificou dezenas de tecnologias, ferramentas e protocolos para o monitoramento das instalações de armazenamento de $\mathrm{CO}_{2}$ (WRI, 2008; DOE, 2009; DIXON, 2015; JENKINS, 2015; IEAGHG, 2015; HARBERT, 2016; DEAN, 2017; DOE, 2017; IEAGHG 2021). A enorme quantidade detectada bem como diversos cenários possíveis de uso inviabilizaria, por ora, um aprofundamento em cada uma das tecnologias e ferramentas. Porém, foram observadas características bastantes latentes entre todos os autores no que se diz respeito à relevância do aprimoramento, pesquisas e desenvolvimentos das tecnologias e ferramentas de monitoramento, ao qual iremos explorar. 
Desta forma, conforme também mencionado em Materiais e Métodos, foi construído uma esquemática, consolidando em uma única imagem, como as tecnologias e ferramentas podem ser utilizadas para realização do monitoramento, tanto onshore (em terra) quanto offshore (no mar), como mostra a Figura 7 e descrito na Tabela 2.

Figura 7 - Tecnologias e ferramentas utilizadas para o monitoramento das instalações de armazenamento de $\mathrm{CO}_{2}$ onshore e offshore

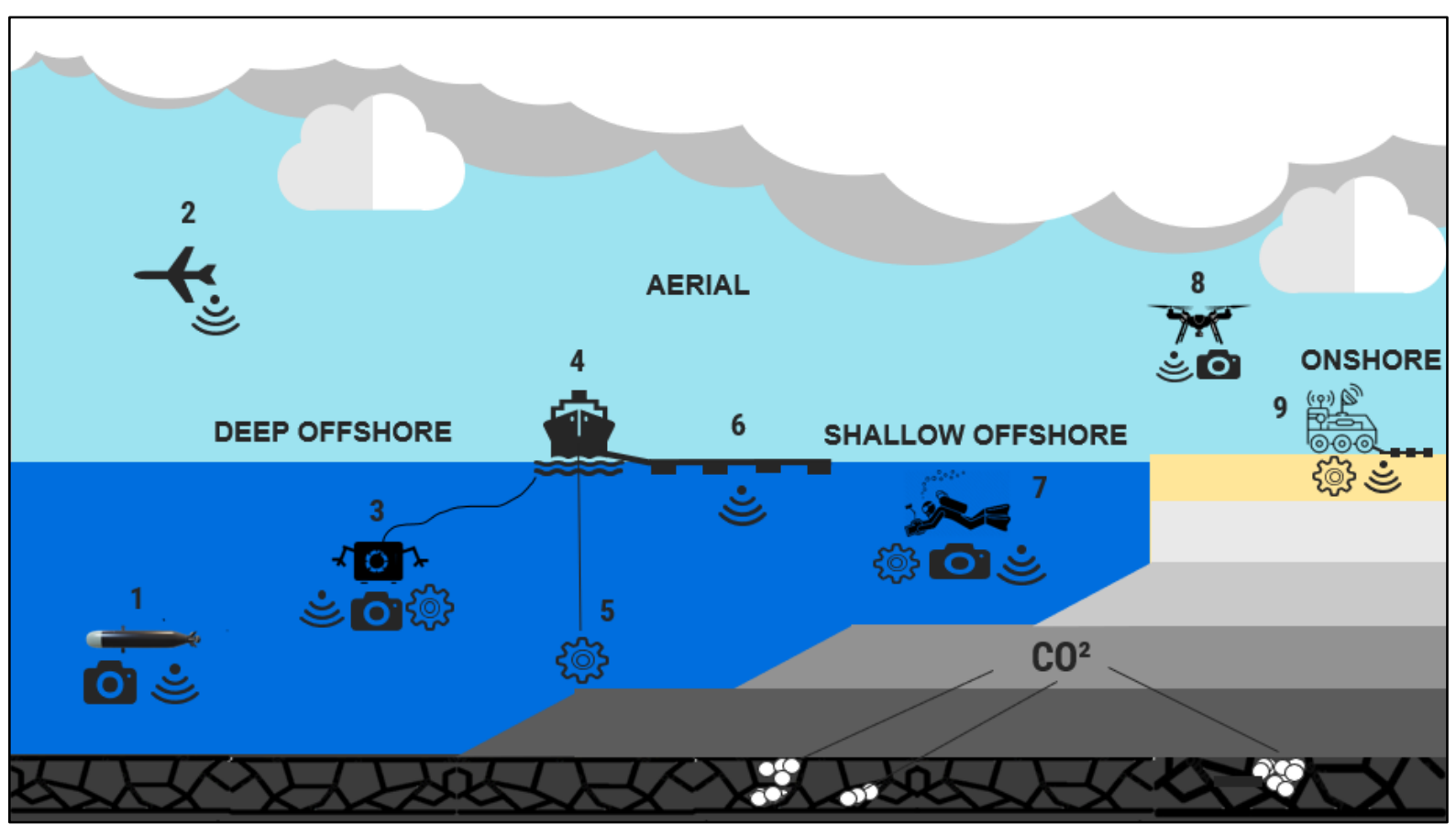

Fonte: Elaborado pelo autor

Tabela 2 - Tecnologias e ferramentas utilizadas para realização do monitoramento onshore e offshore

\begin{tabular}{ll}
\hline Referencial & Descrição \\
\hline $\mathbf{1}$ & AUV (Autonomous Underwater Vehicle) \\
\hline $\mathbf{2}$ & Aeronave de apoio \\
\hline $\mathbf{3}$ & ROV (Remotely Operated Vehicle) \\
\hline $\mathbf{4}$ & RSV (ROV Support Vessel) \\
\hline $\mathbf{6}$ & Equipamentos/Ferramentas Submarinas \\
\hline $\mathbf{7}$ & Hidrofones \\
\hline $\mathbf{8}$ & Mergulhador profissional (raso ou profundo) \\
\hline $\mathbf{9}$ & Drone \\
\hline
\end{tabular}

Fonte: Elaborado pelo autor 
Com objetivo de tornar ainda mais didática a imagem, a pesquisa selecionou exemplos de técnicas utilizadas para cada tecnologia e ferramenta identificada, conforme tabela a seguir:

Tabela 3 - Exemplos de técnicas utilizadas para monitoramento das instalações de armazenamento de $\mathrm{CO}_{2}$

Exemplo de Técnica
$\begin{aligned} & \text { Gravimetria, pesquisas sísmicas 3D, perfil sísmico vertical, dados de satélites ou } \\ & \text { aerotransportados. }\end{aligned}$
$\begin{aligned} & \text { Mudanças na vegetação observadas no solo, ROV para deteç̧ão de vazamentos } \\ & \text { (bolhas), anomalias na vida marinha e Terrestre. }\end{aligned}$
$\begin{aligned} & \text { Anomalias químicas na água do mar, amostras de fundo de mar, amostras do ar, do } \\ & \text { solo e sedimentos, química dos fluxos de bolhas vazadas, pressão/temperatura do } \\ & \text { poço. }\end{aligned}$

Fonte: Elaborado pelo autor a partir de (WRI, 2008; DOE, 2009; DIXON, 2015; JENKINS, 2015; IEAGHG, 2015; HARBERT, 2016; DEAN, 2017; DOE, 2017; IEAGHG 2021).

Em relação às características latentes observadas entre os materiais estudados, podemos verificar um destaque para a importância do aprimoramento das pesquisas e desenvolvimentos das tecnologias e ferramentas de monitoramento. Dixon (2015), por exemplo, traz um contexto histórico, lembrando que desde os primeiros protocolos de monitoramento, importantes avanços foram feitos na detecção e atribuição de vazamentos e importantes conhecimentos foram adquiridos através da experiência do projeto (DIXON, 2015).

Essa discriminação ou atribuição da origem do vazamento também representa um ponto de decisão crítico que pode levar a nenhuma ação ou um monitoramento intenso e realização de remediações, a depender da origem do vazamento (DIXON, 2015). A necessidade do P\&D também abrange o desenvolvimento de técnicas para atribuição da origem dos vazamentos (natural ou através de ação humana), tanto que é considerado assunto relevante em reuniões importantes do IEAGHG denominadas Redes Conjuntas do IEAGHG (DIXON, 2015). 
Essas técnicas foram fundamentais para, por exemplo, explorar as origens do vazamento do "caso Kerr" no projeto de Weyburn (JENKINS, 2015; DIXON, 2015).

O desenvolvimento de linhas de pesquisas e inovação em tecnologias e ferramentas tendem a proporcionar redução de custos, sendo importante escolher bem os protocolos, as tecnologias e ferramentas para evitar que o monitoramento se torne dispendioso (DIXON, 2015; DEAN, 2017). Um exemplo prático encontrado nas pesquisas foi a tecnologia "Time-lapse multi-well DAS VSP", aplicada com sucesso em uma grande empresa petrolífera que trouxe resultados excepcionais, sendo constatada como uma alternativa substituta à outra ferramenta de maior custo e capaz de fornecer imagens de alta resolução perto dos poços de injeção (DEAN, 2017). Um ponto chave também considerado nos estudos é a necessidade de investimento em modelagens de monitoramento, que pode fornecer confiança na identificação dos sinais mais críticos para monitorar, bem como a frequência e duração necessárias para o monitoramento. Um custo-benefício quantitativo, ou análise de VOI - valor de informação, pode então identificar as ferramentas e protocolos de monitoramento mais eficazes para minimizar riscos (HARBERT, 2016).

O desenvolvimento de tecnologias é desafiador, mas também proporciona maior aderência no atendimento à conformidade do projeto (DIXON, 2015; HVIDEVOLD, 2015; DEAN, 2017), como atendimento às regulamentações americanas da Lei de Água Potável Segura e Lei do Ar Limpo, a diretiva da UE 2009/31/CE, Protocolo de Londres de 1996 e à Convenção OSPAR (HVIDEVOLD, 2015). O desenvolvimento de tecnologias poderia auxiliar, por exemplo, no atendimento à Lei do Ar Limpo, que exige quantificação de fontes de emissões, um plano de monitoramento, emissão de relatórios e verificação (MRV) (JENKINS, 2015).

Há necessidade adicional de explorar e desenvolver os Planos de Monitoramento que, quando bem definidos, são capazes de detectar e quantificar o vazamento, determinar as causas, potenciais consequências e as remediações, atendendo à regulamentação do local (DIXON, 2015). Há desafios adicionais em relação à quantificação de vazamento, pois além de ser cara, as técnicas de medição para quantificação exigem altas sensibilidades, baixas incertezas e alta densidade espacial - que pode tornar o projeto ainda mais caro - e também pode depender de quão bem as etapas de monitoramento anteriores foram realizadas. Por outro lado, 
instituir um nível tão alto de monitoramento também pode incitar ansiedade pública desnecessária e, portanto, só deve ser desencadeada nos casos em que o vazamento real tenha sido confirmado (DIXON, 2015).

O desenvolvimento de novas técnicas de monitoramento, compreensão de processos e avanços na aplicação de técnicas existentes associadas à crescente quantidade de técnicas auxiliam na obtenção de confiabilidade do projeto além de melhorar a precisão dos dados relatados (DIXON, 2015; DEAN, 2017). O projeto de monitoramento estratégico orientado ao risco avaliará tecnologias para detecção de variáveis-chaves associadas ao risco, e desenvolverá estratégias e protocolos de monitoramento, fornecendo insights e abordagens mais eficazes para selecionar as melhores tecnologias (HARBERT, 2016). Além disso, a avaliação de riscos e sua mitigação bem como monitoramento tornaram-se importante campo de estudos, com desenvolvimento de metodologias variadas e acúmulo constante de experiências em projetos reais de armazenamento de $\mathrm{CO}_{2}$. Esse desenvolvimento e amadurecimento elevam a maturidade dos processos e percepção do público em geral, que apresenta muitas vezes oposição em relação à tecnologia de CCS em virtude dos potenciais danos causados (JENKINS, 2015; NUNES, 2019). Projetos de pesquisas e desenvolvimento também são importantes para aumentar a compreensão científica em torno do tema e reduzir preocupações públicas (JENKINS, 2011).

A execução do monitoramento não requer apenas o ato de monitorar, mas também constantes pesquisas, desenvolvimentos, observações, comparações entre teoria e prática, dentre outros. Faz-se necessário verificar, por exemplo, o comportamento inesperado de migração de pluma, migração de $\mathrm{CO}_{2}$ fora da formação de contenção primária, verificação de novas tecnologias de monitoramento - que muitas das vezes requer ainda mais desenvolvimento, principalmente no ambiente offshore e até mesmo necessidade de adaptações à novas regulações (DEAN, 2017). Para componentes de superfície, técnicas de monitoramento padrão (por exemplo, medição de vazão e análise de gás) devem ser usadas para compilar inventários de fluxo de gás, incluindo estimativas de emissões evitadas de $\mathrm{CO}_{2}$ e emissões fugitivas, bem como para registro de volume injetado/massa de $\mathrm{CO}_{2}$ (IEA, 2010).

Em virtude da complexidade e relevância do assunto, bem como inúmeras tecnologias e ferramentas para detecção de vazamento de $\mathrm{CO}_{2}$, essa 
pesquisa consolidou os principais manuais e revisões referências na temática, ao qual podem ser verificados no Apêndice B.

Existe uma variedade de tecnologias de monitoramento de CCS, destinadas a monitorar o reservatório, a sobrecarga, o fundo do mar ou a coluna de água. O objetivo comum é detectar, caracterizar e quantificar qualquer vazamento de $\mathrm{CO}_{2}$ do local de armazenamento pretendido, mas a escolha da solução técnica certa para um determinado projeto não é trivial. Os estudos sísmicos, por exemplo, oferecem informações altamente valiosas sobre a migração e desenvolvimento da pluma de $\mathrm{CO}_{2}$ e mudanças nas propriedades geofísicas dentro e acima do reservatório, porém são pesquisas caras e realizadas raramente. Levantamentos eletromagnéticos e gravimétricos também são usados para monitorar $0 \quad \mathrm{CO}_{2}$ armazenado, oferecendo informações potencialmente úteis, mas menos detalhadas (WAARUM, 2016).

Limitações tecnológicas, custos, frequência (contínua, anual etc.), necessidade de mapeamento e descrição do local de armazenamento de $\mathrm{CO}_{2}$ são fatores que influenciam tanto na escolha da tecnologia a ser utilizada quanto na elaboração do plano de monitoramento (IPCC, 2006).

Outro aspecto relevante para estudo e monitoramento é a variação natural das condições do ambiente marinho, já que a atividade biológica, correntes, turbidez, temperatura da água e outros componentes faz com que a concentração da maioria das substâncias na coluna de água tenha flutuações naturais. Estas flutuações serão o resultado de várias flutuações sobrepostas ligadas a mudanças diurnas, lunares ou sazonais. Isso leva a um padrão complexo de variação em cada um dos parâmetros que torna difícil distinguir as flutuações naturais das condições iniciais de uma fuga do $\mathrm{CO}_{2}$ armazenado. Para interpretar medições de $\mathrm{CO}_{2}, \mathrm{pH}$ ou para indicar vazamentos, é necessário ter uma linha de base com flutuações naturais estabelecidas ao longo do tempo, incluindo flutuações diárias e sazonais. 0 monitoramento de vários parâmetros simultaneamente pode ativar a identificação de padrões covariantes que caracterizam mudanças naturais ou relacionadas a vazamentos e podem ser usados para diferenciar cada situação (WAARUM, 2016). 


\subsection{A relevância do P\&D para gerenciamento dos riscos associados ao monitoramento das instalações de armazenamento de $\mathrm{CO}_{2}$}

\subsubsection{Definições de risco e correlação com a etapa de monitoramento no CCS}

Todos os indivíduos, empresas ou sociedade estão suscetíveis a algum tipo de risco. É necessário entender, descrever, analisar, gerenciar e comunicar esses riscos, e a disciplina de avaliação e gerenciamento de riscos foi desenvolvida para atender a essa necessidade (AVEN, 2010). O risco é a chance de um evento acontecer, podendo acomodar resultados desejados ou indesejados, abordando incertezas em vez de probabilidades (AVEN, 2010; PAWAR, 2015).

Nas ciências sociais, o risco pode ser uma situação ou evento onde algo de valor humano (incluindo os próprios humanos) está em jogo e o resultado é incerto ou ainda uma consequência incerta de um evento ou atividade com respeito a algo que os humanos valorizam. Essas definições, que por si só são bastante complexas, expressam basicamente que o risco é um evento ou uma consequência de um evento. A atividade considerada pode produzir eventos e consequências e estes estão sujeitos a diversas incertezas (NARDOCCI, 2002; AVEN, 2010).

Uma definição amplamente adotada para risco pode ser verificada na ISO 31000 (ISO 31000, 2009), que traz consigo um complemento ainda mais detalhado da própria definição, como mostra a Figura 8. Segundo a ISO 31000, o risco é ainda muitas vezes caracterizado pela referência aos eventos potenciais e às consequências, ou uma combinação destas, sendo também expresso em termos de uma combinação de consequências de um evento (incluindo mudanças de circunstâncias) e a probabilidade de ocorrência associada (ISO 31000, 2009). 
Figura 8 - Riscos de armazenamento geológico de $\mathrm{CO}_{2}$
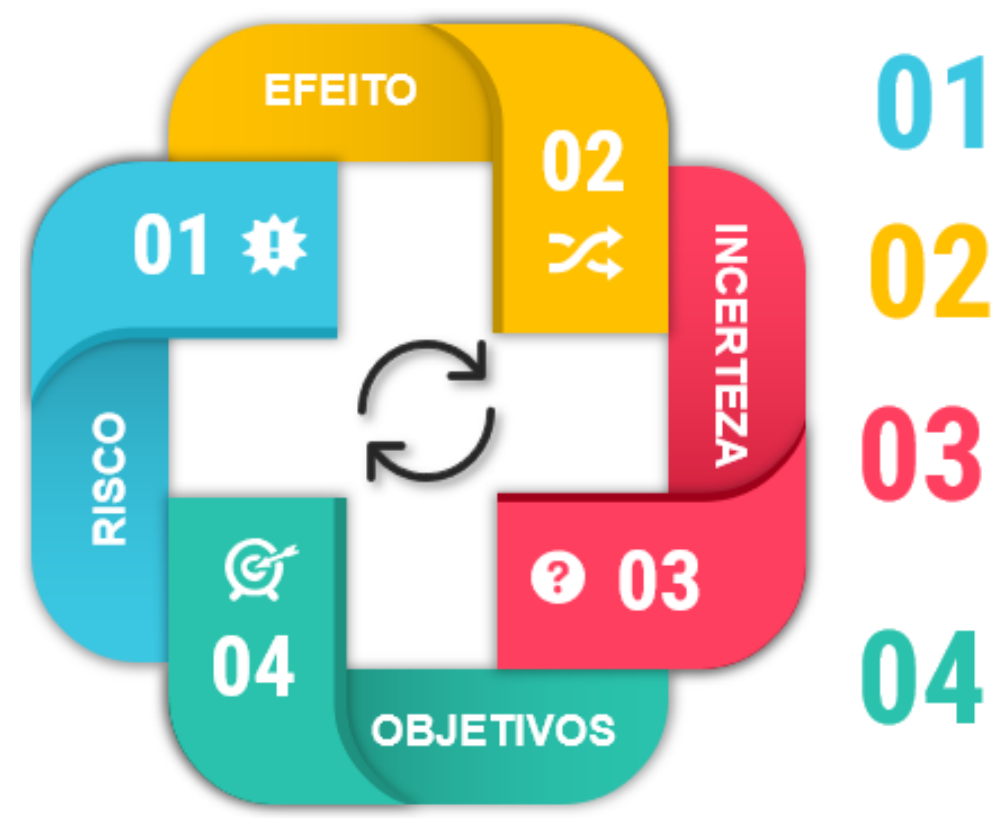

Risco é efeito da incerteza nos objetivos

Um efeito é um desvio em relação ao esperado - positivo e/ou negativo

A incerteza é o estado, mesmo que parcial, da deficiência das informações relacionadas a um evento, sua compreensão, seu conhecimento, sua consequência ou sua probabilidade

Os objetivos podem ter diferentes aspectos (metas financeiras, de saúde e segurança e ambientais) e aplicar-se em diferentes níveis (estratégico, organizacional, de projeto, de produto e de processo)

Fonte: Elaborado pelo autor

Outro conceito tão importante quanto é o que diz respeito à gestão de risco, que é o conjunto de ações e medidas preventivas e mitigadoras que devem ser tomadas depois de avaliadas e analisadas as causa e impactos de possíveis acidentes e seus efeitos sobre o meio ambiente e a saúde pública, através de técnicas apropriadas de análise de riscos, cujos resultados fornecem subsídios para uma decisão gerencial (GUERRA, 2019).

A gestão de riscos vem ganhando espaço na indústria mundial desde a década de 1950, e hoje se mostra como um procedimento padrão dentro das organizações que zelam pela qualidade de seus processos. A gestão de risco possibilita a antecipação de possíveis problemas, criando um cenário favorável ao planejamento estratégico e à prevenção (GUERRA, 2019).O Environmental Due Diligence é de suma importância para complemento à gestão de riscos, uma vez que é uma investigação legal e técnica conduzida para satisfazer certas proteções de responsabilidade utilizando leis ou normas ambientais estaduais e federais. A Due Diligence também pode ser usada para desenvolver informações sobre condições ambientais utilizadas para alocar responsabilidades e gerenciar riscos ambientais. (CEA, 2021) 
Ainda de acordo com a ISO 31000, no processo de gestão de riscos há necessidade da realização de um monitoramento da atividade em pauta que pode oferecer riscos. Segundo a norma, o monitoramento seria a verificação, supervisão, observação crítica ou identificação da situação, executadas de forma contínua, a fim de identificar mudanças no nível de desempenho requerido ou esperado. O monitoramento pode ser ainda aplicado à estrutura da gestão de riscos, ao processo de gestão de riscos, ao risco ou ao controle (ISO 31000, 2009).

Neste caso, o monitoramento das instalações de armazenamento do $\mathrm{CO}_{2}$ também é uma etapa fundamental, que envolve várias partes interessadas, tais como o operador, o órgão regulador e outras partes interessadas do projeto, incluindo investidores e o público em geral. O desenvolvimento de programas de monitoramento cada vez mais robustos possibilitam a aceleração da aceitação da tecnologia e futura implantação em larga escala (IEA, 2010; TARAKKI, 2018; NUNES, 2019). Monitorar as atividades de CCS é essencial para apoiar vários elementos cruciais de segurança e proteção e envolverá um portfólio de técnicas de monitoramento para detectar a presença ou ausência de $\mathrm{CO}_{2}$ no armazenamento primário de formação, bem como no complexo de armazenamento e na superfície (IEA, 2010; NUNES, 2019). Os principais propósitos do monitoramento incluem (1) garantir a efetividade dos controles de injeção, (2) detectar a localização e extensão da pluma de $\mathrm{CO}_{2}$ vazado, (3) identificar a eficiência e processos de armazenamento, (4) detectar e quantificar qualquer $\mathrm{CO}_{2}$ vazado, e (5) manter a segurança (Sato, 2011). O monitoramento pode ainda (1) garantir a integridade ambiental e a segurança do local de armazenamento geológico, (2) confirmar que $\mathrm{O}_{\mathrm{CO}_{2}}$ injetado está contido dentro do local de armazenamento geológico e dentro do limite do projeto e (3) garantir que o $\mathrm{CO}_{2}$ injetado esteja se comportando como previsto, a fim de minimizar o risco de qualquer infiltração ou outros impactos adversos (DIXON, 2015).

Segundo a IEA (2010), os principais objetivos do monitoramento de subsuperfície incluem o seguinte:

- Operação apropriada: para garantir que o modo acordado e permitido de operação seja seguido (por exemplo, pressão segura do reservatório). 
- Alerta precoce: para identificar eventuais irregularidades na injeção e migração de $\mathrm{CO}_{2}$, incluindo quaisquer sinais de vazamento potencial ou migração não intencional, de modo a iniciar medidas corretivas e remediação.

- Validação e calibração de modelos: validação de previsões do comportamento do nível de $\mathrm{CO}_{2}$ e destino em comparação com o comportamento observado é uma parte essencial das melhores práticas de gestão nos locais de armazenamento de $\mathrm{CO}_{2}$. Observações podem fornecer novas informações sobre as características da sub superfície que afetam o comportamento e o destino da $\mathrm{CO}_{2}$ (por exemplo, compartimentação de reservatórios, hidrogeologia e geometria), permitindo calibração do modelo e reformulação de previsões.

- Inventário de emissões: para quantificar qualquer vazamento de $\mathrm{CO}_{2}$ no caso de ser detectado. Se o vazamento for detectado, técnicas adicionais de monitoramento podem ser necessárias para apoiar a quantificação das emissões.

A atividade de CCS pode ser considerada como um projeto e abrange diversas fases e escopos. A Figura 9 mostra onde o monitoramento está inserido dentro desse escopo e em quais fases do projeto o monitoramento se correlaciona.

Figura 9: Fases de um projeto de CCS de acordo com o - Model Regulatory Framework

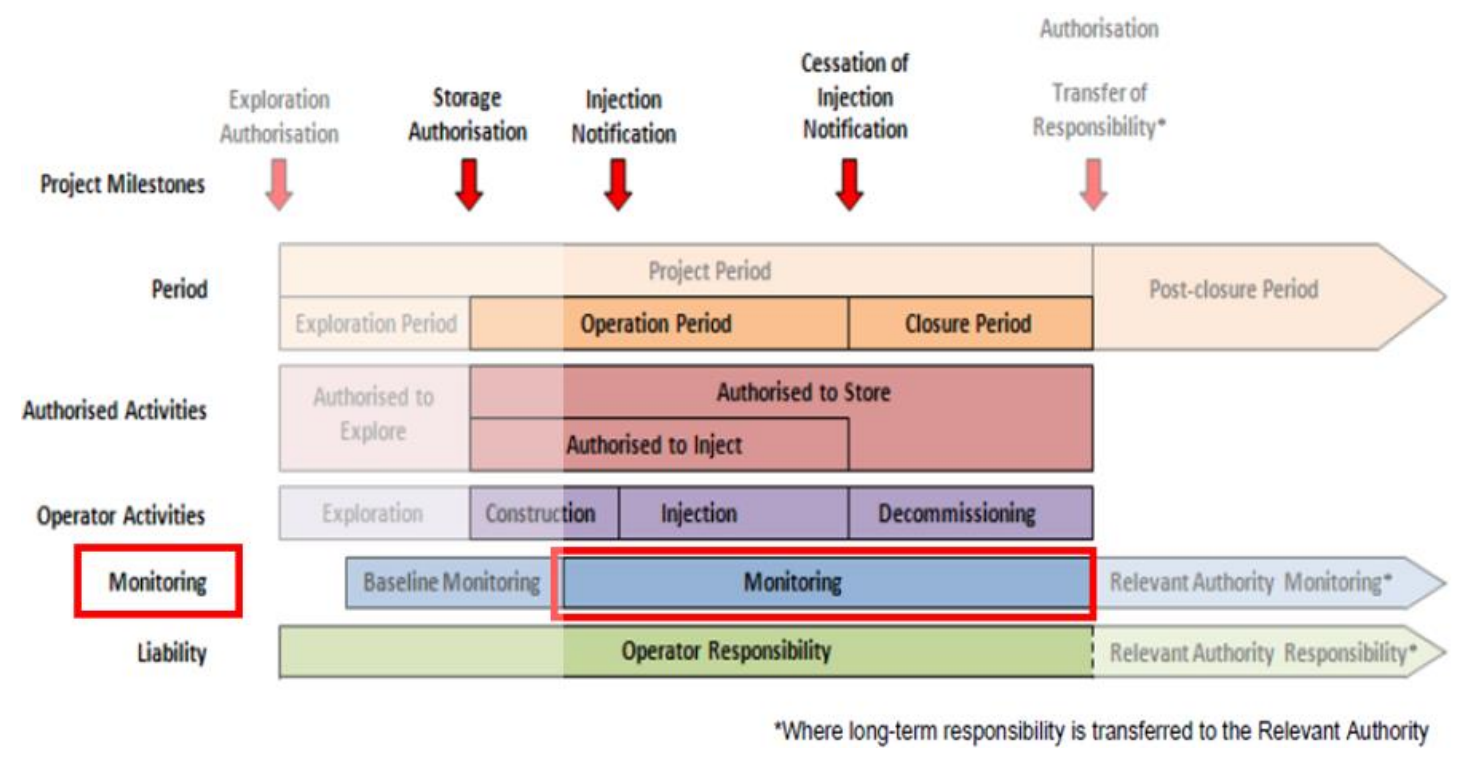

Fonte: IEA (2010)

Para a realização do monitoramento de uma instalação de armazenamento de $\mathrm{CO}_{2}$, um Plano de Monitoramento deve ser construído a fim de 
formalizar e registrar junto aos órgãos reguladores e obter as licenças para operação, uma padronização a ser seguida na fase de armazenamento de $\mathrm{CO}_{2}$ e pósdescomissionamento (NUNES, 2019). Os dados obtidos na etapa de viabilidade técnica - presentes no Plano de Monitoramento, permitirão a caracterização dos locais de armazenamento e parâmetros operacionais seguros (KETZER, 2016). Também é necessária caracterização rigorosa para um processo minucioso de avaliação de riscos, com objetivo de aferir a probabilidade de vazamento e os impactos associados, de forma que o vazamento possa ser identificado, monitorado e mitigado de forma adequada (KETZER, 2016).

O monitoramento de superfície ou próximo à superfície também precisa ser realizado antes da injeção para fornecer dados de referência e também durante e após a injeção para detectar quaisquer alterações ou impactos que possam surgir no caso improvável de vazamento (KETZER, 2016). Portanto, o monitoramento, o reporte e a verificação de $\mathrm{CO}_{2}$ (MRV) em projetos de CCS vão além dos limites do reservatório geológico alvo da injeção, ou à rocha selo de confinamento, uma vez que devem ser consideradas todas as áreas em que $0 \mathrm{CO}_{2}$ possa migrar, incluindo solo, corpos d'água e atmosfera (KETZER, 2016).

O monitoramento também será necessário após a interrupção da injeção no descomissionamento e, possivelmente, no pós-descomissionamento. Nestes períodos, o risco de fuga ou migração não intencional deve reduzir porque a injeção, que é a força principal em processos e fluxos acionados por pressão na subsuperfície, cessou. Além disso, a compreensão da subsuperfície também deve ter evoluído ao longo do tempo a partir da injeção inicial por causa do processo de aprendizagem e histórico do local (IEA, 2010). Isto significa que as previsões do modelo devem convergir cada vez mais com o comportamento ao longo do tempo. No entanto, o monitoramento nas fases de descomissionamento e pós-descomissionamento pode ainda ser necessária, pois o $\mathrm{CO}_{2}$ continuará a fluir e dispersar-se na subsuperfície após a interrupção da injeção (IEA, 2010).

Porém, se houver um alto nível de confiança de que as condições estão dentro dos parâmetros previamente estabelecidos, pode ser possível finalizar completamente qualquer atividade de monitoramento antes do prazo inicial. $\mathrm{O}$ 
monitoramento pode precisar recomeçar no caso de eventos que possam ter um efeito sobre a estabilidade de armazenamento ou novos riscos identificados (IEA, 2010).

Dada a importância da realização do monitoramento, será abordado nas próximas subseções os riscos associados à atividade de armazenamento de $\mathrm{CO}_{2}$, tanto operacionais - associados à segurança de processos, meio ambiente e saúde, bem como envolvendo aspectos do ESG. Embora vazamento de $\mathrm{CO}_{2}$ para o aquífero ou superfície gerem grandes custos financeiros, onde em alguns casos há necessidade de paralização completa das operações (ANYOSA, 2021), os riscos financeiros não serão explorados neste trabalho.

\subsubsection{Riscos operacionais e suas consequências}

Para diminuir os riscos inerentes à atividade de armazenamento de $\mathrm{CO}_{2}$, os operadores destas instalações são obrigados a monitorar a segurança destas instalações com uma perspectiva de longo prazo, principalmente para projetos offshore em larga escala. Esses projetos possuem investimentos significativos e potencial de riscos elevados e devem, portanto, possuir planos de monitoramento, reporte e verificação personalizados e economicamente viáveis (ANYOSA, 2021). O monitoramento também é necessário para garantia da conformidade com as principais recomendações mundiais, como o IPCC, que recomenda vazamento de $\mathrm{CO}_{2}$ injetado com menos de $1 \%$ de perda para a superfície ao longo de 1000 anos (PAWAR, 2015; ROBERTS, 2020).

Em virtude dos riscos associados, o monitoramento é realizado antes, durante e depois do projeto, onde há levantamentos de delineamento de reservatórios e monitoramento de linhas de base antes da operação, monitoramento periódico regular e levantamentos de contingência durante a fase de operação e monitoramento de garantia de conformidade durante a fase de fechamento (SATO, 2011). Um eventual vazamento poderia comprometer o projeto e acarretar danos e despesas, sendo um dos motivos de hoje os operadores buscarem desenvolver um monitoramento eficaz das instalações de armazenamento de $\mathrm{CO}_{2}$ (ANYOSA, 2021). 
Segundo Li (2016), existem duas categorias de riscos aos quais os vazamentos de $\mathrm{CO}_{2}$ poderiam acarretar, os riscos globais e riscos locais. Os riscos globais são associados à consequência mais amplas, como o aquecimento global e seus efeitos colaterais - que nesse caso, podem envolver inclusive incertezas quanto à eficácia da tecnologia de CCS junto às partes interessadas (LI, 2016). Tanto os riscos globais quanto locais abordados por $\mathrm{Li}(2016)$ foram mapeados e inseridos na Figura 10.

Figura 10 - Riscos de armazenamento geológico de $\mathrm{CO}_{2}$

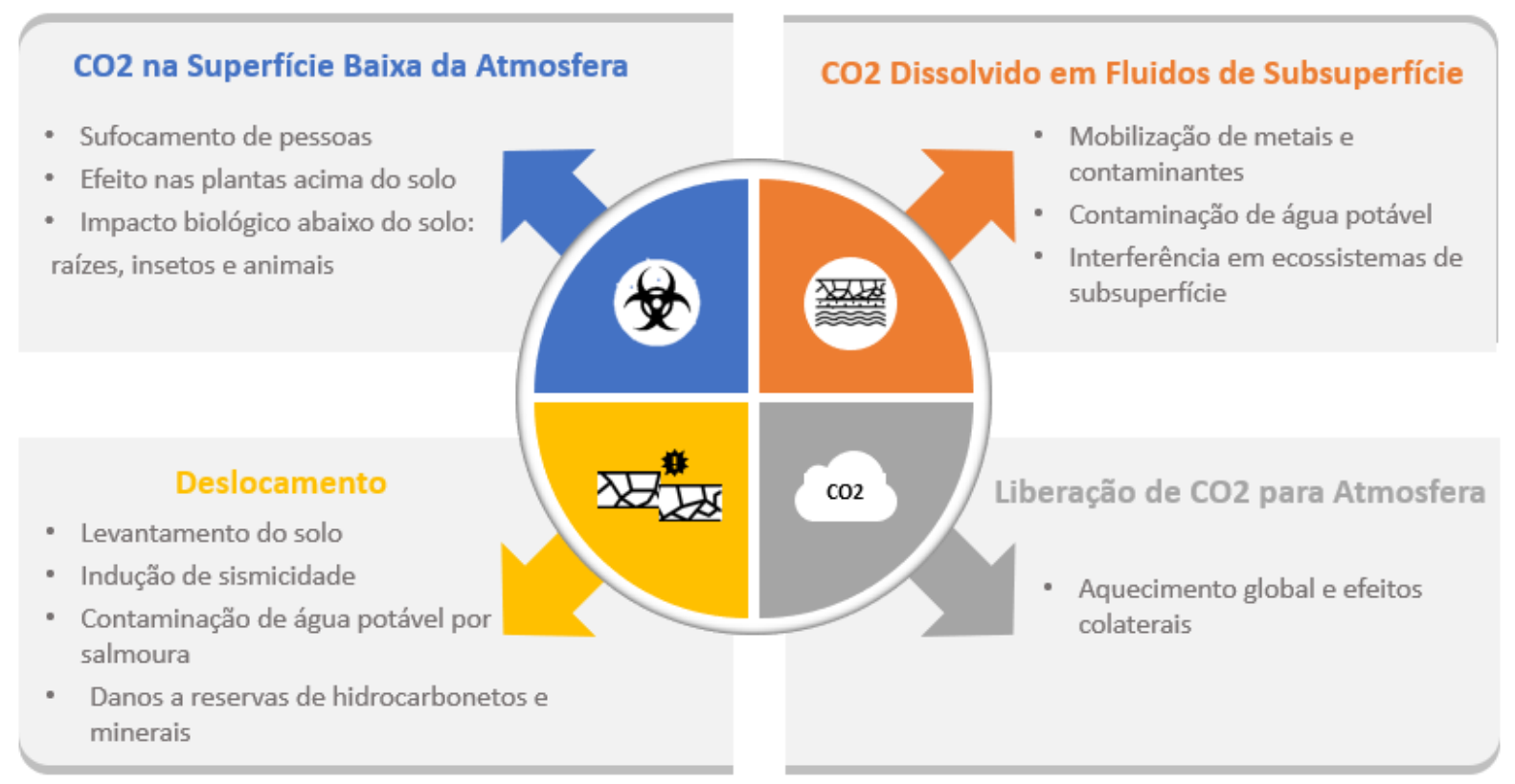

Fonte: Elaborado pelo autor

Além dos impactos acima destacados, verificou-se que o ambiente marinho seria um dos maiores prejudicados com um eventual vazamento de $\mathrm{CO}_{2}$ das instalações de armazenamento. É vital, portanto, que qualquer avaliação de risco da tecnologia de CCS inclua uma avaliação de risco dos potenciais impactos no ecossistema marinho (BLACKFORD, 2010).

Ainda em relação ao ambiente marinho, o Protocolo de Londres estabelece que devam existir programas de monitoramento em diversas esferas, como a forma que o $\mathrm{CO}_{2}$ injetado é retido na formação geológica, comportamento das camadas geológicas e detecção de migração de $\mathrm{CO}_{2}$ no leito marinho e comunidade marinha como um todo (DIXON, 2015; HVIDEVOLD, 2015). 
Em relação às águas subterrâneas, os impactos podem ser ainda maiores. Tanto que a Agência de Proteção Ambiental dos EUA (EPA), exige uma série de protocolos de monitoramento e cumprimento de leis específicas para realização do armazenamento de $\mathrm{CO}_{2}$. O Programa de Controle de Injeção Subterrânea (UIC) para proteção de águas subterrâneas sob a Lei de Água Potável Segura (SDWA) e a Lei do Ar Limpo (CAA), são apenas alguns outros exemplos de regulamentação que abordam aspectos relacionados ao monitoramento, reportes e verificações (HARBERT, 2016).

\subsubsection{Riscos para o ESG e suas consequências}

Os riscos relacionados à ESG associados ao monitoramento das instalações de armazenamento de $\mathrm{CO}_{2}$ podem se estender a diversas vertentes, às quais não poderiam ser explorados neste trabalho de forma exaustiva. Porém, apresenta-se uma breve análise dos impactos que tais riscos trariam aos operadores das instalações de armazenamento de $\mathrm{CO}_{2}$ bem como possíveis consequências, caso o monitoramento não seja realizado da forma correta.

Primeiro, conforme disposto pela Agência Internacional de Energia, para que o armazenamento de $\mathrm{CO}_{2}$ esteja devidamente enquadrado conforme as normas internacionais, é necessário o aprisionamento definitivo do gás em quantidade superior à $95 \%$ do $\mathrm{CO}_{2}$ injetado (IEA, 2010).

A ocorrência de vazamento pode acarretar uma série de riscos ao operador junto às partes envolvidas no projeto. De forma geral, estudos apontam que empresas com maiores escores de ESG e intensidade de Responsabilidade Social Corporativa (RSE) oferecem menores riscos às partes interessadas e menor risco dessas empresas passarem por dificuldades financeiras. Todos esses aspectos contribuem para uma redução geral de riscos (CERQUETI, 2021).

Nesse sentido, em consonância com a redução do risco das partes interessadas, outro estudo descobriu que as empresas com um padrão mais alto de 
transparência se engajam em acumulação de notícias menos prejudiciais, diminuindo assim sua exposição ao risco de acidentes (CERQUETI, 2021). A transparência em relação ao tratamento e divulgação de informação de ESG é importante, pois à medida que mais investidores seguem a abordagem responsável do investimento, a quantidade e a qualidade dos dados de ESG divulgados pelas empresas torna-se mais importantes para análise e tomada de decisão na alocação do capital investido (YU, 2021).

Portanto, como visto, há uma forte relação entre ESG e a forma ao qual as informações são coletadas, tratadas e divulgadas ao público de interesse. Neste ínterim, o principal objetivo a ser analisado é o como as informações são coletadas, tratadas e divulgadas, que interpolam com o P\&D e o Plano de Monitoramento das instalações de armazenamento de $\mathrm{CO}_{2}$. Esse objetivo começa a ser alcançado ao analisar-se o último relatório da Global CCS Institute, denominado Global Status of CCS 2021 - CCS Accelerating to Net Zero, ao qual dedica uma parte de seu relatório para o ESG relacionado ao CCS. No relatório, é citado justamente a necessidade de as empresas analisarem e reportarem atentamente os dados que possam impactar seu ESG, já que tais informações são consideradas cada vez mais importantes para os investidores, acionistas e público em geral. Ressalta ainda que os custos para captação de investimentos e capitais bem como o olhar atento das instituições financeiras sobre ESG levam as empresas a uma análise crítica ainda mais robusta sobre suas próprias atividades (GLOBAL CCS INSTITUTE, 2021b).

Nesse âmbito, o Plano de Monitoramento fica como responsável por estabelecer os parâmetros a serem monitorados, em quais etapas (antes, durante e depois do comissionamento das instalações), a periodicidade do monitoramento e da análise e emissão dos relatórios aos órgãos competentes, da realização de auditorias para adequação à legislação vigente, reportes e contingência em casos de vazamento de $\mathrm{CO}_{2}$ (NUNES, 2019). Além disso, a execução plena do Plano de Monitoramento dá robustez ao projeto, demonstra organização da empresa e mostra aos investidores e aos órgãos, confiança quanto à estrutura de gestão da empresa e seu empenho no quesito de Qualidade, Segurança, Meio Ambiente e Saúde (NUNES, 2019). A Agência Internacional de Energia propôs um modelo de Plano de Monitoramento com requisitos mínimos a serem seguido, ao qual pode ser analisado no Apêndice $C$. 
Além das empresas analisarem e reportarem atentamente os dados que possam impactar seu ESG (GLOBAL CCS INSTITUTE, 2021b), com transparência em relação ao tratamento e divulgação de informação (YI, 2020; CERQUETI, 2021) e ainda, no caso em tela, analisar e reportar periodicamente informações inerentes à operação de armazenamento de $\mathrm{CO}_{2}$ através do Plano de Monitoramento, faz-se necessário atentar ao cumprimento do estabelecido na ISO 31000 no que tange ao item 4.3.7 "Estabelecimento de mecanismos de comunicação e reporte externos", que afeta diretamente o ESG. Segundo a norma, convém que a organização desenvolva e implemente um plano sobre como se comunicará com partes interessadas externas. Para tanto, é necessário assegurar a troca eficaz de informações, realizar corretamente o reporte externo para atendimento de requisitos legais, regulatórios e de governança, fornecer retroalimentação, usar comunicação para construir confiança na organização e comunicar devidamente as partes interessadas em evento de crise ou contingência. Convém ainda que estes mecanismos incluam processos para consolidar a informação sobre os riscos, a partir de uma variedade de fontes, levando em consideração sua sensibilidade (ISO 31000, 2009).

Outro aspecto importante em relação ao ESG e monitoramento se relaciona aos créditos de carbono ${ }^{6}$. Apesar de o ideal ser sempre evitar emissões, CCS é tecnologia end-of-pipe necessária aos cenários de emissões reduzidas e negativas, sobretudo em indústrias muito difíceis de descarbonizar, como cimento e aço (EPE, 2018). Projetos de CCS no âmbito do MDL (Mecanismo de Desenvolvimento Limpo) poderiam gerar uma quantidade importante de créditos à curto prazo e consequente ganho de tempo para a economia atual para a transição para o baixo carbono, já que ainda baseada em combustíveis fósseis (IEA,2010; CÂMARA, 2011).

Dito isto, uma vez que o armazenamento de $\mathrm{CO}_{2}$ é capaz de gerar crédito de carbono e ser uma importante ferramenta para monitorar o cumprimento de MDL, é necessário que haja constante pesquisa e desenvolvimento relacionado ao

\footnotetext{
${ }^{6}$ Segundo a Sustainable Carbon, um crédito de carbono é a representação de uma tonelada de carbono que deixou de ser emitida para a atmosfera, contribuindo para a diminuição do efeito estufa. $O$ crédito de carbono é a moeda utilizada no mercado de carbono, onde empresas que possuem um nível de emissão muito alto e poucas opções para a redução podem comprar créditos de carbono para compensar suas emissões. (SUSTAINABLE CARBON, 2021)
} 
método de validação da quantidade de $\mathrm{CO}_{2}$ de fato armazenado e também garantia que não haja vazamento de $\mathrm{CO}_{2}$, que poderia comprometer não só o $\mathrm{ESG}$ da empresa operadora e o uso da tecnologia de CCS como um todo, mas o próprio cumprimento dos acordos celebrados bem como eventuais reembolsos inerentes aos créditos.

Esses riscos mencionados ainda são potencializados em virtude da pouca informação que os investidores têm sobre como usar o ESG na escolha do melhor investimento, havendo opiniões bastante diferentes entre acadêmicos e profissionais de como o ESG irá ajudar ou prejudicar as partes envolvidas (PEDERSEN, 2020). Primeiro, porque é necessário que o ESG seja capaz de dar uma visão holística aos investidores, demonstrando por exemplo a pegada de carbono da empresa, uso e destino de produtos químicos tóxicos envolvidos nos processos (como o $\mathrm{CO}_{2}$ ) e esforços de sustentabilidade da empresa (FORBES, 2021). Depois, o foco pode estar voltado tanto às métricas de emissões de $\mathrm{CO}_{2}$ por fonte quanto às métricas focadas em resultados, que podem incluir aquelas que olham para os impactos ecológicos e de biodiversidade. Ainda assim, as métricas baseadas nas emissões de Gases de Efeito Estufa - GEE das empresas podem incluir, dentre outros, a medição da pegada de carbono, indicadores de redução de emissões de GEE relacionados à eficiência energética e emissões financiadas (OECD, 2020).

Todos esses relatos, acerca dos impactos que o monitoramento pode trazer ao ESG se conectam ao fato do P\&D aparecer como objeto principal e responsável por toda a parte técnica e tecnológica do como coletar, tratar e divulgar os dados obtidos in loco. Necessário lembrar que o desenvolvimento de P\&D tem sido extremamente importante há pelo menos um século para progresso econômico que é justamente impulsionado pela invenção e aplicação de novas tecnologias (UGONNA, 2021). 


\subsection{A relevância do monitoramento das instalações de armazenamento de $\mathrm{CO}_{2}$ na visão de ESG}

\subsubsection{Estruturas regulatórias associadas ao comissionamento e operação das instalações de armazenamento de $\mathrm{CO}_{2}$}

A Agência Internacional de Energia (IEA) produziu em seu Modelo de Estrutura de Regulamentação uma série de processos e normas para obtenção de autorizações ao longo do projeto.

Em virtude do nível de detalhamento abarcado pela IEA e pela ampla aplicabilidade nas mais diversas regulamentações dos países, foram retirados os principais trechos da estrutura que evidenciam a relevância do monitoramento das instalações de armazenamento de $\mathrm{CO}_{2}$.

De acordo com a IEA (2010), as abordagens reguladoras de CCS devem exigir que os operadores que desejam desenvolver e operar as instalações de armazenamento solicitem ao órgão regulador competente uma autorização específica de armazenamento antes de prosseguir com o desenvolvimento do projeto. Um processo de autorização permite a divulgação de detalhes técnicos do local proposto e o modo de operação planejado além de oportunidade de os reguladores avaliarem os detalhes técnicos do local e de mensurarem a capacitação do operador, bem como permitirem a consulta das partes interessadas sobre o projeto, incluindo o público em geral (IEA, 2010).

O Modelo de Estrutura de Regulamentação da IEA (2010) também aborda detalhes acerca do pedido de autorização de armazenamento que geralmente exigirá a divulgação das seguintes informações:

- Detalhes da entidade legal proponente do desenvolvimento e operação; 
- Evidência da competência técnica da entidade que irá desenvolver e operar no local;

- Fonte(s) de $\mathrm{CO}_{2}$ a ser recebida para injeção, incluindo composição, taxa de entrega, tempo e data prevista de cessação da oferta de $\mathrm{CO}_{2}$;

- Local(is) de injeção planejada, local(is) de armazenamento, massa de injeção (por unidade de tempo e total) e assim por diante;

- Localização e extensão geográfica do local de armazenamento, incluindo detalhes do complexo de armazenamento;

- Resultados do processo de caracterização do local, incluindo todas as informações coletadas e pesquisas realizadas (conjuntos de dados, mapas etc.) e os resultados da interpretação e análise;

- Resultados de estudos de modelagem de reservatórios e análise de sensibilidade;

- Resultados das avaliações de risco realizadas;

- Modos de operação propostos para o complexo de armazenamento (locais de injeção, pressões, taxas de injeção etc.);

- Planos de contingência no caso de qualquer vazamento significativo, migração não intencional ou irregularidade em um local de armazenamento;

- Resultados preliminares da pesquisa de base para o local e proposta de plano de monitoramento;

- Consideração de outras atividades de armazenamento em formações conectadas e interações de pressão como consequência de novos desenvolvimentos;

- Detalhes de outras atividades na área, incluindo a subsuperfície e arredores adjacentes e na área que cobre o local de armazenamento planejado.

A entidade reguladora deve avaliar um requerimento sobre os méritos técnicos, jurídicos e determinar se a autorização será concedida. O órgão regulador 
deve então lidar com quaisquer questões colocadas e determinar se deve emitir uma autorização. Se o órgão regulador não se sentir suficientemente informado sobre a segurança a curto, médio e longo prazo do local ou da viabilidade econômica das operações, deve ser dada ao requerente a oportunidade de fornecer informações e análises adicionais ou o pedido de autorização deve ser negado (IEA, 2010).

Pode ser útil, também, estabelecer um volume mínimo de armazenamento de $\mathrm{CO}_{2}$ em uma estrutura para simplificar o processo de aprovação de projetos de escala de pesquisa e desenvolvimento (IEA, 2010). A Diretiva de CCS da União Europeia, por exemplo, fixou o seu limiar regulamentar mínimo em 100.000 toneladas de $\mathrm{CO}_{2}$, o que, efetivamente, isenta projetos de pequena escala dos requisitos de aprovação ou autorização que se aplicam para projetos maiores. No entanto, projetos em escala de pesquisa e desenvolvimento podem, ainda, exigir processos de autorização para algumas atividades na União Europeia (IEA, 2010).

Sob a ótica legal, é importante que as estruturas regulatórias para armazenamento de $\mathrm{CO}_{2}$ garantam que qualquer vazamento significativo, migração não intencional ou outra irregularidade nas operações do local de armazenamento sejam corrigidas de maneira que quaisquer danos sejam remediados. Estruturas regulatórias de $\mathrm{CO}_{2}$ devem estipular quem será financeiramente responsável por medidas corretivas e medidas de remediação e quem executará essas medidas (IEA, 2010).

Neste ínterim, do conjunto de países que possuem legislação específica sobre atividades de CCS, questões relacionadas à operacionalidade, tal como rotinas de Monitoramento, Reporte e Verificação (MRV) possuem definições de metodologia para obter o licenciamento de operações de captura e armazenamento de $\mathrm{CO}_{2}$, bem como a forma como os proprietários dos locais e operadores devem gerir tais operações, especificando também periodicidade e características técnicas mínimas para emissão de relatórios de acompanhando das atividades (IEA, 2010).

As regulamentações que orientam a atividade de CCS geralmente trazem diversos aspectos e obrigações relacionadas à etapa de monitoramento das instalações de armazenamento de $\mathrm{CO}_{2}$. Foram selecionadas legislações de quatro 
países e retirados alguns trechos como exemplo para verificar como essas legislações tratam a etapa de monitoramento.

A Austrália tem um sistema de regulação CCS em constante evolução. Segundo Cook (2009), um fator-chave nessa situação é o fato de que a Austrália é um dos maiores emissores de GEE per capita do mundo, apesar de ser responsável por apenas $1,5 \%$ das emissões globais, devido à sua alta dependência da energia dos combustíveis fósseis.

Portanto, a Austrália estava preocupada em regular a implementação da tecnologia CCUS. O país possui regulamentações específicas sobre o mecanismo de sequestro geológico de carbono, detalhando vários critérios importantes, como competência, jurisdição, limites de emissão, incentivos fiscais e prestação de contas (MONTEIRO JÚNIOR, 2015).

A lei australiana chamada Greenhouse Gas Geological Sequestration Act (2008) declara que antes de iniciar a injeção de $\mathrm{CO}_{2}$ ou outros gases de efeito estufa, o detentor de uma injeção, monitoramento e licença deve submeter ao Ministro um "plano de monitoramento e injeção", incluindo a descrição das técnicas de monitoramento propostas, plano de monitoramento e verificação detalhando como o comportamento de qualquer gás de efeito estufa armazenado será monitorado e uma estimativa do custo das atividades de monitoramento e verificação (IEA, 2010).

Em relação ao Canadá, em todos os níveis do governo existem leis que regulam o impacto das atividades poluidoras no meio ambiente. A proteção ambiental não está expressa na Constituição canadense; assim, a competência de legislar é simultânea, apresentando regulamentações ambientais complexas que, em muitos casos, se tornam vagas, o que permite uma aplicação mais flexível das leis (MESQUITA, 2017).

Por isso, o regulamento de posse de sequestro de carbono canadense (Canadian Carbon Sequestration Tenure Regulation) complementa a questão do licenciamento. Este regulamento determina a necessidade de todos os planos de MRV apresentarem análise da probabilidade de as operações interferirem na recuperação de minerais além de vincular a renovação do contrato/locação à renovação trienal do 
MRV. Esta lei também estabelece obrigações para obter contratos condicionadas ao envio de um plano de monitoramento, medição e verificação para aprovação e envio de um plano de descomissionamento (IEA, 2010).

Nos Estados Unidos, como aponta Monteiro Júnior (2015), as atividades de injeção de substâncias e resíduos subterrâneos e em formações geológicas são realizadas há mais de 40 (quarenta) anos por meio de Enhanced Oil Recovery - EOR. Por isso, os Estados Unidos têm várias regulamentações também aplicáveis a essas atividades específicas de armazenamento de $\mathrm{CO}_{2}$.

Em um contexto macro, o Código Norte Americano de Regulamentos Federais, Título 40: Proteção do Meio Ambiente, Partes 78 (Procedimentos de Recurso) e 98 (Regras obrigatórias de Relatório de Armazenamento de $\mathrm{CO}_{2}$ ), traz importantes marcos e definições, como sendo uma das poucas legislações que explicitam a diferença entre o poço injetor para armazenamento de $\mathrm{CO}_{2}$ e poço injetor para EOR, bem como determina as obrigações e deveres de operadores do proprietário (IEA, 2010).

Essa regulamentação norte-americana também estabelece diretrizes técnicas e administrativas bem definidas, tais como a necessidade de proprietários e operadores de tais instalações de sequestro de $\mathrm{CO}_{2}$ seguirem procedimentos de monitoramento e emissão de relatórios, garantia de qualidade, estimativa de falta de dados e manutenção de registros especificados, bem como monitoramento de carbono, relatando por exemplo a quantidade de $\mathrm{CO}_{2}$ recebido, injetado, produzido, emitido por vazamento superficial e emissões de equipamentos vazamentos e emissões ventiladas de equipamentos de superfície (IEA, 2010).

A legislação brasileira, sobretudo ambiental, é muito abrangente, cobrindo uma ampla gama de tópicos (COSTA, 2017), embora as atividades específicas de CCS ainda não estejam abarcadas (COSTA, 2018). Primeiro, é necessário entender que a fase de monitoramento (incluindo a emissão de relatórios e eventuais inspeções) pode depender do tipo de licenciamento obtido pelo operador. De acordo com art. 225, $\S 1^{\circ}$, IV, cabe ao Poder Público exigir, na forma da lei, estudo prévio de impacto à instalação de uma obra ou atividade potencialmente causando degradação ambiental significativa. Além disso, o art. 23 define a competência comum 
da União, os Estados, a Distrito Federal e Municípios para proteger o meio ambiente e combater poluição em qualquer das suas formas (COSTA, 2017).

Portanto, para desempenhar esse papel, a Lei n. 6.938/81 (Lei da Política Nacional do Meio Ambiente) prevê no artigo 10, § 4, a competência do IBAMA para atividades de licenciamento e obras com significativo impacto, nacional ou regional, posteriormente, regulado pelo Decreto n. 99.274/90. Na indústria do petróleo e gás, a execução de atividades empresariais é majoritariamente monitorada pela Agência Nacional de Petróleo, Gás Natural e Biocombustíveis (ANP).

É importante ressaltar que o setor de petróleo e gás domina as técnicas de captura, transporte e injeção de gás em reservatórios geológicos. Ou seja, os agentes atuantes no setor de petróleo e gás no Brasil têm experiência em utilizar tecnologias de separação de gases na produção de gás natural que seriam similares às tecnologias utilizadas para a captura de $\mathrm{CO}_{2}$, por exemplo. Sendo assim, faz sentido que o órgão regulador que deverá adequar e fiscalizar projetos de CCS no Brasil tenha expertise em regulação no setor de petróleo e gás natural (RATHMANN, 2017).

Em geral, nas regulações também é importante abordagem clara acerca de questões envolvendo responsabilidade e compensação devido a riscos de longo prazo em um futuro distante e de incerteza, levantando, entre outros, questões sobre a disponibilidade de financiamento caso ocorram danos e o operador não esteja mais no negócio, e danos potenciais de liberação acidental de $\mathrm{CO}_{2}$ na atmosfera, o que representa o risco de instabilidade (FAURE, 2016).

Nesse contexto, a implementação de um sistema regulatório para a responsabilidade civil na atividade da CCS deve contar com políticas que abordam mecanismos de prevenção, como o protocolo de monitoramento e verificação, mitigação e remediação, bem como o marco regulatório e legal (WILSON, 2007).

Especificamente em relação à ESG, emissões de relatórios voluntários estão sendo substituídos por abordagens mais formais, por meio de políticas e intervenções regulatórias. Em diversas jurisdições, as emissões de relatórios financeiros estão sendo complementados com informações que envolvam divulgação 
de informações e decisões de investimentos que possam afetar o ESG (GLOBAL CCS INSTITUTE, 2021b).

Exemplo disso é que órgãos regulatórios industriais já estão cobrando a emissão desses relatórios, como o Reserve Bank of Australia, Australian Securities and Investment Commission e Australian Prudential Regulation Authority, todos da Austrália. O governo do Reino Unido e os reguladores da indústria adotaram um procedimento semelhante. Em novembro de 2020, o governo do Reino Unido formalizou um roteiro, estabelecendo requisitos para emissão de relatórios obrigatórios relacionados ao clima para empresas e proprietários de ativos. Estes relatórios estão alinhados com as recomendações do Grupo de Trabalho sobre Clima Divulgações Financeiras (TCFD) (GLOBAL CCS INSTITUTE, 2021b).

\subsubsection{O papel chave do monitoramento na garantia da integridade e segurança das instalações}

Para garantir a integridade e segurança das instalações de armazenamento de $\mathrm{CO}_{2}$ existem mecanismos de aprisionamento que têm como função prevenir que o $\mathrm{CO}_{2}$ injetado migre de volta à superfície. Além disso, a pressão - resultante da profundidade necessária ao seu armazenamento - faz com que o $\mathrm{CO}_{2}$ permaneça sob a forma de fluido supercrítico, estado físico que proporciona sua fixação nos espaços intersticiais das rochas, quando então irá se penetrar nos poros existentes, quando atingida a profundidade crítica. Parte desse $\mathrm{CO}_{2}$ fica definitivamente bloqueado após a selagem dos furos de injeção, enquanto outra parte poderá mover-se durante alguns anos, até reagir com fluidos e rochas existentes, mineralizando (ALVES, 2008).

Associado a isto, segundo Gaspar (2014), com a escolha de um local adequado, um programa de monitoramento para detecção de problemas, um sistema regulatório e o uso adequado dos métodos corretivos para parar ou controlar eventuais fugas de $\mathrm{CO}_{2}$, os riscos ambientais do armazenamento de $\mathrm{CO}_{2}$, a saúde da população local e os riscos de segurança devem ser comparáveis aos riscos de 
armazenamento de gás natural e extração de petróleo. Porém, para que o operador mantenha as garantias contínuas de que o $\mathrm{CO}_{2}$ está sendo armazenado com sucesso, devem ser realizadas atividades de monitoramento e relatórios para projetos de CCS (IEA,2010). Geralmente, para garantia da integridade da instalação de armazenamento de $\mathrm{CO}_{2}$, considera-se que um vazamento de $1 \%$ do $\mathrm{CO}_{2}$ armazenado em mil anos seria um valor aceitável (KETZER, 2016).

Para tanto, para garantir de fato a integridade da instalação, atendimento às legislações aplicáveis e, caso ocorra evento de vazamento, consiga ser rapidamente detectável o ponto de vazamento e devidamente contido, é necessário uso de ferramenta que estabeleça uma série de barreiras a serem cumpridas antes e depois do evento de vazamento. Nesse sentido, o bowtie é um método capaz de identificar previamente as barreiras degradadas para manutenção da integridade da instalação e de propor barreiras corretivas para o caso de ocorrência de evento indesejado. O método fornece uma estrutura para avaliação sistemática de riscos de eventos com o potencial de afetar o desempenho do armazenamento (DEAN, 2017) e pode ser representado pela Figura 11.

Figura 11 - Esquemática do diagrama de Bowtie

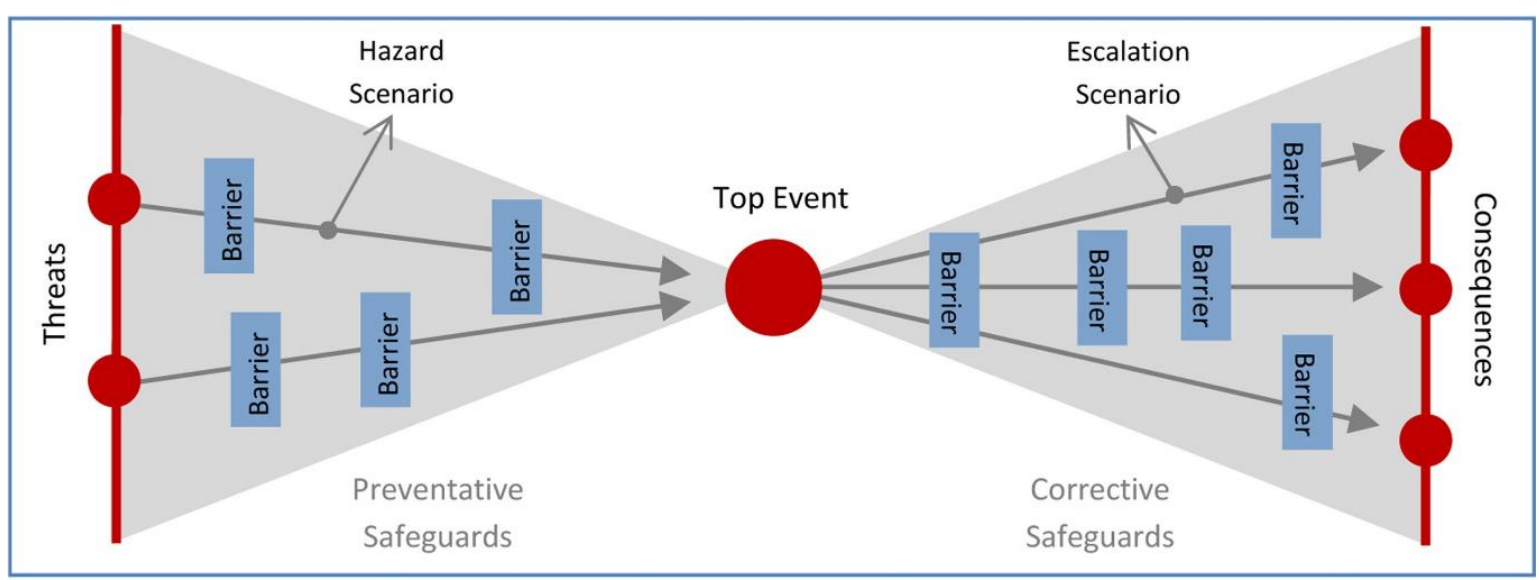

Fonte: DEAN (2017)

A gravata borboleta acima ilustrada - tradução livre para a palavra bowtie, representa a relação entre os cinco elementos-chave que o formam (DEAN, 2017): 
a) Evento principal: este é o evento indesejado, colocado no centro da gravata. Nesse caso, o evento principal é o movimento da nuvem de $\mathrm{CO} 2$ fora do complexo de armazenamento;

b) Ameaças: essas condições podem levar ao evento principal. Por exemplo, a presença de um sistema de falhas ou fraturas permeáveis, tensões relacionadas à injeção (pressão / térmica) ou poços abandonados mal conectados;

c) Consequências: Esses são os possíveis resultados adversos devido a ocorrência inesperada do evento principal. Por exemplo, a emissão para o ambiente marinho impactando localmente a biota;

d) Salvaguardas preventivas: diminuem a probabilidade de ameaça de levar ao evento principal. Por exemplo, é provável que os efeitos da pressão de injeção sejam pequenos, pois a injeção é boa e o local de armazenamento está sob pressão sub-hidrostática;

e) Salvaguardas corretivas: diminuem a probabilidade de consequências significativas devido a um evento de topo. Por exemplo, a presença de uma formação permeável abaixo do selo do complexo de armazenamento fornece um armazenamento secundário alternativo.

Portanto, para garantia da integridade da instalação de armazenamento de $\mathrm{CO}_{2}$ foi desenvolvido um processo dentro de uma estrutura de gerenciamento de riscos que se baseia na abordagem bem estabelecida de barreiras (salvaguarda). $O$ objetivo é identificar as tarefas de monitoramento necessárias e suas respectivas tecnologias para reduzir os riscos de armazenamento de $\mathrm{CO}_{2}$ para o mínimo possível. A seguir, é apresentada a abordagem passo a passo (DEAN, 2017):

a) Avalie os riscos de armazenamento específicos do site: Estabeleça definições para perda de conformidade e perda de contenção. Identifique ameaças e consequências potenciais associadas a esses eventos de risco usando o método da gravata borboleta.

b) Caracterize salvaguardas geológicas: identificar e avaliar a integridade de cada selo geológico dentro e acima do complexo de armazenamento; 
c) Selecione salvaguardas projetadas por engenharia: identifique e avalie as seleções do conceito de engenharia que fornecem salvaguardas contra a perda inesperada da integridade do poço. Avalie salvaguardas iniciais como eficácia esperada dessas salvaguardas em relação às ameaças de conformidade e contenção identificadas e suas possíveis consequências.

d) Estabeleça requisitos de monitoramento: Defina tarefas de monitoramento para verificar o desempenho dessas salvaguardas iniciais e, se necessário, adicione medidas corretivas oportunas.

e) Selecione planos de monitoramento: Selecione as tecnologias de monitoramento considerando cenários de vazamento de acordo com uma relação custo-benefício. Os benefícios são julgados pela eficácia de cada tecnologia em cada tarefa. Isso inclui o monitoramento da linha de base, bem como o monitoramento durante as fases de injeção e fechamento.

f) Estabeleça metas de desempenho: avalie os recursos de monitoramento esperados.

g) Identifique o monitoramento de contingência: desenvolva planos alternativos de monitoramento para investigar suspeitas de irregularidades e estabeleça critérios claros para quando e como implementar essas contingências. Os resultados do monitoramento de contingência devem ser inseridos em um plano de medidas corretivas.

Porém, é necessário auditar a correta implementação, controle e atualização dessas barreiras. Por isso, as estruturas regulatórias de CCS devem capacitar o órgão regulador para verificar, por meio de auditorias locais, se os projetos de armazenamento estão sendo executados conforme planejado (IEA, 2010). Auditorias não são exclusivas de operações de CCS, ocorrendo na maioria das operações industriais, onde envolvem $o$ acesso aos locais de atividades e documentos. O poder de auditar concedido por uma estrutura reguladora de armazenamento de $\mathrm{CO}_{2}$ pode estender-se ao acesso a propriedade de terceiros, ou seja, a propriedades além do local controlado pelo operador (IEA, 2010). 
O órgão regulador competente pode realizar auditorias rotineiras e não rotineiras de um local de armazenamento, tendo acesso a qualquer local que tenha sido ou esteja sendo usado em conexão com um projeto, incluindo propriedade de terceiros (IEA, 2010). Auditorias podem incluir instalações de pesquisa, visitas de instalações de injeção, avaliação das atividades de injeção, avaliação das operações de monitoramento, verificação de conformidade do local de armazenamento com o plano aprovado pelo órgão regulador competente e acesso a todos os registros relevantes (IEA, 2010). As auditorias podem começar quando uma autorização de exploração for concedida e continuar até a transferência da responsabilidade bem como sua frequência variar, aumentando se houver vazamento significativo, migração ou outra irregularidade no local de armazenamento (IEA, 2010).

A Agência Internacional de Energia (2010) alerta que as auditorias devem incluir, mas não necessariamente limitar-se, a visitas diretas ao local para examinar a superfície de instalações, verificação de registros referentes à massa de $\mathrm{CO}_{2}$ recebida, massa de $\mathrm{CO}_{2}$ injetada, atividades de desligamento, desligamentos não planejados ou incidentes não intencionais e monitoramento de resultados. O momento preciso e a frequência das auditorias variarão de acordo com a prática particular na região e dependendo do histórico de desempenho do site. No entanto, boa prática sugere, segundo IEA (2010) combinações dos seguintes:

a) Pelo menos, relatórios anuais das atividades operacionais e revisão pelo órgão regulador;

b) Pelo menos inspeções de rotina anuais ou bianuais das operações;

c) Pelo menos uma verificação anual de terceiros, com supervisão do órgão regulador;

d) Inspeções não-rotineiras, a fim de investigar quaisquer relatos de vazamentos, migração imprevista, irregularidades significativas, reclamações ou outras situações, conforme necessário.

As auditorias devem continuar durante 0 período de descomissionamento, embora a frequência das inspeções possa ser modificada durante esta fase de acordo com as considerações específicas do local e o nível de 
confiança no desempenho do local de armazenamento alcançado pelo órgão regulador (IEA, 2010).

É geralmente aceito pela indústria e pelos reguladores atualmente envolvidos em CCS que o operador, como a entidade que supervisiona a operação de um local de armazenamento, é a entidade que está melhor posicionada para qualquer responsabilidade por danos causados por um local de armazenamento durante a exploração, operação e descomissionamento (IEA, 2010).

\subsubsection{Falhas no processo de monitoramento e responsabilização das partes}

Em virtude dos riscos advindos das atividades realizadas pelas organizações, a ISO 31000 aborda trechos importantes relacionado à responsabilização das partes. Segundo a norma, convém que a organização assegure que haja responsabilização, autoridade e competências apropriadas para gerenciar riscos, incluindo implementar e manter o processo de gestão de riscos, e assegurar a suficiência, a eficácia e a eficiência de quaisquer controles (ISO 31000, 2009).

A partir disto, a norma discorre sobre as condições necessárias para que haja a devida responsabilização das partes envolvidas no risco em tela. Será realizado a partir de então alusão ao tema deste trabalho para que fique mais claro as recomendações emanadas da ISO 31000 aplicáveis ao armazenamento de $\mathrm{CO}_{2}$.

Basicamente, a norma cita que para a responsabilização das partes, é necessário identificar a quem pertencem os riscos e que, portanto, tem a responsabilidade e a autoridade para gerenciá-los. Neste caso, é necessário que a legislação inerente à atividade de CCS deixe explícita a responsabilização das partes envolvidas no projeto (ISO 31000, 2009).

A norma ainda cita que é necessário identificar os responsáveis pelo desenvolvimento, implementação e manutenção da estrutura para gerenciar riscos que nesse caso seria o operador da instalação de armazenamento de $\mathrm{CO}_{2}-$ e identificar outros responsáveis, em todos os níveis da organização no processo de 
gestão de riscos - que nesse caso, poderia ser incluído o órgão regulador, já que possui suas corresponsabilidades, por ser quem aprovou o projeto inicial de armazenamento de $\mathrm{CO}_{2}$ e quem teoricamente deveria auditar as instalações, como abordado na seção anterior (ISO 31000, 2009).

Por fim, cita ainda a necessidade de se estabelecer medição de desempenho e processos de reportes internos ou externos e relação às partes interessadas. No trecho 4.3.6 "Estabelecimento de mecanismos de comunicação e reporte internos", a ISO 31000 complementa essa necessidade, ao citar que deve haver mecanismos que assegurem que quaisquer alterações subsequentes em sua estrutura de gestão de riscos, sejam comunicados adequadamente. Neste caso, podese associar ao Plano de Monitoramento, ao qual de fato, caso seja alterado, deve-se comunicar às partes interessadas - internas e externas e, por vezes, serem previamente aprovadas (ISO 31000, 2009; IEA, 2010; DEAN, 2017).

Necessário lembrar que um operador geralmente terá responsabilidade por quaisquer danos causados ao meio ambiente, saúde humana ou a outros recursos e ser obrigado a tomar quaisquer medidas corretivas ou medidas de remediação associadas ao local de armazenamento e seus respectivos custos. No caso em que tenham sido dados incentivos ao operador para realizar as operações de CCS, o operador também pode ser responsável por compensar qualquer vazamento de $\mathrm{CO}_{2}$ na atmosfera no contexto do regime de incentivos (IEA, 2010).

A responsabilidade por quaisquer efeitos localizados decorrentes de emissão ou armazenamento de $\mathrm{CO}_{2}$ pode ser legal/administrativa (por exemplo, violação das condições de autorização), penal (por negligência, homicídio culposo e crimes ambientais) ou lei civil propriamente dita (por exemplo, através de danos a terceiros), além da civil ambiental. A responsabilização dependerá das leis vigentes na jurisdição local, da causa do vazamento (ex.: por condições de autorização por parte do operador, negligência) e ainda o nível de dano causado (IEA, 2010).

No Brasil, por exemplo, a Lei n. 9.605/98 (Lei de Crimes Ambientais) e Decreto no 3.179 / 99, que a regulamenta, definem a responsabilidade da entidade legal - administrativo, civil e criminal - e também permite que a pessoa física autora da infração seja incriminada. As ações de fiscalização são realizadas pela ANP - 
Agência Nacional do Petróleo, Gás Natural e Biocombustíveis sob a forma de auditorias, através de amostras e análise de dados e evidências, que visam verificar a conformidade do operador com os requisitos da documentação técnica regulamentados pela Resolução ANP 37/2015, que dispõe sobre a concessão de prazo para o tratamento de não-conformidades e eventual elaboração de auto de infração.

Importante citar que a opinião pública é sempre importante e por isso governos e empresas procuram minimizar os impactos negativos de suas operações. Nesses casos, é benéfico para o operador minimizar os danos à reputação documentando que possui um robusto e eficiente processo de monitoramento e que é capaz de localizar, quantificar e caracterizar qualquer vazamento ainda no estágio inicial (WAARUM, 2016).

A Agência Internacional de Energia sugere uma série de responsabilização das partes envolvidas na operação de armazenamento de $\mathrm{CO}_{2}$, aos quais são descritas a seguir (IEA, 2010):

i) A responsabilização das partes deve prever um enquadramento que aborde de forma clara questões acerca da responsabilidade pela execução das medidas corretivas e de remediação de eventual vazamento. Dada a natureza muito específica das medidas que possam vir serem necessárias, há tendência que o órgão regulador determine quando as medidas corretivas e de remediação serão necessárias e o que elas implicarão;

ii) Deve ser previsto que caso ocorra fuga significativa, migração não intencional ou outra irregularidade, o operador deve notificar imediatamente ao órgão regulador competente. O operador deve realizar quaisquer medidas corretivas, conforme determinado pelo órgão regulador, para proteger o ambiente, a saúde humana, outros recursos e ativos de terceiros, incluindo ações estabelecidas no plano de medidas corretivas do operador, aprovado pelo órgão regulador - bem como quaisquer medidas de remediação; 
iii) Ao órgão regulador, compete tomar medidas corretivas ou medidas de reparação a qualquer momento, inclusive às custas do operador, enquanto a responsabilidade pelo local de armazenamento reside com o operador;

iv) Faz-se necessário adoção de medidas corretivas imediatas para resolver quaisquer danos associados a vazamentos significativos, migração não intencional ou outra irregularidade na operação de um local de armazenamento ${ }^{7}$;

v) Deve-se projetar mecanismos apropriados para fornecer clareza sobre a entidade a ser responsável pelos danos remanescentes, a nível global ou local. Os efeitos potenciais são vitais ao se projetar estruturas regulatórias do CCS; e

vi) No desenvolvimento de estruturas regulatórias de CCS, há duas questões principais a serem consideradas. Primeiro, regulamentos devem assegurar que os processos de autorização estabeleçam poderes para o órgão regulador competente para investigar e apresentar acusações em caso de violação das condições da autorização. Em segundo lugar, quaisquer leis existentes relativas a acidentes industriais, civis e ambientais, de proteção ambiental e responsabilidade ambiental devem ser cuidadosamente revisadas.

Varela (2014) lembra que a ausência ou falha no monitoramento pode levar à ocorrência de grandes desastres socioambientais, onde é comum queda imediata no valor das ações das empresas responsáveis. Nesse caso, é esperado que muitos investidores vendam suas ações em virtude do risco associado e pelo motivo

\footnotetext{
${ }^{7}$ Os melhores exemplos são daquelas adotadas no campo petrolífero como técnicas de entupimento de poço usando lama pesada, como aplicado no caso de blowouts, técnicas padronizadas de reparo de poços em caso de falha do poço e interceptação de vazamento de fluidos perfurando um poço próximo para interceptar o vazamento. Outras medidas podem envolver a remoção parcial de $\mathrm{CO}_{2}$ do armazenamento para reduzir o reservatório pressão e remediação das águas subterrâneas em caso de contaminação. (IEA, 2010)
} 
de poder levar anos para as causas do acidente serem conhecidas. Por isso, será abordado na próxima subseção dois casos reais para comprovar tal constatação.

\subsection{4 $O$ papel do P\&D e monitoramento na prevenção de acidentes de processos e impactos ao ESG}

Segurança de processo refere-se a acidentes por falhas dos equipamentos de processos (barragens de contenção, torres, tubulações, estruturas, dentre outros) caracterizadas por rupturas e vazamentos, levando a perda de contenção de produtos agressivos ao meio ambiente, pessoa física e consequências como incêndios, explosões ou desmoronamentos. Esses acidentes podem ter efeitos catastróficos, com consequências severas para pessoas, meio ambiente e patrimônio, incluindo contaminações de rio, lagos e mares (GUERRA, 2019). Portanto, acidentes relacionados a falhas nas instalações de armazenamento de $\mathrm{CO}_{2}$ e consequente vazamento do gás pode ser classificados como tal.

Um acidente de processo é ainda um evento que deve ser analisado profundamente pois tem muitos aprendizados envolvidos. Seu potencial de perda é elevado e deve ser motivo de preocupação constante das lideranças corporativas (GARCIA, 2017).

Figueredo (2022) relembra que falhas de segurança em indústrias de alto risco podem produzir resultados catastróficos, ao qual podem expor inclusive as fraquezas regulatórias associadas à fiscalização dessas indústrias. Esses fatos têm enormes implicações para minar a confiança pública em corporações e reguladores governamentais.

A partir da exploração dos conceitos de segurança de processo, foram pesquisados, selecionados e analisados dois eventos que podem ser caracterizados como acidentes de processos para discussão dentro do escopo de P\&D e ESG. O CASO 1 refere-se ao rompimento da barragem de Mariana e o CASO 2 à um falso vazamento de $\mathrm{CO}_{2}$ até então advindo de operações de CCS detectado na Fazenda Kerr no Canadá. Seguem, portanto, as descrições: 
CASO 1: No dia 5 de novembro de 2015, o rompimento da barragem de uma mineradora privada, em Mariana, no estado de Minas Gerais - Brasil, despejou sessenta bilhões de litros de rejeitos de mineração de ferro ao longo de mais de $500 \mathrm{~km}$ na bacia do rio Doce. A avalanche de rejeitos gerada no estado de Minas Gerais pelo rompimento causou danos ambientais e sociais imensuráveis e irreversíveis. Provocou um cenário de devastação no distrito de Bento Rodrigues, a cerca de $2 \mathrm{~km}$ de onde ocorreu o rompimento, sendo que 85 famílias perderam as casas, 17 pessoas foram encontradas mortas sob a lama e 3 permanecem desaparecidas (SOUZA, 2017).

Um estudo realizado pela Comissão de Grandes Barragens identificou as principais causas de rompimento de barragens de aterro no mundo, onde é possível identificar que várias destas causas se relacionam aos pilares de segurança de processo "Procedimentos Operacionais" e "Integridade e Segurança de Ativos". Isso mostra que, independentemente da causa, o desastre poderia ser evitado ou amenizado por um programa de Segurança de Processos, que exige dos gestores uma análise profunda do processo base bem como o acompanhamento e diagnóstico prévio das instalações e alterações que possam afetar o curso natural do mesmo, ou seja, monitoramento (GONZALEZ, 2019).

Segundo a denúncia, existia o "Manual de Segurança e Operação" da empresa - que constava a indicação de ações pertinentes a serem executadas para eliminação/correção de anomalias identificadas, bem como o "Manual de Riscos Corporativos da empresa", - que apresentava a governança e metodologia da gestão de riscos da empresa. Desta forma, a empresa poderia identificar, avaliar e tratar os riscos que poderiam impactar seus objetivos. Porém, segundo a denúncia, tais riscos e relatórios eram negligenciados (MPF, Brasil).

Após 5 anos da tragédia, no final de 2020, a empresa recuperou as licenças ambientais e investiu em uma nova tecnologia para processar rejeitos do minério de ferro, voltando, portanto, a operar, ainda 
que com um quarto de sua capacidade - os $100 \%$ da atividade só devem ser alcançados em 2030. Para tanto, a empresa investiu 400 milhões de reais só na atualização dos maquinários e para instalar a chamada planta de filtragem. Em relação à planta de filtragem, nos últimos anos, ela também ganhou eficiência e evolução tecnológica (EXAME, 2021).

Existe atualmente diversos processos e multas em aberto, inclusive multa estipulada no início deste ano de $\mathrm{R} \$ 3$ milhões além de $\mathrm{R} \$$ 1 milhão diário em virtude do atraso na entrega de moradias às vítimas de Mariana (MPMG, 2021).

CASO 2: Cameron e Jane Kerr realizaram uma coletiva de imprensa em 11 de janeiro de 2011 exigindo uma investigação pública completa em virtude de problemas relacionados à superfície e água do poço em sua fazenda perto de Goodwater, nas proximidades da operação de CCS Cenovus Weyburn. Os Kerrs disseram que notaram pela primeira vez mudanças que ocorreram em sua propriedade em 2004, um ano após a injeção de $\mathrm{CO}_{2}$ começar perto de sua fazenda (BOYD, 2016; IEAGHG, 2021).

Um estudo encomendado pelos Kerrs concluiu que a presença de $\mathrm{CO}_{2}(<=\sim 11$ vol. \%) e CH4 ( $30 \mathrm{ppm})$ na fazenda Kerr tinha origem de operações de armazenamento de $\mathrm{CO}_{2}$. No entanto, os dados levantaram dúvidas sobre confiabilidade do estudo (ROMANAK, 2013).

A partir disto, sob a direção do Dr. Jerry Sherk, diretor de operações do IPAC- $\mathrm{CO}_{2}$, uma equipe de especialistas internacionais foi reunida para conduzir uma investigação independente da fazenda Kerr. Katherine Romanak do Centro de Carbono da Costa do Golfo, a Bureau of Economic Geology e a Universidade do Texas em Austin, EUA, lideraram a investigação sobre gases do solo (ROMANAK, 2013; IEAGHG, 2021).

A suspeita de vazamento na Fazenda Kerr era de origem natural, mas havia sido imprecisamente atribuída ao CCS. A alegação de 
vazamento foi posteriormente refutada pelos profissionais utilizando as mais recentes técnicas de atribuição (DIXON, 2015). Foi utilizada inclusive o método de monitoramento baseado em processos ${ }^{8}$, realizando diversas análises, como bio-respiração, dissolução de $\mathrm{CO}_{2}$ e reação com carbonato de solo, dissolução de gás do solo através de mistura atmosférica, dentre outros. Adicionalmente, dois outros estudos foram realizados, inclusive um deles fora aclamado como sendo o primeiro e mais extenso conjunto de dados contínuos de gás emanado de um solo em um local voltado à CCS. A conclusão foi que a origem do gás não era advinda da operação de CCS, tendo sido detectado emanação natural do gás (ROMANAK, 2013).

Baseado neste caso, foi realizado ainda em 2011 uma pesquisa para verificar a opinião pública acerca deste evento, com entrevistas de moradores da localidade. A maior parte das pessoas relataram que não achavam que haveria de fato um vazamento de $\mathrm{CO}_{2} \mathrm{e}$ que, caso houvesse, confiavam na equipe de pesquisadores que estavam trabalhando no local para dar o parecer real (BOYD, 2016). A confiança naqueles que gerenciavam o projeto de injeção de $\mathrm{CO}_{2}$ bem como dos pesquisadores/investigadores foi descrito no estudo como uma das causas fundamentais para a positividade e segurança do público envolvido no suposto vazamento de $\mathrm{CO}_{2}$ da fazenda (BOYD, 2016).

Em relação ao CASO (i), é possível observar a relevância não apenas da realização de um monitoramento eficaz e adequado, mas também a correta interpretação dos dados e tradução em níveis de riscos. Neste caso também se observa a importância do P\&D ao passo que fora necessária desenvolver e adaptar novas tecnologias para adequação da empresa perante a legislação e então retomada das operações. Além disso, houve impactos severos em todos os níveis do ESG ao passo que no âmbito ambiental, este evento foi considerado um dos piores e mais danosos desastres ao meio ambiente, enquanto houve impactos significativos à toda

\footnotetext{
${ }^{8} \mathrm{O}$ método baseado em processo é uma técnica para monitoramento de zona vadosa acima dos locais CCUS que usa proporções de gases de solo coexistentes para distinguir um sinal de vazamento de uma zona vadosa natural de $\mathrm{CO}^{2}$ sem a necessidade de monitoramento de fundo. (Romanak, 2013)
} 
sociedade entorno da barragem, incluindo diversos óbitos e na governança por meio de negligência de diversos entes denunciados pelo Ministério Público, além é claro dos impactos financeiros. Em virtude da proporção dos danos, estes foram identificados, consolidados e categorizados no Apêndice D deste trabalho.

Em relação ao CASO (ii), nota-se o oposto, com destaque para o investimento e aplicação prática do $\mathrm{P \& D}$, utilizando-se não só as principais técnicas disponíveis naquele momento, mas também uso de equipe especializada. Isso se refletiu não só na emissão conclusiva do laudo técnico - eliminando qualquer risco que envolvesse a atividade de CCS, mas também na influência positiva na opinião pública e ESG que o uso dessas tecnologias e práticas de monitoramento puderam exercer, mostrando os resultados obtidos advindos de fatos e dados bastante robustos.

De qualquer forma, para ambos os casos, faz-se necessário a realização de uma gestão de riscos de processo. A melhor forma de realização de uma gestão dos riscos de processo é por meio de um modelo de gestão. Existem diversos modelos para a gestão dos riscos ocupacionais. Já para os riscos de processo há o modelo "ouro" largamente utilizado no mercado que fora desenvolvido pelo American Institute of Chemical Engineers por meio do Center for Chemical Process Safety (CCPS). Este centro desenvolveu o modelo de gestão Risk Based Process Safety (RBPS) que pode ser aplicado para a gestão dos riscos de processo de uma corporação (GARCIA, 2017; GUERRA, 2019). Este modelo de gestão se baseia em 4 pilares $^{9}$, como viso na Figura 12 (GARCIA, 2017):

\footnotetext{
${ }^{9} \mathrm{Na}$ indústria do petróleo encontramos exemplos bem sucedidos do quarto pilar "Aprendizagem com a experiência". Nos EUA os reguladores elaboram e modificam diversas normas de segurança por lições aprendidas de acidentes. Sea Gem (1965), Alexander Kiellend (1980), Piper Alpha (1988), Transocean Deepwater Horizon (2010) são exemplos de acidentes offshore que transformaram as normas de segurança, inclusive em diversos lugares do mundo. No Brasil, Enchova (1984), naufrágio da P-36 (2001), perda de estabilidade da P-34 (2002), vazamento de óleo no campo de Frade (2011) e explosão da Cidade São Matheus (2015) foram acidentes marítimos críticos responsáveis por alterar as exigências e regulamentação de segurança brasileira (FIGUEREDO, 2022).
} 
Figura 12 - Pilares do modelo de gestão

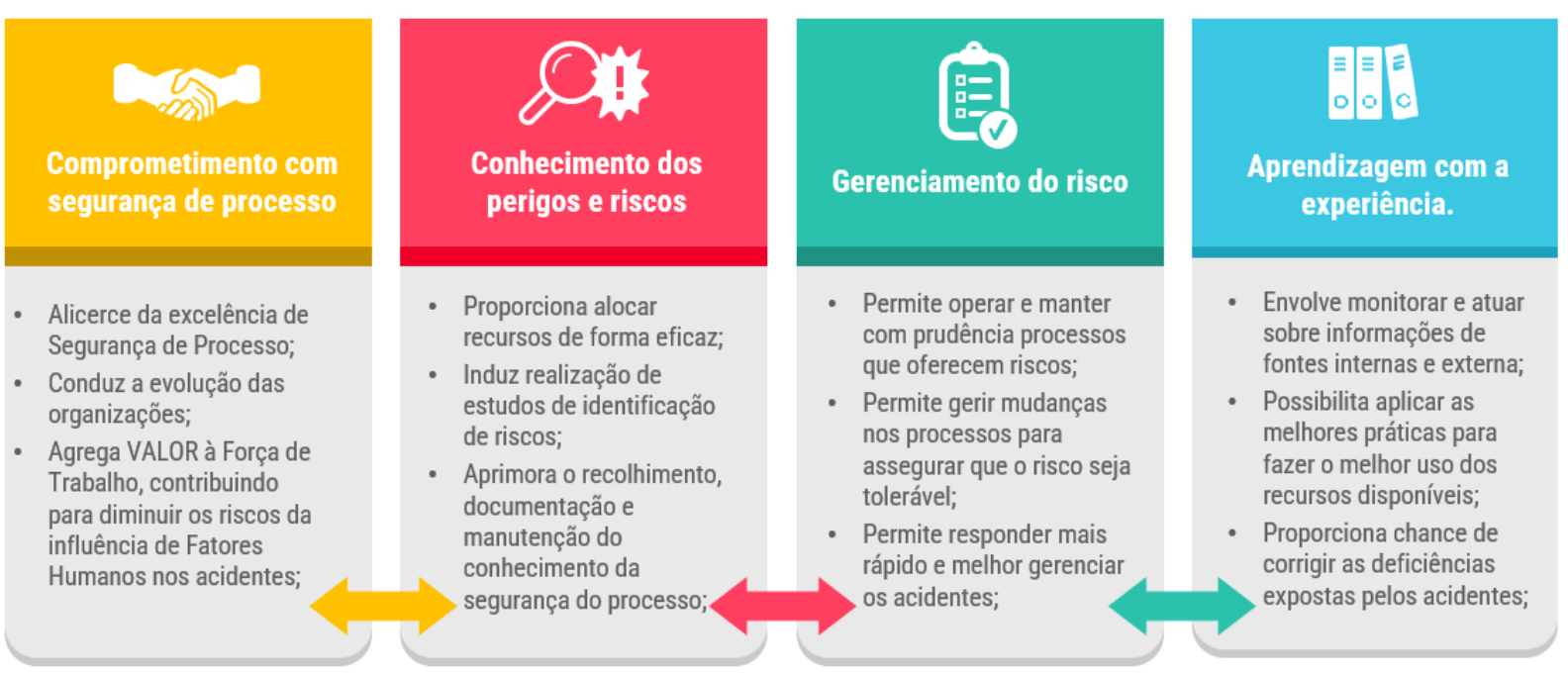

Fonte: Elaborado pelo autor

A necessidade de um modelo de gestão de riscos se conecta ao ESG ao correlacionar ao disposto na ISO 31000 , ao qual no item 5.3.2 aborda que, se tratando de riscos, é necessário levar-se em consideração estabelecimento do contexto externo à instituição. O contexto externo é o ambiente externo no qual a organização busca atingir seus objetivos, onde entender tal contexto é importante para assegurar que os objetivos e as preocupações das partes interessadas sejam considerados no desenvolvimento dos critérios de risco. O contexto externo é baseado no contexto de toda a organização, porém com detalhes específicos sobre requisitos legais e regulatórios, percepções de partes interessadas e outros aspectos dos riscos específicos para o escopo do processo de gestão de riscos (ISO 31000, 2009). Além disso, a ISO também reforça que nesse sentido, o contexto externo também pode incluir os ambientes regulatórios e relações com as partes interessadas e suas percepções e valores, reforçando o aspecto de ESG, e também aspectos tecnológicos utilizados no modelo de gestão de riscos, abarcando o fator P\&D (ISO 31000, 2009).

Por isso, dada a criticidade de acidentes de processos, principalmente no ambiente offshore, em 2015 a ANP (Agência Nacional do Petróleo, Gás e Biocombustíveis), órgão governamental responsável pela regulação do setor de petróleo e gás, apresentou uma regulamentação de segurança específica para instalações submarinas e equipamentos denominados SGSS (Regulamento Técnico 
do Sistema de Gestão da Segurança Operacional do Sistema Submarino). Essa iniciativa indicou que esse ambiente tem diferentes riscos e condições operacionais em relação às instalações tradicionais offshore (FIGUEREDO, 2022). Neste caso, entende-se que a atividade de armazenamento de $\mathrm{CO}_{2}$ em instalações offshore também deveriam seguir tais normas de segurança de processo.

Adicionalmente, no âmbito do P\&D, Figueredo (2022) lembra que, no desenvolvimento da tecnologia, a avaliação de maturidade utiliza diferentes ferramentas para medir o nível geral de prontidão dos sistemas, como Níveis de Prontidão Tecnológica $(T R L)^{10}$, Nível de Prontidão de Sistemas (SRL) e Nível de Prontidão de Integração (IRL). A maturidade tecnológica pode ser utilizada para avaliar o risco técnico e a maturidade de um conceito em consonância com as metas e requisitos especificados, comparar tecnologias, determinar se um programa de pesquisa e desenvolvimento é apropriado e, identificar o caminho de qualificação adequado para a tecnologia selecionada (FIGUEREDO, 2022).

\subsection{Desafios para o progresso da pesquisa e desenvolvimento e sua relevância no cenário de ESG}

A pesquisa e desenvolvimento de novas tecnologias e ferramentas tanto para o monitoramento quanto para contingência nas instalações de armazenamento de $\mathrm{CO}_{2}$ está bastante ligado ao ESG. Uma pesquisa realizada em 2018 pela Ernst \& Young detectou que os investidores estão usando cada vez mais ferramentas e informações de desempenho não financeiras para tomada de decisão. Para ter ideia, cerca de $97 \%$ dos investidores entrevistados alegam que avaliam de forma informal (65\%) ou de forma metódica e estruturada (32\%) essas divulgações não-financeiras da empresa-alvo do investimento (EY, 2018). No caso em tela, as informações não financeiras das empresas que utilizam a tecnologia de CCS seriam, por exemplo,

\footnotetext{
${ }^{10}$ Os Níveis de Prontidão tecnológica (TRL) são um tipo de sistema de medição usado para avaliar o nível de maturidade de uma determinada tecnologia. Cada projeto de tecnologia é avaliado em relação aos parâmetros para cada nível de tecnologia e, em seguida, é atribuído uma classificação TRL com base no progresso dos projetos. Há nove níveis de prontidão tecnológica. TRL 1 é o mais baixo e TRL 9 é o mais alto. (NASA, 2021)
} 
relatórios com os métodos - incluindo tecnologia e ferramentas utilizadas para coleta dos dados - e resultados obtidos com base no Plano de Monitoramento das suas instalações de armazenamento de $\mathrm{CO}_{2}$.

A conexão entre essas duas vertentes (P\&D e ESG) fica ainda mais forte quando a mesma pesquisa mostra que os investidores acreditam que os dois primeiros parâmetros que incentivam as empresas a relatarem detalhes sobre atividades não financeiras e ESG são, nesta ordem, a conformidade regulatória (90\%), seguida pela gestão de riscos (87\%) (EY, 2018). O caso do rompimento da barragem de Mariana, usado como exemplo neste trabalho, entra para reforçar a constatação desta mesma pesquisa onde em virtude do risco ou histórico de más práticas de governança faria com que $63 \%$ excluíssem um eventual investimento naquela empresa imediatamente (EY, 2018).

Nesta esteira, puxando a gestão de riscos, mais especificamente de riscos climáticos, segundo a Task Force on Climate-Related Financial Disclosures (TCFD), composta por investidores de diversos setores, os riscos climáticos podem ser classificados em riscos de transição e riscos físicos ${ }^{11}$. A incorporação de novas tecnologias contribui para amenizar o risco climático e pode trazer vantagens competitivas para a empresa, principalmente nos riscos de transição, já que podem ser regulatórios ou tecnológicos (WAYCARBON, 2018).

Contudo, nem todas as empresas executam práticas de $\mathrm{P} \& \mathrm{D}$ voltadas à ESG como deveriam. Embora as empresas do setor privado realizem projetos de pesquisa e desenvolvimento, elas estão focadas principalmente em projetos de pesquisa "aplicados", onde o pagamento ao seu resultado final provavelmente só os beneficiará (UGONNA, 2021).

Embora pareça haver consenso nos benefícios socioambiental e financeiros advindos do ESG, as empresas que participam da cadeia de processo de armazenamento de $\mathrm{CO}_{2}$ parecem não estar adequadas à tal situação, mesmo a realidade mostrando que o investimento em ESG se associa à redução do risco das

\footnotetext{
11 Os riscos de transição são aqueles que surgem no caminho para uma economia de baixo carbono, podendo ser regulatórios, legais, tecnológicos, de mercado ou reputacionais. Já os riscos físicos podem ser agudos, quando desencadeados por eventos climáticos extremos, como ciclones e inundações, ou crônicos, relativos a consequências que virão a longo prazo, como o progressivo aumento do nível dos oceanos. (WAYCARBON, 2018)
} 
partes, de futuros litígios com as partes interessada, risco de exposição negativa de sua imagem e até financeiros (CERQUETI, 2021) e claro, redução no risco de acidentes, (DÍAZ, 2021) como rompimento da barragem de Mariana, trazido à tela neste trabalho.

Para reforçar a situação acima, foi conduzido neste trabalho uma pesquisa, coleta e consolidação de todas as empresas selecionadas para o Ranking 2021 da B Corporations ${ }^{12}$, ao qual consolida as melhores empresas do mundo em ESG, segmentando-as em quatro categorias e principais ramos industriais. A consolidação da pesquisa pode ser verificada na Tabela 4.

Tabela - 4 Categorias e ramos industriais presentes no Ranking 2021da B Corporations

\begin{tabular}{lll}
\hline Category & Industry & Number \\
\hline Community List & Environmental Remediation & 0 \\
\cline { 2 - 3 } & Carbon Capture \& Credits & 0 \\
\cline { 2 - 3 } Customers List & Others & 161 \\
& Environmental Remediation & 0 \\
\cline { 2 - 3 } & Carbon Capture \& Credits & 0 \\
\cline { 2 - 3 } & Others & 162 \\
\hline Environment List & Environmental Remediation & 1 \\
\cline { 2 - 3 } & Carbon Capture \& Credits & 0 \\
\cline { 2 - 3 } & Others & 179 \\
\hline Governance List & Environmental Remediation & 0 \\
\cline { 2 - 3 } & Carbon Capture \& Credits & 0 \\
\cline { 2 - 3 } & Others & 182 \\
\hline Workers List & Environmental Remediation & 2 \\
\cline { 2 - 3 } & Carbon Capture \& Credits & 1 \\
\cline { 2 - 3 } & Others & 161 \\
\hline
\end{tabular}

Fonte: Elaborado pelo próprio autor, a partir de B Corporations, 2021

A pesquisa verificou que o Ranking 2021 da B Corporations elegeu, como as melhores empresas em seus segmentos e categorias, 849 empresas dos

\footnotetext{
${ }^{12}$ As Corporações B certificadas são empresas que atendem aos mais altos padrões de desempenho social e ambiental verificados, transparência pública e responsabilidade legal para equilibrar lucro e finalidade. A B Corps está acelerando uma mudança de cultura global para redefinir o sucesso nos negócios e construir uma economia mais inclusiva e sustentável. (B CORPORATIONS, 2021)
} 
mais de 71 segmentos industriais. Dentre os 71 segmentos - detalhados no Apêndice E, o "Environmental Remediation" e o "Carbon Capture \& Credits" que seriam os segmentos alvos de nossa pesquisa, possuem somente 4 empresas ranqueadas em 2021, o que representa menos de $0,5 \%$ do total.

A pesquisa ainda verificou outro dado preocupante. Conforme Apêndice E, das 3.841 empresas que participam do projeto da B Certification e, por conseguinte, atendem aos critérios mínimos para ingresso, apenas 13 (Environmental Remediation - 8; Carbon Capture \& Credits - 5) são dos segmentos alvos de nossa pesquisa. Esse número representa cerca de $0,34 \%$.

Foi constatado que existe um longo caminho para que as empresas que realizam CCS desenvolvam tecnologias e ferramentas capazes de dar robustez aos riscos associados as atividades e, portanto, amadurecer o ESG corporativo, além da pandemia da COVID-19 tornar ainda mais latente a necessidade de acelerar tais processos. Os fatores socioeconômicos dinâmicos, agravados pela pandemia, obrigam as empresas a reorganizar seus projetos de P\&D, alterando seu portifólios de projetos, modificações organizacionais, novos e aprimorados métodos de gestão, dentre outros (UGONNA, 2021).

Outro desafio é a necessidade de investimento em pesquisas para avaliação das não conformidades encontradas no monitoramento e coleta/tratamento dos dados. A depender do caso, desvios substanciais podem não significar qualquer perspectiva de perda de contenção, enquanto em outros casos um desvio mínimo pode sinalizar até a perda de uma contenção (JENKINS, 2015). O monitoramento das atividades de armazenamento de $\mathrm{CO}_{2}$ e os próprios conceitos acerca do monitoramento não são simples e já possuem certo grau de dificuldade e desafios, sendo indispensável valorizar e priorizar a informação obtida nesta atividade (SATO, 2011; JENKINS, 2015). Para manutenção da conformidade, contenção de vazamentos e minimização de impactos ambientais é necessário mostrar consistência entre observação e expectativa ou observação e exigência (JENKINS, 2015).

A regulação, embora necessária para manutenção da conformidade e segurança das instalações, apresenta-se como desafio adicional para o progresso da pesquisa e desenvolvimento e concomitantemente atendimento ao ESG. Atualmente, 
a regulação para armazenamento de $\mathrm{CO}_{2}$ se desenvolve ou através de negociação de acordos regulatórios ad hoc - na ausência de legislação específica - ou por requisitos obrigatórios específicos. Em ambos os casos, adicionando requisitos para monitoramento mesmo sem terem sido amplamente testados (JENKINS, 2015). Se por um lado, a regulação afeta a pesquisa e desenvolvimento, também pode afetar o ESG da empresa. Em 2017, por exemplo, tanto União Europeia quanto Cingapura introduziram obrigações relacionadas à elaboração de declarações ou relatórios com informações sobre ESG, incluindo proteção ambiental e responsabilidade social, que podem ser associados diretamente aos eventuais impactos de vazamento de $\mathrm{CO}_{2}$. (GROSSI, 2019)

Há o desafio da regulação e também o desafio de atender as premissas de contabilização das emissões de $\mathrm{CO}_{2}$, tanto armazenados quanto eventualmente vazados. A contabilidade de gases de efeito estufa (GEE) é um método importante para mostrar conformidade com os compromissos de emissões assumidos sob protocolos vinculativos (ou seja, Protocolo de Quioto), para documentar créditos de esforços de mitigação de GEE em áreas onde os gases de efeito estufa são regulados (DIXON, 2015).

A necessidade de correlacionar desenvolvimento de tecnologia e ferramentas com ESG torna-se crítica, pois o ESG vem recebendo atenção mundial e sendo balizador para os investidores para tomada de decisão na escolha do investimento justamente por estarem associados à negócios sólidos e resilientes contra riscos associados ao clima e sustentabilidade. No Brasil, por exemplo, companhias e investidores passaram a dar ainda mais atenção no tema após o rompimento da barragem em Brumadinho (MG) (GROSSI, 2019).

As empresas que realizam armazenamento de $\mathrm{CO}_{2}$ e não investem em pesquisa e desenvolvimento podem ter sua imagem afetada em um eventual vazamento de $\mathrm{CO}_{2}$ e ainda perder a oportunidade de investimentos em ESG. Como dito anteriormente, a quantidade emitida de títulos de sustentabilidade, que podem ser chamados de títulos ESG, aumentou de 14,8 bilhões de dólares em 2013 para 261,4 bilhões de dólares em 2018, o que é dezessete vezes mais do que o montante em 2013. Além disso, em 2019, foram 465 bilhões de dólares, quase o dobro do montante em 2018 (KANAMURA, 2021). 
Um eventual vazamento de $\mathrm{CO}_{2}$ afeta diretamente aspectos de ESG da empresa, uma vez que as partes interessadas estão analisando cada vez mais métricas ambientais e sociais. Um vazamento é capaz de afetar toda uma comunidade em torno do site bem como prejudicar a percepção pública da tecnologia (GROSSI, 2019). A exposição de seres humanos, animais ou ecossistemas a elevadas concentrações de $\mathrm{CO}_{2}$ pode causar danos à sua saúde ou integridade, sendo que a exposição prolongada a altas concentrações de $\mathrm{CO}_{2}$ (acima de 20-30\%) leva à perda da vida por sufocamento da maioria dos animais (BENSON, 2002).

Além disso, as empresas que investem em CCS devem planejar e antecipar as preocupações do público sobre possíveis vazamentos e, quando houver suspeita de vazamento, tomar as medidas que reforcem a confiança do público diretamente envolvido bem como opinião pública em geral (BOYD, 2016). O caso da Fazenda Kerr, por exemplo, mesmo que possa trazer algum efeito negativo ainda no futuro, é um caso que através da elaboração de um robusto sistema de monitoramento e uso de tecnologias pode constatar que não havia de fato vazamento de carbono antropogênico e que não afetou a opinião pública (BOYD, 2016; DIXON, 2015).

As empresas que utilizam a tecnologia de CCS devem investir em pesquisa e desenvolvimento para auxiliar na manutenção de seus compromissos com o meio ambiente e contribuição para alcance das metas do Acordo de Paris. Uma análise publicada recentemente, atribuiu às empresas de 14 dos maiores índices de ações do mundo uma "pontuação de temperatura" com base em dados de emissões divulgados publicamente entre 2015 e 2019 (CNN, 2021). Constatou-se que menos de $25 \%$ das empresas estão no caminho certo para alcançar as metas do acordo de Paris até 2050, que visa limitar o aumento da temperatura global a 1,5 graus Celsius. Esses dados são usados, inclusive, para avaliar o desempenho da sustentabilidade corporativa (CNN, 2021). Esse é outro fator que ratifica a necessidade dos operadores de instalações de armazenamento de $\mathrm{CO}_{2}$ investirem em atendimento ao $\mathrm{ESG}$, já que é tecnologia de CCS pode ser usada justamente por essas empresas para se adequarem ao novo cenário.

Nesta esteira, os governos também deveriam investir em P\&D na área de CCS, seja através de disponibilização de recursos às instituições educacionais ou financiamento de projetos e/ou incentivos fiscais à iniciativa privada. O governo já tem 
por si só esse know-how de patrocínio de projetos de pesquisa "básicos" que buscam uma ampla compreensão científica que pode afetar indústrias inteiras, em vez de empresas individuais (UGONNA, 2021).

O último relatório emitido pela Global CCS Institute reforça quanto à necessidade de investimentos na tecnologia de CCS no cenário atual de pressões internacionais para redução da emissão de $\mathrm{CO}_{2}$ bem como necessidade de abordagem de seus impactos perante o ESG. Ressalta ainda que a maior implantação de CCS e consequente aumento da exposição da tecnologia tendem a atrair maiores capitais para o desenvolvimento da mesma e que é necessário garantir que as metodologias de reportes de atividades que impactam o ESG na atividade de CCS é crítica (GLOBAL CCS INSTITUTE, 2021b).

\section{Conclusões e Sugestões}

Neste trabalho, além da realização de uma ampla revisão sistemática de literatura, incluindo atualização do status das instalações de armazenamento de $\mathrm{CO}_{2}$ no mundo, conforme Apêndice $A$, foi possível identificar através dos principais manuais e sites, os conceitos fundamentais relacionados ao P\&D, o papel desse processo na gestão de risco para armazenamento de $\mathrm{CO}_{2}$ - principalmente os riscos durante a operação de armazenamento de $\mathrm{CO}_{2}$, bem como sua relevância para o ESG como um todo, apresentando inclusive consequências não exploradas em outras literaturas.

Da mesma forma, o trabalho explorou lacunas na literatura relacionadas ao uso, na prática, das ferramentas e tecnologias para identificação e contenção dos vazamentos de $\mathrm{CO}_{2}$, identificando as principais técnicas utilizadas para o monitoramento das instalações de armazenamento de $\mathrm{CO}_{2}$ e a importância do aprimoramento das pesquisas e desenvolvimentos das tecnologias e ferramentas de monitoramento. Adicionalmente, através do Apêndice B, apresentou-se de forma consolidada as principais tecnologias, ferramentas, autores, manuais e sites que dissertam sobre $o$ assunto. 
O trabalho explorou de forma ampla, com uma abordagem multidisciplinar, a relevância do P\&D para o gerenciamento dos riscos associados ao monitoramento das instalações de armazenamento de $\mathrm{CO}_{2}$, mostrando através de estudos, pesquisas e ampla literatura que nesta atividade os riscos não podem ser, de forma alguma, negligenciados pois os riscos são elevados e com grande potencial de danos às operações das instalações de armazenamento, ao ESG da empresa operadora bem como à própria reputação da tecnologia de CCS.

A relevância da atividade de monitoramento numa visão de ESG trouxe um extenso arcabouço advindo da Agência Internacional de Energia, ao qual abordou como na teoria a atividade de armazenamento de $\mathrm{CO}_{2}$ deveria ser monitorada, bem como na prática é efetuada em diversos países. Diretrizes para a garantia da integridade das instalações também foram exploradas, sendo abarcada a visão do operador, quanto aos melhores métodos de gestão de integridade, bem como na visão do órgão regulador com orientações e boas práticas relacionadas a auditorias e inspeções de integridade, culminando em uma proposta de Plano de Monitoramento, detalhado no Apêndice $\mathrm{C}$. Nessa linha, foram explorados aspectos relacionados à responsabilização das partes em uma visão internacional geral - através da ISO, na visão geral específica para CCS - através da Agência Internacional de Energia, bem como aspectos regulatórios locais, com leis específicas para a atividade de CCS ou correlatas - como o caso do Brasil.

Foi dedicado uma seção especial para amarrar todo os aspectos trazidos até então sobre o tema desse trabalho, mostrando através de casos reais como o P\&D e o monitoramento podem impactar na prevenção de acidentes de processos aos quais poderiam gerar impactos imediatos ao ESG da empresa operadora do armazenamento de $\mathrm{CO}_{2}$, informações estas evidenciadas através dos dados consolidados no Apêndice D. Concluiu-se que as disciplinas de segurança de processos, gestão de riscos e desenvolvimento da tecnologia - para a avaliação de maturidade do nível geral de prontidão dos sistemas (TRL) - são fundamentais para a manutenção da segurança da atividade de armazenamento de $\mathrm{CO}_{2}$ e integridade das instalações de armazenamento.

Foi possível identificar no trabalho que ainda há diversos desafios para o progresso do P\&D que está intrinsicamente ligado ao ESG, processo que ganha a 
cada ano relevância internacional. O trabalho traz diversas interpretações e fatos que conectam ambos os processos, como os resultados da pesquisa realizado pela Ernst Young, a posição dos investidores da Task Force on Climate-Related Financial Disclosures (TCFD), quanto à necessidade de incorporação de novas tecnologias para diminuição dos riscos climáticos, bem como a crescente exposição das empresas segundo critérios de ESG. Exposição inclusive abordada e criticada na dissertação, que se compilou no Apêndice $E$ o número de empresas com certificadas pela $B$ Corporation, onde aparecem poucas do ramo de CCS.

Portanto, foi possível atender ao objetivo do trabalho e responder à questão central do trabalho, ao concluir que o P\&D, de fato, exerce um papel protagonista e fundamental para a atividade de CCS, sobretudo na fase de monitoramento das instalações de armazenamento de $\mathrm{CO}_{2}$, impactando diretamente - de forma positiva, ou negativa - todos os parâmetros que englobam o ESG, permitindo inclusive atendimento às regulamentações aplicáveis à atividade. Com isso, a hipótese investigada ao longo da dissertação fora confirmada, mostrando que avanços em pesquisas e conhecimentos são aplicáveis à atividade de armazenamento de $\mathrm{CO}_{2}$ e que existem diversos benefícios advindos desta prática no contexto atual, principalmente às empresas operadoras e ao ESG.

Sugere-se que sejam ampliadas a partir de agora a literatura que interconecte $\mathrm{P} \& D$, CCS e ESG, já que este trabalho reforçou a conexão e interdependência entre esses três aspectos. As empresas, Governos e academia devem investir em P\&D na atividade de CCS, sobretudo na atividade de monitoramento, dado a criticidade desta etapa e consequentes impactos que poderiam ser trazidos às próprias empresas, aos Governos - que geralmente regulam as atividades - e à reputação, uso e desenvolvimento da própria tecnologia de CCS. As empresas operadoras também devem investir no ESG, assim como empresas de outros setores, pois dentre outros benefícios, haveria uma melhora na percepção dos investidores e público em geral acerca da atividade de CCS. Sugere-se ainda regulamentação da atividade de CCS no Brasil, com inclusão de trechos acerca da atividade de monitoramento na atividade de armazenamento de $\mathrm{CO}_{2}$, explorando inclusive aspectos relacionados ao Plano de Monitoramento, ao exemplo das recomendações da Agência Internacional de Energia e regulamentações locais em 
outros países. Adicionalmente, recomenda-se que a legislação e sobretudo as empresas operadoras devam se inspirar, adaptar e usar o Risk Based Process Safety (RBPS) - amplamente utilizado em nível mundial e aplicável à atividade de armazenamento de $\mathrm{CO} 2$ - para melhor gerenciamento dos riscos, incentivar o desenvolvimento de tecnologias específicas para monitoramento e prontidão dos sistemas, aumento da segurança de processos e garantia do atendimento às vertentes do ESG, como concluído por este trabalho.

\section{Referências Bibliográficas}

AULD, G. et al. Evaluating the effects of policy innovations: Lessons from a systematic review of policies promoting low-carbon technology. Global Environmental Change. V. 29. 2014. Doi: https://doi.org/10.1016/j.gloenvcha.2014.03.002

AGÊNCIA BRASIL. 2019. Samarco pagou menos de 7\% das multas ambientais após Mariana. Acesso em: 19/09/2021. Disponível em: https://agenciabrasil.ebc.com.br/geral/noticia/2019-01/samarco-pagoumenos-de-7-das-multas-ambientais-apos-mariana

ALVES, D. Sequestro e Armazenamento de CO2 - Aplicação da tecnologia em Portugal. Tese de Mestrado em engenharia do ambiente. Universidade de Aveiro, Aveiro, 2008.

ANYOSA, S. et al. 2021. Assessing the value of seismic monitoring of $\mathrm{CO} 2$ storage using simulations and statistical analysis. International Journal of Greenhouse Gas Control. Vol. 105. Doi: https://doi.org/10.1016/j.ijggc.2020.103219

ASHWORTH, P. et al. 2010. From research to action: Now we have to move on CCS communication. International Journal of Greenhouse Gas Control. Vol. 4. Issue 2. Pages 426-433. Doi: https://doi.org/10.1016/j.jiggc.2009.10.012

ASL, H.F. et al. 2020. Key factors for achieving emission reduction goals cognizant of CCS. International Journal of Greenhouse Gas Control. Volume 99. Doi: https://doi.org/10.1016/j.ijggc.2020.103097

AVEN, T., Misconceptions of Risk, John Wiley \& Sons, Ltd. 2010, ISBN: 978-0-470-68388-0

BACHU, S., GUNTER W. D, PERKINS, E.H. 1994. Aquifer disposal of CO2: hydrodynamic and mineral trapping, Energy Conversion and Management, 35 (4), pp. 269-279.

BLACKFORD, J. et al. 2010. Environmental risks and performance assessment of carbon dioxide (CO2) leakage in marine ecosystems. Developments and Innovation in Carbon Dioxide (CO2) Capture and Storage Technology. Vol. 2. Pages 344-373. Doi: https://doi.org/10.1533/9781845699581.3.344

BOYD, A.D. 2016. Risk perceptions of an alleged CO2 leak at a carbon sequestration site. International Journal of Greenhouse Gas Control. Vol. 50. Pages 231-239. Doi: https://doi.org/10.1016/j.jiggc.2016.03.025

BCORPORATION. Best for the world 2021. Acesso em: 19/09/2021. Disponível em: https://bcorporation.net/best-for-the-world-2021 
BENSON, S.M. et al. 2002. Lessons Learned from Natural and Industrial Analogues for Storage of Carbon Dioxide in Deep Geological Formations. Joint Industry Carbon Capture Project (US). Doi: https://doi.org/10.2172/805134

BRASIL, Decreto no 3.179 (1999).

BRASIL, Decreto no 99.274 (1990).

BRASIL, Lei no 6.938 (1981).

BRASIL, Lei no 9.605 (1998).

CÂMARA, G.A.B.; ROCHA, P.S.; ANDRADE, J.C. 2011. Tecnologia de armazenamento geológico de dióxido de carbono: panorama um dial e situação brasileira. VII Congresso Nacional de Excelência em Gestão. ISSN 1984-9354

CEA - Corporate Environmental Advisors. 2021. The Basics of Environmental Due Diligence. Disponível em: https://cea-inc.com/the-basics-of-environmental-due-diligence/

CERQUETI, R. et al. 2021. ESG investing: A chance to reduce systemic risk. Journal of Financial Stability. Vol. 54. Doi: https://doi.org/10.1016/j.jfs.2021.100887

CNN. 2021. Companies are crucial to solving the climate crisis. $75 \%$ are falling short. Acesso em: 19/09/2021. Disponível: https://edition.cnn.com/2021/04/21/business/corporate-emissions-climatecrisis/index.html

Cook, P.J., 2009. Demonstration and deployment of carbon dioxide capture and storage in Australia. Energy Procedia. Volume 1, Versão 1. Pages 3859-3866. Doi: https://doi.org/10.1016/j.egypro.2009.02.188

COSTA, H.K.M; SANTOS, M. M.; MATAI, P. H. L. S.. Questões ambientais e Licenciamento ambiental Cap. 17. In: José R. Simões Moreira. (Org.). Energias Renováveis, Geração Distribuída e Eficiência Energética. 1ed.Rio de Janeiro: LTC editorial - Grupo GEN, 2017, v. 1, p. 354-367.

COSTA, H.K.M; MUSARRA, R. M. L. M.; MIRANDA, M. F.; MOUTINHO DOS SANTOS, E. Environmental License for Carbon Capture and Storage (CCUS) Projects in Brazil. Journal of Public Administration and Governance, v. 8, p. 163-185, 2018.

D'ÁVILA, M.Z. 2021. B3 muda metodologia de índice de sustentabilidade e permite que investidor acompanhe agenda ESG de empresas na Bolsa. Acesso em: 19/09/2021. Disponível em: https://www.infomoney.com.br/mercados/b3-muda-metodologia-de-indice-de-sustentabilidade-epermite-que-investidor-acompanhe-agenda-esg-de-empresas-na-bolsa/

DEAN, M., Tucker, O. 2017. A risk-based framework for Measurement, Monitoring and Verification (MMV) of the Goldeneye storage complex for the Peterhead CCS project, UK. International Journal of Greenhouse Gas Control. Vol. 61, Pages 1-15. Doi: https://doi.org/10.1016/j.ijggc.2017.03.014

DÍAZ, V.; Ibrushi, D.; Zhao, J. 2021. Reconsidering systematic factors during the Covid-19 pandemic The rising importance of ESG. Finance Research Letters. Vol. 38. Doi: https://doi.org/10.1016/j.frl.2020.101870

DIXON, T.; Romanak, K.D. 2015. Improving monitoring protocols for $\mathrm{CO} 2$ geological storage with technical advances in $\mathrm{CO} 2$ attribution monitoring. International Journal of Greenhouse Gas Control. Vol. 41. Pages 29-40. Doi: https://doi.org/10.1016/j.ijggc.2015.05.029

DNV. 2021. Carbon Capture and Storage - an effective tool to speed up decarbonization of industry. Acesso em: 19/19/2021. Disponível em: https://www.dnv.com/to2030/technology/carbon-captureand-storage.html 
DOE - Department of Energy. 2009. Best Practices for: Monitoring, Verification, and Accounting of CO2 Storage in Deep Geologic Formations. NETL - National Energy Technology Laboratory. Acesso em: 19/09/2021 Disponível em: https://www.globalccsinstitute.com/archive/hub/publications/159708/best-practices-monitoringverification-accounting-co2-stored-deep-geologic-formations.pdf

DOE - Department of Energy. 2017. Best Practices: Monitoring, Verification, and Accounting (MVA) for Geologic Storage Projects. NETL - National Energy Technology Laboratory. Acesso em: 19/09/2021 Disponível em: https://netl.doe.gov/sites/default/files/2018-10/BPM-MVA-2012.pdf

EGMOND, V. et al. 2012. Overview and analysis of the Dutch CCS program as a knowledge network. International Journal of Greenhouse Gas Control. Volume 11, Supplement, November 2012, Pages S1S9. Doi: https://doi.org/10.1016/j.ijggc.2012.11.004

EPE -Empresa de Pesquisa Energética. 2018. Estudos de Longo Prazo. Mecanismos de Carbono. Ministério de Minas e Energia. Governo Federal. Acesso em: 19/09/2021. Disponível em: https://www.epe.gov.br/sites-pt/publicacoes-dados-

abertos/publicacoes/PublicacoesArquivos/publicacao-227/topico-

457/14.\%20Mecanismos\%20de\%20Carbono.pdf

EXAME. 2021. Novos filtros e sem barragem: a retomada da Samarco, 5 anos após Mariana. Acesso em: 19/09/2021. Disponível em: https://exame.com/negocios/como-a-samarco-zerou-riscos-evoltou-a-extrair-ferro-5-anos-apos-mariana/

EY - Ernst \& Young. 2018. Does your nonfinancial reporting tell your value creations story? Acesso em: 19/19/2021. Disponível em: https://www.ey.com/en_gl/assurance/does-nonfinancial-reporting-tellvalue-creation-story

FAURE, M., 2016. Liability and compensation for damage resulting from CO2 storage sites. William and Mary Environmental Law and Policy Review, Volume 40, Versão 2.

FIGUEREDO, A.K.M. et al. 2022. How does subsea processing safety policy impact safety? Lessons learned from the Brazilian experience. Journal of Loss Prevention in the Process Industries. Volume 74, January 2022. Doi: https://doi.org/10.1016/j.jp.2021.104668

FORBES. 2021. Environmental, Social and Governance: What Is ESG Investing?. Acesso em: 24/10/2021. Disponível em: https://www.forbes.com/advisor/investing/esg-investing/

GARCIA, C. 2017. Gerenciamento de Segurança de Processo. Disponível em: http://menezeseassociados.com.br/gerenciamento-de-seguranca-de-processo/

GASPAR, HUGO ALEXANDRE CURADO. Captura e armazenamento de $\mathrm{CO} 2$, Faculdade de Ciências e Tecnologia Universidade Nova de Lisboa, Lisboa. 2014

GORAIEB, C.L.; IYOMASSA, W.S.; APPI, C.J. 2005. Estocagem Subterrânea de Gás Natural: Tecnologia Para Suporte ao Crescimento do Setor de Gás Natural no Brasil. Editora: IPT. São Paulo, SP, 2005. 226p.

GERHARDT, T. E SILVEIRA, D.T. 2009. Métodos de pesquisa. Série Educação à Distância. Editora da UFRGS. 120p.

GLOBAL CCS INSTITUTE. 2017. The Global Status of CCS 2017. Disponível em: https://www.globalccsinstitute.com/wp-content/uploads/2018/12/2017-Global-Status-Report.pdf

GLOBAL CCS INSTITUTE. 2018. Fact Sheet, Transporting-CO2-1. Disponível em: https://www.globalccsinstitute.com/wp-content/uploads/2018/12/Global-CCS-Institute-FactSheet_Transporting-CO2-1.pdf 
GLOBAL CCS INSTITUTE. 2020. The Global Status of CCS 2020. Disponivel em: https://www.globalccsinstitute.com/wp-content/uploads/2021/03/Global-Status-of-CCS-ReportEnglish.pdf

GLOBAL CCS INSTITUTE. 2021a. co2re - Facilities. Disponível em: https://co2re.co/FacilityData

GLOBAL CCS INSTITUTE. 2021b. The Global Status of CCS 2021. Disponível em: https://www.globalccsinstitute.com/resources/global-status-report/download/

GONZALEZ, R.S.; ROSSI, R.A.S.; GONZALEZ, B.C.R.; 2019. Estudo de caso de impactos econômicofinanceiros oriundos de falhas em gerenciamento de segurança de processos. Disponível em: http://corecon-sc.org.br/anais-cbe2019/arquivos/anais-cbe2019-4707.pdf

GROSSI, M. 2019. ESG: as três letras que estão mudando os investimentos. Conselho Empresarial Brasileiro para o Desenvolvimento Sustentável. Acesso em: 19/09/2021. Disponível em: https://cebds.org/esg-as-tres-letras-que-estao-mudando-comportamento-os-investimentos/

GUERRA, C.C.S. et al. 2019. Segurança de Processo. Pesquisa e Ação V.5 №3 ISSN 2447-0627

HARBERT, W. et al. 2016. Progress in monitoring strategies for risk reduction in geologic $\mathrm{CO} 2$ storage. International Journal of Greenhouse Gas Control. Vol. 51. Pages 260-275. Doi: https://doi.org/10.1016/j.ijggc.2016.05.007

HVIDEVOLD, H.K., et al. 2015. Layout of CCS monitoring infrastructure with highest probability of detecting a footprint of a $\mathrm{CO} 2$ leak in a varying marine environment. International Journal of Greenhouse Gas Control. Vol. 37. Pages 274-279. Doi: https://doi.org/10.1016/j.ijggc.2015.03.013

IEA. 2010. Carbon Capture and Storage- Model Regulatory Framework. Paris: OECD/IEA, 130pp.

IEAGHG. 2015. Review of offshore monitoring for CCS projects. Acesso em: 19/09/2021. Disponível em: https://ieaghg.org/docs/General_Docs/Reports/2015-02.pdf

IEAGHG. 2021. IEAGHG Funds research into the development and deployment of carbon capture and storage (ccs) Technologies. Acesso em: 19/09/2021. Disponível em: https://ieaghg.org/2uncategorised/267-ipac-report

Inc. 2020. Research and Development. Acesso em: 19/09/2021. Disponível em: https://www.inc.com/encyclopedia/research-and-development.html

IPCC, Diretrizes para Inventários Nacionais de Gases de Efeito Estufa Volume 2, Capítulo 5, Energia, 2006.

IPCC, Emissions Gap Report. Disponível em: https://www.ipcc.ch/site/assets/uploads/2018/12/UNEP1.pdf

ISO. 2009. ABNT NBR ISO 31000 - Gestão de riscos - Princípios e diretrizes. Disponível em: https://edisciplinas.usp.br/pluginfile.php/4656830/mod_resource/content/1/ISO31000.pdf

JENKINS, C.; CHADWICK, A.; HOVORKA, S.D. 2015. The state of the art in monitoring and verificationTen years on. International Journal of Greenhouse Gas Control. Vol. 40. Pages 312-349. Doi: https://doi.org/10.1016/j.jiggc.2015.05.009

JENKINS, C. et al. 2011. Safe storage and effective monitoring of CO2 in depleted gas Fields. PNAS. Doi: $10.1073 /$ pnas. 1107255108

KANAMURA, T. 2021. Risk Mitigation and Return Resilience for High Yield Bond ETFs with ESG Components. Finance Research Letters. Vol. 41. Doi: https://doi.org/10.1016/j.frl.2020.101866 
KETZER, J.M.M. et al. 2016. Atlas brasileiro de captura e armazenamento geológico de CO2. Publishing: EDIPUCRS. ISBN: 9788539707652

KHESHGI, H., DE CONINCK, H. \& KESSELS, J. 2012. Carbon dióxido de carbono captura e armazenamento: Sete anos após o relatório especial do IPCC. Mitigation and Adaptation Strategies for Global Change 17, 563-567. https://doi.org/10.1007/s11027-012-9391-5

LAI, X. ET AL. 2012. Carbon capture and sequestration (CCS) technological innovation system in China: Structure, function evaluation and policy implication. Energy Policy. Vol. 50. Pages 635-646. Doi: https://doi.org/10.1016/j.enpol.2012.08.004

LONGA, F.D.; DETZ, R.; ZWAAN, B.; 2020. Integrated assessment projections for the impact of innovation on CCS deployment in Europe. International Journal of Greenhouse Gas Control. Vol. 103. Doi: https://doi.org/10.1016/j.ijggc.2020.103133

LORIA, P. 2021. Lessons captured from 50 years of CCS projects. The Electricity Journal. Volume 34, Issue 7. Doi: https://doi.org/10.1016/j.tej.2021.106998

LI, Q.; LIU, G. 2016. Risk Assessment of the geological storage of CO2: A review. Springer International Publishing Switzerland. Doi: 10.1007/978-3-319-27019-7-13

MACURA, B. et al. 2019. Systematic reviews of qualitative evidence for environmental policy and management: an overview of different methodological options. Environmental Evidence. Doi: https://doi.org/10.1186/s13750-019-0168-0

MANUAL DE OSLO, 2005. Diretrizes para Coleta e Interpretação de Dados sobre Inovação. 3 a Edição.

MESQUITA, C.H.A; REZENDE, E.N. 2017. A responsabilidade civil ambiental no Canadá: retrocesso ambiental? Argumentum. Versão 18, número 1. pp. 163-179

METZ, B., et al. IPCC Special Report on Carbon Dioxide Capture and Storage. Prepared by Working Group III of the Intergovernmental Panel on Climate Change, 2005, 443pp.

MILJAND, M. 2020. Using systematic review methods to evaluate environmental public policy: methodological challenges and potential usefulness. Environmental Science \& Policy. Vol. 105. Doi: https://doi.org/10.1016/j.envsci.2019.12.008

MONTEIRO JÚNIOR, J.V., 2015. A regulação do sequestro geológico de carbono como instrumento de fomento ao desenvolvimento na indústria do petróleo brasileira. Natal, 2015. Disponível em: https://repositorio.ufrn.br/jspui/bitstream/123456789/21999/1/Regula\%c3\%a7\%c3\%a3oSequestroG eol\%c3\%b3gico_MonteiroJunior_2015.pdf

MPF - Ministério Público Federal - Brasil. Denúncia oferecida aos envolvidos no caso do rompimento da barragem de Mariana.

MPMG - Ministério Público de Minas Gerais - Brasil. MPMG requer aplicação de multa milionária na Vale. Disponível em: https://www.mpmg.mp.br/comunicacao/noticias/mpmg-requer-aplicacao-demulta-milionaria-na-vale-samarco-e-bhp-em-razao-do-atraso-na-entrega-de-moradias-as-vitimas-demariana.html

NARDOCCI, A.C., 2002. Gerenciamento Social de Riscos. Revista de Direito Sanitário. Disponível em: periódicos.usp.br

NASA. 2021. Technology Readiness Level. Disponível em: https://www.nasa.gov/directorates/heo/scan/engineering/technology/technology_readiness_level 
NETL - National Energy Technology Laboratory - Disponível em: <https://www.netl.doe.gov/coal/carbon-storage/faqs/carbon-storage-faqs>. Acesso em: 13 jun. 2019.

NOAA - National Oceanic and Atmospheric Administration (2021). Climate Change: Atmospheric Carbon Dioxide. Available: https://www.climate.gov/news-features/understanding-climate/climatechange-atmospheric-carbon-dioxide Acesso em: 15/07/2021

NUNES, R.; COSTA, H. Operação e fechamento de instalações de armazenamento para atividades de CCS no Brasil. Aspectos Jurídicos da Captura e Armazenamento de Carbono. Publishing: Lumen Juris. ISBN: 9788551915639

OECD - Organization for Economic Co-operation and Development. 2020. ESG Investing: Environmental Pillar Scoring and Reporting. Disponível: https://www.oecd.org/finance/ESG-Investing-EnvironmentalPillar-Scoring-Reporting.pdf

OECD - Organization for Economic Co-operation and Development. 2013. Frascati Manual 2015. Guidelines for collecting and reporting fata on research and experimental development.

PAWAR, R. et al. 2015. Recent advances in risk assessment and risk management of geologic CO2 storage. International Journal of Greenhouse Gas Control. Vol. 40. Pages 292 - 311. Doi: https://doi.org/10.1016/j.jiggc.2015.06.014

PEDERSEN, L.H.; FITZGIBBONS, S.; POMORSKI, L. 2020. Responsible investing: The ESG-efficient frontier. Journal of Financial Economics. Doi: https://doi.org/10.1016/j.jfineco.2020.11.001

RATHMANN, RÉGIS. 2017. Opções transversais para mitigação de emissões de gases de efeito estufa captura, transporte e armazenamento de carbono. Brasília. Ministério da Ciência, Tecnologia, Inovações e Comunicações.

RELATÓRIO DO CONSELHO NACIONAL DOS DIREITOS HUMANOS - CNDH. 2017. Relatório sobre o rompimento da barragem de rejeitos da mineradora samarco e seus efeitos sobre o vale do rio doce. Governo Federal. Disponível em: https://www.gov.br/mdh/pt-br/acesso-a-informacao/participacaosocial/old/cndh/relatorios/RelatriodaBarragemdoRioDoce_FINAL_APROVADO.pdf

RELATÓRIO FINAL DA COMISSÃO EXTERNA DO ROMPIMENTO DE BARRAGEM NA REGIÃO DE MARIANA - MG. 2016. Câmara dos Deputados - Congresso Nacional. Disponível em: https://www.camara.leg.br/proposicoesWeb/prop_mostrarintegra?codteor=1472309

ROBERTS, J.; STALKER, L. 2020. What have we learnt about CO2 leakage from CO2 release field experiments, and what are the gaps for the future? Earth-Science Reviews. Vol. 209. Doi: https://doi.org/10.1016/j.earscirev.2019.102939

ROMANAK, K. et al. 2013. Assessment of Alleged CO2 Leakage at the Kerr Farm using a Simple Processbased Soil Gas Technique: Implications for Carbon Capture, Utilization, and Storage (CCUS) Monitoring. Energy Procedia. Vol. 37. Pages 4242-4248 Doi: https://doi.org/10.1016/j.egypro.2013.06.326

SATO, K. 2011. Value of information analysis for adequate monitoring of carbon dioxide storage in geological reservoirs under uncertainty. International Journal of Greenhouse Gas Control. Vol. 5 Issue 5 Pages 1294-1302. Doi: https://doi.org/10.1016/j.ijggc.2011.07.010

SEIXAS, J. et al. 2015 - Captura e armazenamento de CO2 em Portugal: Uma ponte para uma economia de baixo carbono. Publishing: Universidade Nova de Lisboa. Faculdade de Ciências e Tecnologia. ISBN 9789728893354 
SOUZA, F.M.; TARIFA, M.R.; PANHOCA, L. 2017. O rompimento da barragem de mariana (mg): mudanças no disclosure ambiental do setor de mineração. Engema. ISSN: 23591048. Disponível em: http://engemausp.submissao.com.br/19/anais/arquivos/219.pdf

STEPHENS, J.C.; JIUSTO, S. 2010. Assessing innovation in emerging energy technologies: Socio-technical dynamics of carbon capture and storage (CCS) and enhanced geothermal systems (EGS) in the USA. Energy Policy. Vol. 38. Issue 4. Pages 2020-2031. Doi: https://doi.org/10.1016/j.enpol.2009.12.003

STORSET, S. et al. 2019. Profiting from CCS innovations: A study to measure potential value creation from CCS research and development. International Journal of Greenhouse Gas Control. Vol. 83. Pages 208-215. Doi: https://doi.org/10.1016/j.ijggc.2019.02.015

SUSTAINABLE CARBON. 2021. Acesso em: 19/09/2021. Disponível em: https://www.sustainablecarbon.com/como-sao-gerados/

TARAKKI, N. et al. 2018. A meta-analysis of the surface soil gas measurement monitoring and verification (MMV) program at the Aquistore Project. International Journal of Greenhouse Gas Control. Volume 75, August 2018, Pages 189-197. Doi: https://doi.org/10.1016/j.ijggc.2018.06.007

UGONNA, C.U.; OCHIENG, E.G.; ZUOFA, T. 2021. Augmenting the delivery of public research and development projects in developing countries. Technological Forecasting and Social Change. Vol. 169. Doi: https://doi.org/10.1016/j.techfore.2021.120830

UNESCO. 2010. Measuring Research and Development: challenges faced by developing countries. Technical Paper No 5, UNESCO Institute for Statistics. Publishing: Online ISBN: 9789291890941

UN GLOBAL COMPACT. 2021. Entenda o significado da sigla ESG (Ambiental, Social e Governança) e saiba como inserir esses princípios no dia a dia de sua empresa. Acesso em: 19/09/2021. Disponível em: https://www.pactoglobal.org.br/pg/esg

VARELA, CARMEN AUGUSTA; MILONE, DÉBORA. 2014. A Resposta do mercado aos Acidentes Ambientais na Indústria Petrolífera: Estudo do Caso do Desastre no Golfo do México. Encontro Internacional sobre Gestão Empresarial e Meio Ambiente.

WAARUN, IVAR-KRISTIAN, et al. 2016. CCS leakage detection technology - Industry needs, government regulations, and sensor performance. 13th International Conference on Greenhouse Gas Control Technologies, GHGT-13, 14-18 November 2016, Lausanne, Switzerland.

WAYCARBON. 2018. Risco climático: uma chamada para a geração de valor. Acesso em: 19/19/2021. Disponível em: https://blog.waycarbon.com/2018/08/risco-climatico-geracao-de-valor/

WILSON, E.J., FRIEDMANN, S.J., 2007. Research for deployment: incorporating risk, regulation, and liability for carbon capture and sequestration. Environmental Science and Technology. Doi: https://doi.org/10.1021/es062272t

WRI - WORLD RESOURCES INSTITUTE. 2008. CCS Guidelines. Disponível em: https://files.wri.org/d8/s3fs-public/pdf/ccs_guidelines.pdf

YU, E.P.; LUU, B.V. 2021. International variations in ESG disclosure - Do cross-listed companies care more? International Review of Financial Analysis. Vol. 75. Doi: https://doi.org/10.1016/j.irfa.2021.101731

ZAMAN, R. BRUDERMANN, T. 2018. Energy governance in the context of energy service security: A qualitative assessment of the electricity system in Bangladesh. Applied Energy. Vol. 223. Doi: https://doi.org/10.1016/j.apenergy.2018.04.081 
ZHANG, T. et al. 2021. CO2 capture and storage monitoring based on remote sensing techniques: A review. Journal of Cleaner Production. Vol. 281. Doi: https://doi.org/10.1016/j.jclepro.2020.124409

ZOBACK, M. 2007. Reservoir Geomechanics. Cambridge: Cambridge University Press. doi:10.1017/СВO9780511586477.

\section{Apêndices}




\section{Apêndice A}

Status das instalações de armazenamento de $\mathrm{CO}_{2}$ no mundo Fonte: Global CCS Institute (2021) 


\begin{tabular}{|c|c|c|c|c|c|c|c|c|c|c|c|c|c|c|c|c|}
\hline \multirow{3}{*}{ País } & & & & & \multicolumn{12}{|c|}{ Status das Intalações } \\
\hline & \multicolumn{4}{|c|}{ Instalações } & \multicolumn{2}{|c|}{ Operacional } & \multirow{2}{*}{\begin{tabular}{|c|} 
Operando \\
2020 \\
\end{tabular}} & \multirow{2}{*}{$\begin{array}{c}\begin{array}{r}\text { Operação } \\
\text { Suspensa }\end{array} \\
2021 \\
\end{array}$} & \multicolumn{2}{|c|}{ Descomissionadas } & \multicolumn{2}{|c|}{ Em Contrução } & \multicolumn{2}{|c|}{$\begin{array}{c}\text { Desenvolvimento } \\
\text { Inicial }\end{array}$} & \multicolumn{2}{|c|}{$\begin{array}{c}\text { Desenvolviment } \\
\text { o Avançado }\end{array}$} \\
\hline & 2020 & 2021 & $\%$ & Total & 2020 & 2021 & & & 2020 & 2021 & 2020 & 2021 & 2020 & 2021 & 2020 & 2021 \\
\hline Argélia & 1 & 1 & 0 & 0,6 & & & & & 1 & 1 & & & & & & \\
\hline Austrália & 11 & 13 & 18,2 & 7,8 & 4 & 4 & 1 & & 2 & 2 & & 1 & 1 & 1 & 3 & 5 \\
\hline Bélgica & 2 & 1 & $-50,0$ & 0,6 & & & & & & & 2 & 1 & & & & \\
\hline Brasil & 2 & 2 & 0,0 & 1,2 & & 1 & 1 & & 1 & 1 & & & & & & \\
\hline Canadá & 14 & 11 & $-21,4$ & 6,6 & 4 & 7 & 2 & & 3 & 3 & 3 & & & & 2 & 1 \\
\hline China & 28 & 19 & $-32,1$ & 11,4 & 11 & 8 & 2 & & 3 & 3 & 4 & 5 & 5 & 1 & 3 & 2 \\
\hline Croácia & 1 & 1 & 0,0 & 0,6 & 1 & 1 & & & & & & & & & & \\
\hline Dinamarca & 2 & 2 & 0,0 & 1,2 & & & & & 2 & 2 & & & & & & \\
\hline França & 4 & 3 & $-25,0$ & 1,8 & 1 & & & & 2 & 2 & & & & & 1 & 1 \\
\hline Alemanha & 3 & 3 & 0,0 & 1,8 & & & & & 3 & 3 & & & & & & \\
\hline Islândia & 1 & 1 & 0,0 & 0,6 & 1 & 1 & & & & & & & & & & \\
\hline Índia & 2 & 1 & $-50,0$ & 0,6 & 1 & & & & 1 & 1 & & & & & & \\
\hline Indonesia & 1 & 1 & 0,0 & 0,6 & & & & & & & & & & & 1 & 1 \\
\hline Irlanda & 1 & 1 & 0,0 & 0,6 & & & & & & & & & 1 & 1 & & \\
\hline Itália & 1 & 1 & 0,0 & 0,6 & & & & & 1 & 1 & & & & & & \\
\hline Japão & 7 & 6 & $-14,3$ & 3,6 & 3 & 3 & & & 2 & 2 & 2 & 1 & & & & \\
\hline Países Baixos & 7 & 4 & $-42,9$ & 2,4 & 3 & & & & 2 & 2 & & & 1 & 1 & 1 & 1 \\
\hline Nova Zelândia & 0 & 1 & 100,0 & 0,6 & & & & & & & & & & 1 & & \\
\hline Noruega & 7 & 7 & 0,0 & 4,2 & 3 & 3 & & & 3 & 2 & & 1 & & & 1 & 1 \\
\hline Catar & 0 & 1 & 100,0 & 0,6 & & 1 & & & & & & & & & & \\
\hline Arábia Saudita & 2 & 1 & $-50,0$ & 0,6 & 1 & 1 & 1 & & & & & & & & & \\
\hline Árrica do Sul & 1 & 1 & 0,0 & 0,6 & & & & & & & & & & & 1 & 1 \\
\hline Coréia do Sul & 3 & 3 & 0,0 & 1,8 & & & & & 2 & 2 & & & 1 & 1 & & \\
\hline Espanha & 4 & 4 & 0,0 & 2,4 & 1 & 1 & & & 3 & 3 & & & & & & \\
\hline Suécia & 2 & 2 & 0,0 & 1,2 & 1 & 1 & & & 1 & 1 & & & & & & \\
\hline Emirados Árabes Unidos & 2 & 2 & 0,0 & 1,2 & & 1 & 1 & & & & & & & & 1 & 1 \\
\hline Reino Unido & 14 & 14 & 0,0 & 8,4 & 2 & 2 & & & 5 & 3 & & & 6 & 8 & 1 & 1 \\
\hline Estados Unidos & 50 & 60 & 20,0 & 35,9 & 14 & 20 & 10 & 2 & 15 & 15 & & 1 & 3 & 10 & 8 & 12 \\
\hline TOTAL & 173 & 167 & & $100 \%$ & 51 & 55 & 18 & 2 & 52 & 49 & 11 & 10 & 18 & 24 & 23 & 27 \\
\hline
\end{tabular}




\section{Apêndice B}

Consolidado dos principais manuais e revisões referências em tecnologias e ferramentas relacionadas ao monitoramento das instalações de armazenamento de $\mathrm{CO}_{2}$

Fonte: (WRI, 2008; DOE, 2009; Dixon, 2015; JENKINS, 2015; IEAGHG, 2015; Harbert, 2016; DEAN, 2017; DOE, 2017; IEAGHG 2021). 


\begin{tabular}{cll}
\hline Recomendação & \multicolumn{1}{c}{ Sumário } & Site \\
\hline & $\begin{array}{l}\text { A Ferramenta de Seleção de Monitoramento foi criada para } \\
\text { identificar e priorizar técnicas que podem fazer parte de um } \\
\text { programa de monitoramento. A ferramenta ajudará os usuários }\end{array}$ & $\underline{\text { https://ieaghg.org/ccs- }}$ \\
MONITORING SELECTION TOOL & $\begin{array}{l}\text { a projetar um programa de monitoramento para monitorar um } \\
\text { projeto de armazenamento de CO }{ }^{2} \text { durante todas as fases, } \\
\text { desde a caracterização do local até a pós-injeção. }\end{array}$ \\
\hline
\end{tabular}

Este manual discute o desenvolvimento de MVA baseado em risco planos para projetos de armazenamento geológico de carbono e fornece resultados de pesquisas recentes sobre existentes e emergentes Técnicas de MRV. Embora o foco esteja

BEST PRACTICES:

Monitoring, Verification, and Accounting (MVA) for Geologic Storage Projects (2017 REVISED EDITION) na experiência adquirida através da Iniciativa DOE RCSP, planos MRV e algumas técnicas-chave de monitoramento aplicadas a nível internacional em projetos de campo de grande escala são t/files/2018-10/BPM-MVAdescritos. Os resultados das melhores práticas da aplicação bem- 2012.pdf sucedida de técnicas durante aplicação de campo são documentados por meio de lições aprendidas. Referências técnicas são fornecidas para leitores interessado em mais informações. Também são fornecidos status do andamento de pesquisas focadas em ferramentas.

Monitoring, Verification, and
Accounting
of $\mathrm{CO} 2$
Stored in Deep Geologic
Formations

Foi desenvolvido para regulamentar organizações, desenvolvedores de projetos nacionais e estaduais e formuladores de políticas para aumentar a conscientização sobre os desenvolver técnicas de monitoramento, reporte e verificação (MRV).
O esforço das Diretrizes de Captura e Armazenamento de Dióxido de Carbono (CCS) foi iniciada para desenvolver um conjunto de diretrizes preliminares e recomendações para a implantação de tecnologias de CCS nos Estados Unidos, para garantir que os projetos de CCS sejam conduzidos com segurança e eficácia. Como tal, as Diretrizes CCS são escritas para aqueles que podem estar envolvidos nas decisões sobre um projeto proposto: os desenvolvedores, reguladores, financiadores, seguradoras, operadores de projeto e formuladores de políticas. Estas Diretrizes têm como objetivo orientar a demonstração em grande escala e aumentar a confiança do público nas tecnologias de CCS, informando como os projetos devem ser conduzidos.

Este relatório foi encomendado antes do aconselhamento recebido do CCS sobre como atingir uma meta Net-Zero e

Energy Innovation Needs Assessment - CCUS reflete as prioridades para cumprir a meta anterior de $80 \%$ em 2050. Este relatório enfoca o CCUS e todo o sistema de energia, inovação e oportunidades de negócios e barreiras de mercado à inovação.

Este relatório analisa a prática de monitoramento offshore para projetos de armazenamento de $\mathrm{CO}^{2}$ em termos de recursos da ferramenta, aspectos práticos logísticos e custos. O foco está no monitoramento de armazenamento "comercial" em grande

Review of offshore monitoring for CCS projects escala e reúne a experiência publicada de grandes locais de armazenamento offshore de $\mathrm{CO}^{2}$ existentes, bem como pesquisas de monitoramento em locais de teste experimentais e em áreas de infiltrações naturais de $\mathrm{CO}^{2}$. São discutidos os pontos fortes e as limitações das técnicas, estratégias e metodologias de monitoramento e experiências relevantes. https://www.globalccsinstitute.co $\mathrm{m} /$ archive/hub/publications/1597 08/best-practices-monitoringverification-accounting-co2stored-deep-geologicformations.pdf

https://files.wri.org/d8/s3fspublic/pdf/ccs guidelines.pdf

https://assets.publishing.service. gov.uk/government/uploads/syst em/uploads/attachment_data/fil e/845655/energy-innovationneeds-assessment-ccus.pdf
https://ieaghg.org/docs/General Docs/Reports/2015-02.pdf 


\section{Apêndice C}

Resumo do Plano de Monitoramento recomendado pela Agência Internacional de Energia Fonte: IEA (2010) 


\section{PLANO DE MONITORAMENTO}

Integrar um pedido de autorização de armazenamento.

Delinear um programa de monitoramento e métodos de monitoramento suficiente para:

(a) continuar o levantamento de base para o localde armazenamento até o início da injeção;

b) monitorizar as instalações de injecção, o localde armazenamento (inchuindo a cohnna de $\mathrm{CO} 2$ ) e ambiente circundante;

(c) comparar os resultados do monitoramento em andamento com o levantamento da linha de base para o local de armazenamento;

(d) comparar o comportamento real do local de armazenamento com o comportamento antecipado do local de armazenamento baseado nos resultados do processo de caracterização do site e monitoramento dos resultados;

(e) detectar e avaliar vazamentos significativos, migração não intencional ou outra irregularidade no local de armazenamento;

f) quantificar, conforme exigido pela autoridade competente, os volumes de $\mathrm{CO} 2$ associados vazamento significativo ou migração não intencional;

(g) detectar a migração de $\mathrm{CO} 2$;

(h) detectar efeitos adversos significativos para o meio ambiente; e

(i) avaliar a eficácia de quaisquer medidas corretivas tomadas.

Basear-se em no plano de monitorização específico do local, conforme aprovado pela autoridade competente.

Reportar resultados à autoridade relevante periodicamente para exigido pela autoridade competente.

Ter um plano de monitorização atualizado para os casos de:

(a) mudanças no risco avaliado de vazamento;

(b) mudanças no risco avaliado para o meio ambiente;

c) alterações no risco avaliado para a saúde humana;

d) novos conhecimentos científicos; e

(e) melhorias na melhor tecnologia disponivel 


\section{Apêndice D}

Consolidado dos principais danos causados advindos do rompimento da barragem de Mariana em 2015 categorizados por impactos no ESG da empresa operadora da barragem

Fonte: (Relatório Final da Comissão Externa do Rompimento de Barragem na Região de Mariana - MG, 2016; Relatório do Conselho Nacional dos Direitos Humanos - CNDH, 2017; Agência Brasil, 2019; Gonzalez, 2019; MPF) 


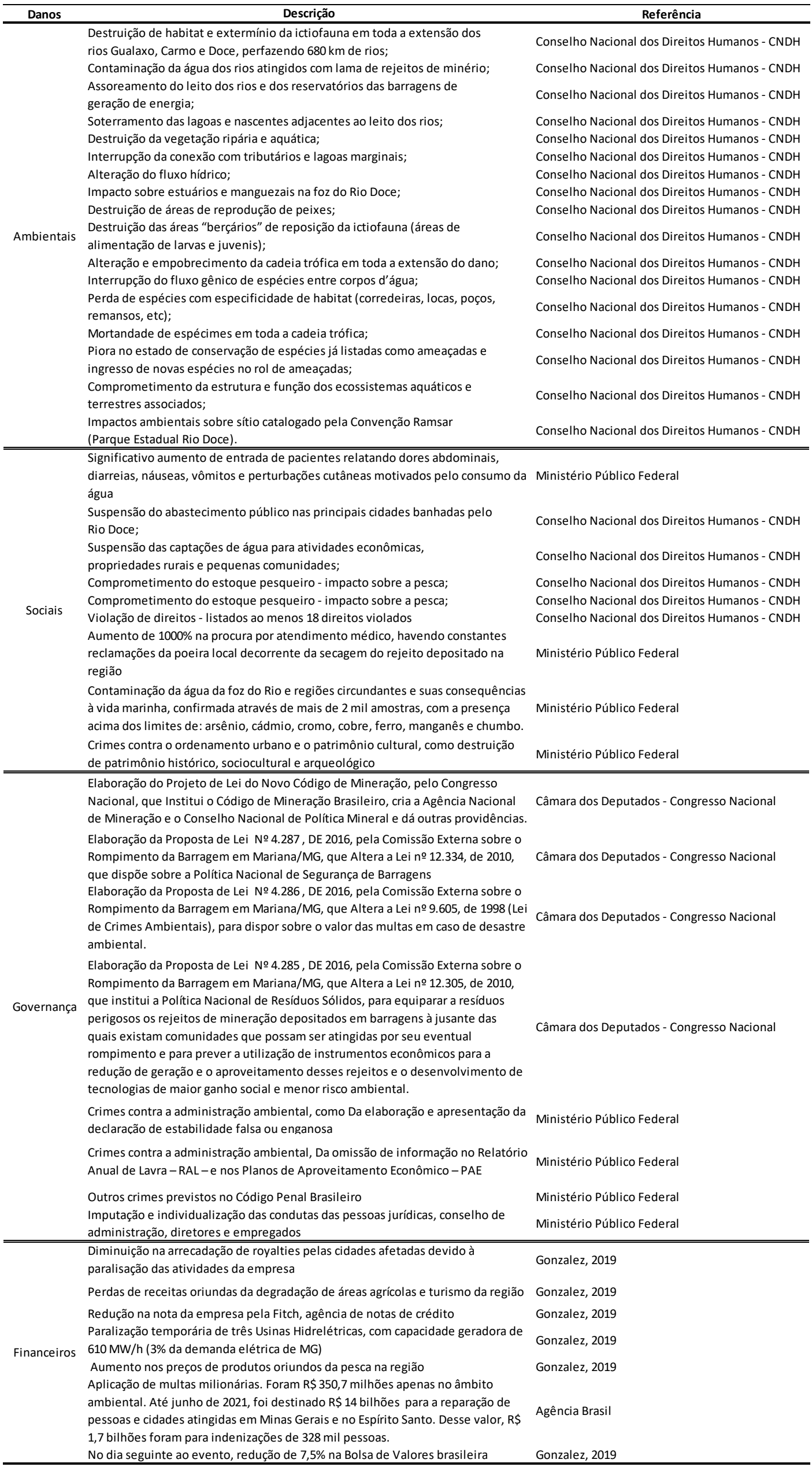




\section{Apêndice E}

Número de empresas certificadas pela B Corporations pelo respectivo segmento industrial Fonte: (B Corporation, 2021). 


\begin{tabular}{|c|c|c|c|c|c|}
\hline \multicolumn{6}{|c|}{ Certificações B Corporation } \\
\hline \multirow{2}{*}{$\begin{array}{l}\text { Indústria } \\
\text { Accounting Services }\end{array}$} & \multicolumn{2}{|c|}{ Número Indústria } & \multicolumn{2}{|c|}{ Número Indústria } & \multirow{2}{*}{$\begin{array}{c}\text { Número } \\
5\end{array}$} \\
\hline & 18 & Fine Arts & 16 & Office Community & \\
\hline Agricultural Services & 73 & Fitness e Wellness Centers & 4 & Oline Marketplace & 25 \\
\hline Animal Health & 3 & Food e Beverage & 470 & Other & 284 \\
\hline Apparel, Footwear e Accessories & 156 & Forest Management & 5 & Other Business Produts & 1 \\
\hline Architecture/Design/Planning & 112 & Growers & 39 & Other Credit - Emerging Mkts & 1 \\
\hline Automotive Sales e Repair & 3 & Healthcare Consulting & 2 & Other Energy Generation & 2 \\
\hline Books e Media & 15 & healthcare Providers & 54 & Pet Products & 4 \\
\hline Building Materials & 5 & Health insurance & 10 & Pharmaceuticals e Supplies & 24 \\
\hline Carbon Capture e Credits & 5 & Home e Personal care & 215 & Print Publications & 14 \\
\hline Catering e Meeting/ Event Management & 5 & Hospitality & 19 & Product Ratings & 1 \\
\hline Consumer Rewards & 2 & Housewares, Home Furnishings e Accessories & 68 & Real estate Development & 45 \\
\hline Contractor e Builders & 28 & HD Consulting e Recruiting & 36 & Recycling Services e Waste Management & 23 \\
\hline Credit Provider & 47 & Industrial Manufacturing & 32 & Renewable Energy Generation e Installation & 97 \\
\hline Design/Build & 15 & Insurance & 34 & Rental Services & 8 \\
\hline Education e Training Services & 138 & Investment Advisor & 117 & Research e Design & 94 \\
\hline Electronic Distribution & 2 & IT Software e Services/Web Design & 279 & Restaurant & 34 \\
\hline Electronics & 23 & Jewelry & 17 & Sports Equipment, Toys e Accessories & 27 \\
\hline Employee Benefits & 4 & legal & 47 & Storefront & 31 \\
\hline Energy Efficiency e Consulting & 15 & Machinery e Equipment & 34 & Sustainability Consulting & 144 \\
\hline Environmental Remediation & 8 & Management and Financial Consulting & 227 & Telecommunications & 6 \\
\hline Equity Investor - Developed Markets & 77 & Marketing e Communications Services & 227 & Transportation e Logistics & 16 \\
\hline Equity Investor - Emerging Markets & 23 & Merchant Services & 10 & Travel e Leisure & 38 \\
\hline Facillities, Grounds e Maintenance & 10 & Nonprofit Consulting e Fundraising & 73 & Waste Management & 34 \\
\hline Film e Music Production & 30 & Office Products e Printing & 31 & & \\
\hline
\end{tabular}

